SAND95-2144 • UC-721

Unlimited Release

Printed October 1995

\title{
Superconducting Technology Program Sandia 1994 Annual Report
}

\author{
E. Peter Roth \\ Superconductivity Materials and Technology Department
}

Prepared by

Sandia National Laboratories

Albuquerque, New Mexico 87185 and Livermore, California 94550

for the United States Department of Energy

under Contract DE-AC04-94AL85000

Approved for public release; distribution is unlimited.
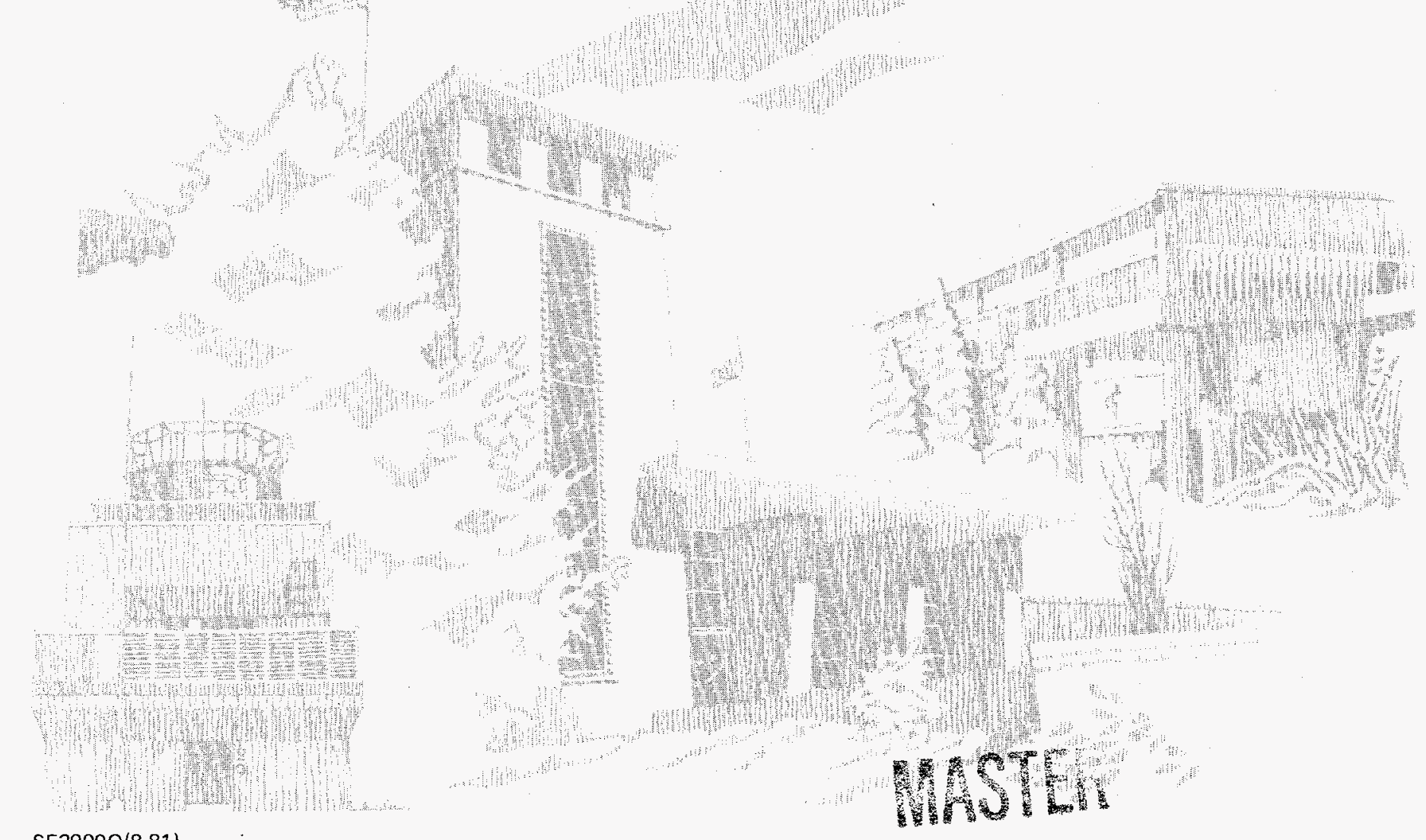
Issued by Sandia National Laboratories, operated for the United States Department of Energy by Sandia Corporation.

NOTICE: This report was prepared as an account of work sponsored by an agency of the United States Government. Neither the United States Government nor any agency thereof, nor any of their employees, nor any of their contractors, subcontractors, or their employees, makes any warranty, express or implied, or assumes any legal liability or responsibility for the accuracy, completeness, or usefulness of any information, apparatus, product, or process disclosed, or represents that its use would not infringe privately owned rights. Reference herein to any specific commercial product, process, or service by trade name, trademark, manufacturer, or otherwise, does not necessarily constitute or imply its endorsement, recommendation, or favoring by the United States Government, any agency thereof or any of their contractors or subcontractors. The views and opinions expressed herein do not necessarily state or refiect those of the United States Government, any agency thereof or any of their contractors.

Printed in the United States of America. This report has been reproduced directly from the best available copy.

Available to DOE and DOE contractors from

Office of Scientific and Technical Information

PO Box 62

Oak Ridge, TN 37831

Prices available from (615) 576-8401, FTS 626-8401

Available to the public from

National Technical Information Service

US Department of Commerce

5285 Port Royal Rd

Springfield, VA 22161

NIIS price codes

Printed copy: $\mathrm{A03}$

Microfiche copy: A01 


\section{DISCLAIMER}

Portions of this document may be illegible in electronic image products. Images are produced from the best available original document. 


\title{
Superconducting Technology Program Sandia 1994 Annual Report
}

\author{
Report prepared by \\ E. Peter Roth \\ Superconductivity Materials \\ and Technology Department \\ Sandia National Laboratories \\ Albuquerque, NM 87185 \\ This report has been prepared for the \\ Advanced Utility Concepts Division \\ Office of Energy Management \\ Energy Efficiency \& Renewable Energy \\ U.S. Department of Energy
}

\begin{abstract}
Sandia's STP program is a four-part high-temperature superconductor (HTS) research and development program consisting of efforts in powder synthesis and process development, thallium-based HTS film development, wire and tape fabrication, and HTS motor design. The objective of this work is to develop high-temperature superconducting conductors (wire and tape) capable of meeting requirements for highpower electrical devices of interest to industry. The four research efforts currently underway are: 1) Process research on the material synthesis of high-temperature superconductors, 2) Investigation of the synthesis and processing of thallium-based high-temperature superconducting thick films, 3) Process development and characterization of high-temperature superconducting wire and tape, and 4) Cryogenic design of a high-temperature superconducting motor. This report outlines the research that has been performed during FY94 in each of these four areas. Major areas of research are described, although no attempt has been made to exhaustively include all work performed in each of these areas.
\end{abstract}




\section{CONTENTS}

1 Process Research on the Synthesis of High Temperature Superconductors .... 1-1

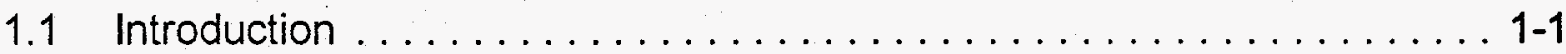

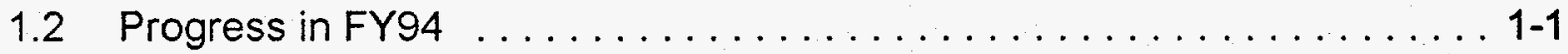

1.2.1 Effect of Ba:Sr Ratio . . . . . . . . . . . . . . . . . . 1-2

1.2.2 Effect of the TI:Pb Ratio . . . . . . . . . . . . . . . 1-3

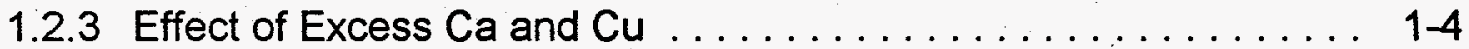

1.2.4 Effect of Stoichiometry on $\mathrm{T}_{\mathrm{c}} \ldots \ldots \ldots \ldots \ldots \ldots \ldots \ldots \ldots \ldots \ldots$

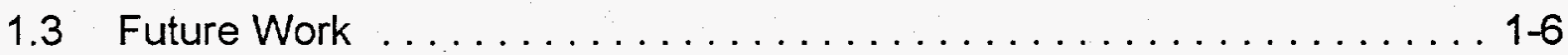

2 Growth of Thick(TI,Pb)-(Ba, Sr)-Ca-Cu-O Superconducting Films Using a Controlled TI-Oxide Source ....................... 2 .1

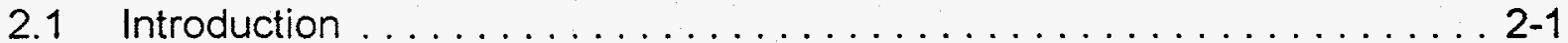

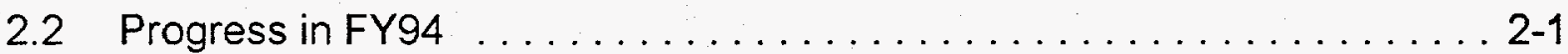

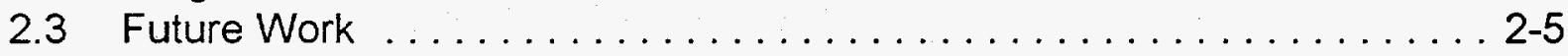

3 Process Development and Characterization of High-Temperature Superconducting Wire and Tape $\ldots \ldots \ldots \ldots \ldots \ldots \ldots \ldots \ldots \ldots \ldots \ldots .1$

3.1 Introduction $\ldots \ldots \ldots \ldots \ldots \ldots \ldots \ldots \ldots \ldots \ldots \ldots \ldots \ldots \ldots \ldots \ldots .1$

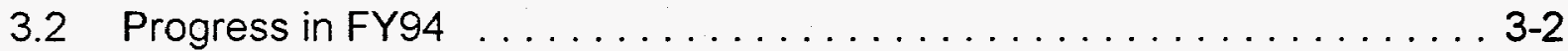

3.2.1 Phase Analysis of RTP Transient-Melt TI-1223 Tapes . . . . . . . . 3-2

3.2.2 Processing Optimization of Ag-Clad TI-1223 Tapes . . . . . . . . . 3-4

3.2.3 Effects of Stoichiometric Variations in the (Pb,Sr)-doped Tl-1223 System .......................... $3-5$

3.2.4 Extrusion of TI-Core Wires . . . . . . . . . . . . . . .

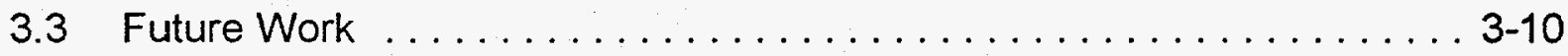

4 Cryogenic Design of a High-Temperature Superconducting (HTS) Motor . . . . . 4-1

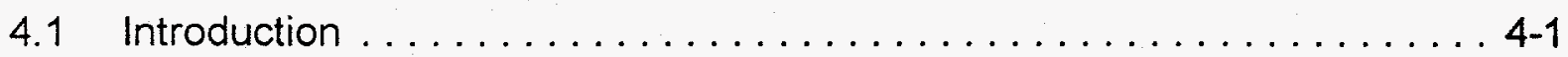

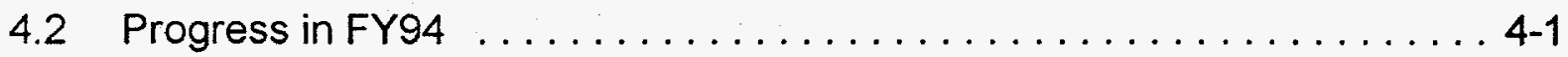

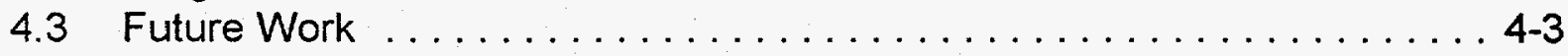




\section{FIGURES}

1-1 DTA of gold foil-wrapped pellets of unreacted $\left(\mathrm{TI}_{0.5} \mathrm{~Pb}_{0.5}\right)\left(\mathrm{Sr}_{0.8} \mathrm{Ba}_{0.2}\right)_{2} \mathrm{Ca}_{2} \mathrm{Cu}_{3} \mathrm{O}_{\mathrm{x}}$

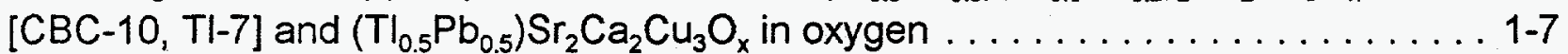

1-2 Meissner data of $\left(\mathrm{Tl}_{0.5} \mathrm{~Pb}_{0.5}\right) \mathrm{Sr}_{2} \mathrm{Ca}_{2} \mathrm{Cu}_{3} \mathrm{O}_{x}$ processed in oxygen at $920^{\circ} \mathrm{C}$ for

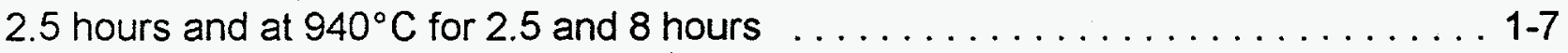

1-3 DTA of gold foil-wrapped pellets of unreacted $\left(\mathrm{TI}_{0.75} \mathrm{~Pb}_{0.25}\right)\left(\mathrm{Sr}_{0.8} \mathrm{Ba}_{0.2}\right)_{2} \mathrm{Ca}_{2} \mathrm{Cu}_{3} \mathrm{O}_{x,}$

$\left(\mathrm{TI}_{0.50} \mathrm{~Pb}_{0.50}\right)\left(\mathrm{Sr}_{0.8} \mathrm{Ba}_{0.2}\right)_{2} \mathrm{Ca}_{2} \mathrm{Cu}_{3} \mathrm{O}_{\mathrm{x}}$ and $\left(\mathrm{TI}_{0.25} \mathrm{~Pb}_{0.75}\right)\left(\mathrm{Sr}_{0.8} \mathrm{Ba}_{0.2}\right)_{2} \mathrm{Ca}_{2} \mathrm{Cu}_{3} \mathrm{O}_{\mathrm{x}}$ in oxygen . . 1-8

1-4 Meissner data of $\left(\mathrm{Tl}_{0.75} \mathrm{~Pb}_{0.25}\right)\left(\mathrm{Sr}_{0.8} \mathrm{Ba}_{0.2}\right)_{2} \mathrm{Ca}_{2} \mathrm{Cu}_{3} \mathrm{O}_{\mathrm{x}}\left(\mathrm{Tl}_{0.50} \mathrm{~Pb}_{0.50}\right)\left(\mathrm{Sr}_{0.8} \mathrm{Ba}_{0.2}\right)_{2} \mathrm{Ca}_{2} \mathrm{Cu}_{3} \mathrm{O}_{x}$, and $\left(\mathrm{Tl}_{0.25} \mathrm{~Pb}_{0.75}\right)\left(\mathrm{Sr}_{0.8} \mathrm{Ba}_{0.2}\right)_{2} \mathrm{Ca}_{2} \mathrm{Cu}_{3} \mathrm{O}_{\mathrm{x}}$ processed in oxygen at $920^{\circ} \mathrm{C}$ for 2.5 hours. . 1-8

1-5 Meissner data of $\left(\mathrm{Tl}_{0.75} \mathrm{~Pb}_{0.25}\right)\left({ }_{\text {sro.8Ba0.2 }}\right)_{2} \mathrm{Ca}_{2} \mathrm{Cu}_{3} \mathrm{O}_{\mathrm{x}},\left(\mathrm{Tl}_{0.50} \mathrm{~Pb}_{0.50}\right)\left(\mathrm{Sr}_{0.8} \mathrm{Ba}_{0.2}\right)_{2} \mathrm{Ca}_{2} \mathrm{Cu}_{3} \mathrm{O}_{x}$, and $\left(\mathrm{Tl}_{0.25} \mathrm{~Pb}_{0.75}\right)\left(\mathrm{Sr}_{0.8} \mathrm{Ba}_{0.2}\right)_{2} \mathrm{Ca}_{2} \mathrm{Cu}_{3} \mathrm{O}_{\mathrm{x}}$ processed in oxygen at $940^{\circ} \mathrm{C}$ for 2.5 hours . 1-9

1-6 Optical photomicrographs of $\left(\mathrm{TI}_{0.75} \mathrm{~Pb}_{0.25}\right)\left(\mathrm{Sr}_{0.8} \mathrm{Ba}_{0.2}\right)_{2} \mathrm{Ca}_{2} \mathrm{Cu}_{3} \mathrm{O}_{\mathrm{x}_{1}}$

$\left(\mathrm{Tl}_{0.50} \mathrm{~Pb}_{0.50}\right)\left(\mathrm{Sr}_{0.8} \mathrm{Ba}_{0.2}\right)_{2} \mathrm{Ca}_{2} \mathrm{Cu}_{3} \mathrm{O}_{\mathrm{x}}$, and $\left(\mathrm{TI}_{0.25} \mathrm{~Pb}_{0.75}\right)\left(\mathrm{Sr}_{0.8} \mathrm{Ba}_{0.2}\right)_{2} \mathrm{Ca}_{2} \mathrm{Cu}_{3} \mathrm{O}_{\mathrm{x}}$ processed

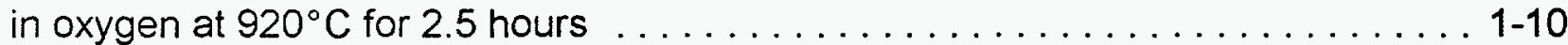

1-7 Optical photomicrographs of $\left(\mathrm{TI}_{0.75} \mathrm{~Pb}_{0.25}\right)\left(\mathrm{Sr}_{0.8} \mathrm{Ba}_{0.2}\right)_{2} \mathrm{Ca}_{2} \mathrm{Cu}_{3} \mathrm{O}_{\mathrm{x}}$,

$\left(\mathrm{Tl}_{0.50} \mathrm{~Pb}_{0.50}\right)\left(\mathrm{Sr}_{0.8} \mathrm{Ba}_{0.2}\right)_{2} \mathrm{Ca}_{2} \mathrm{Cu}_{3} \mathrm{O}_{\mathrm{x}}$, and $\left(\mathrm{Tl}_{0.25} \mathrm{~Pb}_{0.75}\right)\left(\mathrm{Sr}_{0.8} \mathrm{Ba}_{0.2}\right)_{2} \mathrm{Ca}_{2} \mathrm{Cu}_{3} \mathrm{O}_{\mathrm{x}}$ processed

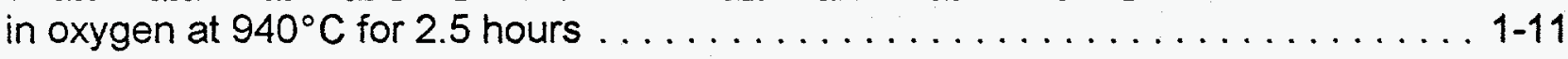

1-8 DTA of gold foil-wrapped pellets of unreacted $\left(\mathrm{Tl}_{0.75} \mathrm{~Pb}_{0.25}\right)\left(\mathrm{Sr}_{0.8} \mathrm{Ba}_{0.2}\right)_{2} \mathrm{Ca}_{2} \mathrm{Cu}_{3} \mathrm{O}_{\mathrm{x}}$,

$\left(\mathrm{Tl}_{0.75} \mathrm{~Pb}_{0.25}\right)\left(\mathrm{Sr}_{0.8} \mathrm{Ba}_{0.2}\right)_{2} \mathrm{Ca}_{2.2} \mathrm{Cu}_{3.3} \mathrm{O}_{\mathrm{x}},\left(\mathrm{TI}_{0.25} \mathrm{~Pb}_{0.75}\right)\left(\mathrm{Sr}_{0.8} \mathrm{Ba}_{0.2}\right)_{2} \mathrm{Ca}_{2} \mathrm{Cu}_{3} \mathrm{O}_{\mathrm{x}}$, and

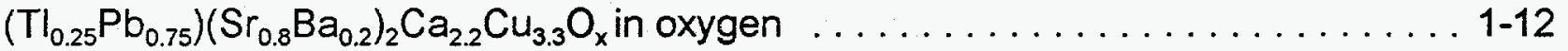

1-9 Meissner data of $\left(\mathrm{TI}_{0.75} \mathrm{~Pb}_{0.25}\right)\left(\mathrm{Sr}_{0.8} \mathrm{Ba}_{0.2}\right)_{2} \mathrm{Ca}_{a} \mathrm{Cu}_{\mathrm{b}} \mathrm{O}_{\mathrm{x}}$ where a,b equal 2.0,3.0, and 2.2,3.3 for samples processed in oxygen at $920^{\circ} \mathrm{C}$ and $940^{\circ} \mathrm{C}$ for 2.5 hours . . 1-12

1-10 Back scattered electron photomicrographs of $\left(\mathrm{TI}_{0.75} \mathrm{~Pb}_{0.25}\right)\left(\mathrm{Sr}_{0.8} \mathrm{Ba}_{0.2}\right)_{2} \mathrm{Ca}_{2} \mathrm{Cu}_{\mathrm{b}} \mathrm{O}_{\mathrm{x}}$, where $a, b$ equal $2.0,3.0$, and $2 \cdot 2,3.3$ for samples processed in oxygen at $940^{\circ} \mathrm{C}$ for 2.5 hours . . . . . . . . . . . . . . . . . . . . . . . . . . .

1-11 Meissner data for various compositions of samples with Tl-to-Pb ratios of 1:3 processed in oxygen at $940^{\circ} \mathrm{C}$ for 2.5 hours . . . . . . . . . . . 14

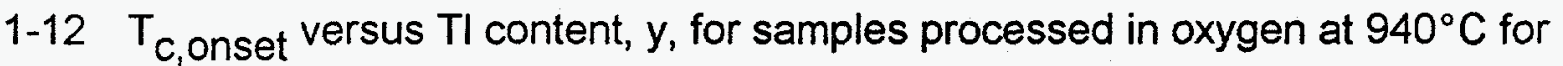

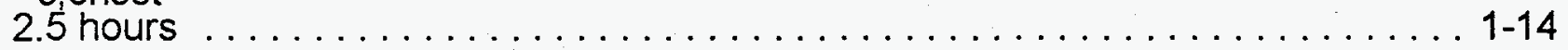

1-13 Lattice parameters of nominally $\left(\mathrm{TI}_{0.5} \mathrm{~Pb}_{0.5}\right)\left(\mathrm{Sr}_{0.8} \mathrm{Ba}_{0.2}\right)_{2} \mathrm{Ca}_{2} \mathrm{Cu}_{3} \mathrm{O}_{\mathrm{x}}$ as a function of $\mathrm{Tl}_{2} \mathrm{O}$ partial pressure for samples processed in 2-zone furnace and $\left(\mathrm{Tl}_{0.75} \mathrm{~Pb}_{0.25}\right)$ $\left(\mathrm{Sr}_{0.8} \mathrm{Ba}_{0.2}\right)_{2} \mathrm{Ca}_{2} \mathrm{Cu}_{3} \mathrm{O}_{\mathrm{x}}$ processed in oxygen at $940^{\circ} \mathrm{C}$ for 2.5 hours $\ldots \ldots \ldots \ldots .1-15$

2-1 X-ray diffraction peak intensities as a function of Tl-oxide source temperature for

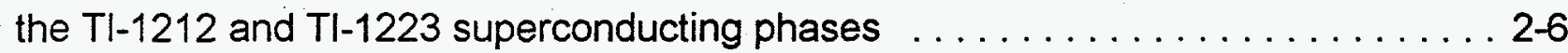

2-2 $J_{c}$ versus applied magnetic field at various temperatures $\ldots \ldots \ldots \ldots \ldots \ldots \ldots$

2-3 Optical microscope image in transmission mode from a $15 \mu \mathrm{m}$ thick film processed in two stages to achieve both melting and thallination $\ldots \ldots \ldots \ldots \ldots \ldots \ldots \ldots .7$ 
2-4 Backscattered electron microscope image from a $15 \mu \mathrm{m}$ thick film processed in two stages to achieve both melting and thallination . . . . . . . . . . . . 2-7

2-5 Backscattered electron microscope image from a $15 \mu \mathrm{m}$ thick film processed in two stages to achieve both melting and thallination $\ldots \ldots \ldots \ldots \ldots \ldots \ldots .2-8$

3-1 DTA of fully reacted TI-1223 Ag tape in oxygen and argon atmospheres . . . . . . 3-12

3-2a Microstructure of TI-1223 Ag tape subjected to a RTP of $930^{\circ} \mathrm{C} / 10$ sec/Ar then

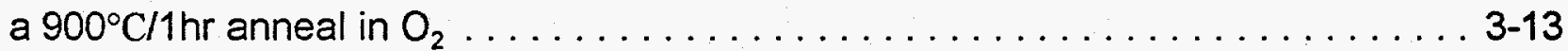

3-2b Ag x-ray map of RTP processed TI-1223 tape . . . . . . . . . . . . . . . 3-13

3-3 SEM micrographs of Rapid Thermal Processed Ag-clad tapes . . . . . . . . . . 3-14

3-4 Meissner data for RTP and $860^{\circ} \mathrm{C} / 8 \mathrm{hr} / \mathrm{O}_{2}$ annealed tapes $\ldots \ldots \ldots \ldots \ldots \ldots$. $3-15$

3-5 Effect of time-temperature processing on TI-1223 tapes . . . . . . . . . . . 3-16

3-6 $J_{c}$ vs. $T_{c}$ as a function of anneal time and temperature $\ldots \ldots \ldots \ldots \ldots \ldots$ 3-16

3-7 $\mathrm{J}_{\mathrm{c}}$ field dependence of $\mathrm{Tl}-1223$ tapes as a function of anneal temperature and time . . . . . . . . . . . . . . . . . . . . . . . . . . . . . . . . .

3-8 Compositional design matrix for the $\mathrm{TI}-1223$ system $\ldots \ldots \ldots \ldots \ldots \ldots \ldots$ 3-18

3-9 DTA comparison of unreacted Hitachi composition powders . . . . . . . . . . . . 3-19

3-10 DTA comparison of reacted TI-1223 Ag-clad tape measured in $\mathrm{O}_{2}$ and Argon . . . . 3-19

3-11 DTA comparisons for $\mathrm{Ag}$-tapes in $\mathrm{O}_{2}$ as a function of TI/Pb ratio $\ldots \ldots \ldots \ldots . . .3-20$

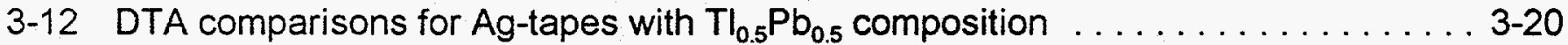

3-13 SEM micrograph of Hitachi composition (TI-7) annealed at $900^{\circ} \mathrm{C} / 2 \mathrm{hr} / \mathrm{O}_{2} \ldots \ldots$. . 3-21

3-14 SEM micrograph of center point composition (TI-1) annealed at $900^{\circ} \mathrm{C} / 2 \mathrm{hr} / \mathrm{O}_{2} \ldots . .3-21$

3-15 SEM micrographs of $\mathrm{Ag}$ tapes from compositional matrix study annealed at

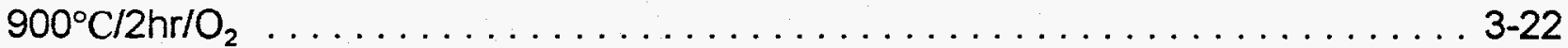

3-16 Meissner comparison of $920^{\circ} \mathrm{C}$ processed pellet and $900^{\circ} \mathrm{C}$ processed $\mathrm{Ag}$ tape with predominantly $\mathrm{Tl}-1223$ phase $\ldots \ldots \ldots \ldots \ldots \ldots \ldots \ldots \ldots . \ldots \ldots$ 3-23

3-17 Meissner comparison of $920^{\circ} \mathrm{C}$ processed pellet and $900^{\circ} \mathrm{C}$ processed $\mathrm{Ag}$ tape showing predominantly $\mathrm{Tl}-1212$ phase $\ldots \ldots \ldots \ldots \ldots \ldots \ldots \ldots .23$

3-18 Summary of $T_{c}$ and $J_{c}$ results for $A g$-clad tapes produced from compositional matrix. $J_{c}$ values are in $\mathrm{A} / \mathrm{cm}^{2}$ measured at $75 \mathrm{~K}$ in zero field $\ldots \ldots \ldots \ldots .3-24$

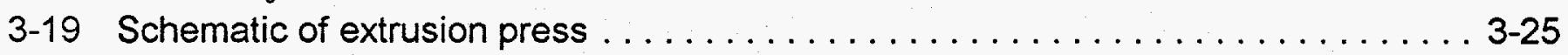

3-20 Computer aided tomograms of multi-core extruded rod $\ldots \ldots \ldots \ldots \ldots \ldots \ldots$ 3-26

3-21 X-radiograms of coextruded superconductor core in Al sheath . . . . . . . . 3-26

4-1 Simplified geometry of Reliance Electric cryogenic motor . . . . . . . . . . . . . . . . 4-4 


\title{
CONTRIBUTORS
}

\author{
Sandia Contributors to the \\ Superconducting Technology Program \\ for Electric Energy Systems \\ Program Manager \\ Thomas C. Bickel \\ Project Leader \\ E. Peter Roth
}

Ceramic Synthesis

James A. Voigt

Diana L. Lamppa

Ceramic Processing

Steve Lockwood

David M. Toupal

Advanced Materials/Magnetic

Characterization

Eugene L. Venturini

Advanced Materials/Phase Diagrams

Terence L. Aselage

Stuart B. Van Deusen
Advanced Materials/Thick Film

Michael P. Siegal

Donald L. Overmyer

Advanced Materials/Electron

Microscopy

Paula P. Newcomer

Advanced Materials/X-ray Diffraction

Bruno Morosin

Roberto G. Dunn

Superconducting Materials/Transport

Properties

Frank Chavez

Thermal \& Fluid Modeling

Ronald C. Dykhuizen 


\section{Process research on the synthesis of high} temperature superconductors

\subsection{Introduction}

The development of high temperature superconducting wires with properties suitable for high-power electrical applications requires an extensive understanding of the processing/property relationships of the superconducting material. It is the goal of this project to develop such understanding for the TI-based class of high temperature superconductors. Specifically, we have focused on the $\mathrm{Pb}$ - and $\mathrm{Sr}$-substituted $\mathrm{TIBa}_{2} \mathrm{Ca}_{2} \mathrm{Cu}_{3} \mathrm{O}_{x}$ phase, $\mathrm{TI}-1223$, because of its high irreversibility line and the ease of formation of the desired TI-1223 structure.

In previous work, we have developed and patented an aqueous coprecipitation process for the preparation of superconductor precursor powders. We have continued to use this process to prepare superconductor powders with a variety of stoichiometries to support our in-house processing studies and several collaborations dealing with wire development (see Section 3.1 for details). This year we have investigated the effect of stoichiometry on the synthesis, processing, and properties of $\mathrm{Tl}-1223$.

\subsection{Progress in FY94}

Much of our wire development work has focused on the TI-1223 stoichiometry as developed by Hitachi which is $\left(\mathrm{Tl}_{0.5} \mathrm{~Pb}_{0.5}\right)\left(\mathrm{Sr}_{0.8} \mathrm{Ba}_{0.2}\right)_{2} \mathrm{Ca}_{2} \mathrm{Cu}_{3} \mathrm{O}_{\mathrm{x}}$. For this study, we used this composition as the baseline and determined the effect compositional deviations had on such properties as the liquid forming temperatures, TI-1223 phase formation, $T_{c}$, and microstructural evolution. Results of this work were used as a processing guide for $\mathrm{Tl}-1223$ wire development studies investigating the effect of stoichiometry, the results of which are discussed in Section 3.2.3. Compositional effects investigated were:

1) the Ba:Sr ratio

ii) the $\mathrm{Tl}: \mathrm{Pb}$ ratio

iii) excess $\mathrm{Ca}$ and $\mathrm{Cu}$ 


\subsubsection{Effect of the Ba:Sr ratio}

Previous researchers have shown that it is difficult to form the desired Tl-1223 phase when no barium is present. To better understand this observation, we prepared precursor powders with three different $\mathrm{Sr}: \mathrm{Ba}$ ratios: 1) no $\mathrm{Ba}$, $\left(\mathrm{Tl}_{0.5} \mathrm{~Pb}_{0.5} \mathrm{Sr}_{2} \mathrm{Ca}_{2} \mathrm{Cu}_{3} \mathrm{O}_{\mathrm{x}}\right)$, 2) the Hitachi formulation with a Sr:Ba ratio of $4: 1$, and 3) a Sr:Ba ratio of 3:2, $\left(\mathrm{Tl}_{0.5} \mathrm{~Pb}_{0.5}\right)\left(\mathrm{Sr}_{0.6} \mathrm{Ba}_{0.4}\right)_{2} \mathrm{Ca}_{2} \mathrm{Cu}_{3} \mathrm{O}_{\mathrm{x}}$. All of the powders were prepared in thallium-free form by our coprecipitation process. After calcination, to convert the coprecipitate to an intimate mixture of constituent oxides, the appropriate amount of $\mathrm{Tl}_{2} \mathrm{O}_{3}$ was mixed with a powder by a dry Spex milling process.

Differential thermal analysis, DTA, was used to determine onset temperatures for liquid-forming reactions. For this analysis, pieces of small pellets pressed from the precursor powder $/ \mathrm{Tl}_{2} \mathrm{O}_{3}$ mixtures were wrapped in gold foil to minimize thallium loss due to $\mathrm{Tl}_{2} \mathrm{O}$ volatilization. DTA experiments were run in oxygen and argon using a constant heating rate of $10^{\circ} \mathrm{C} / \mathrm{min}$. Figure $1-1$ shows the results of DTA analysis for sample with the Hitachi formulation ( $\mathrm{Sr}: \mathrm{Ba}=4)$ and the Ba-free material. Three DTA traces are shown for the Hitachi formulation. Two of the traces are for the same precursor powder batch. These data show that the gold wrapped pellet method of sample preparation is reproducible. The magnitude and temperatures of the melting endotherms are nearly identical for the two DTA experiments. The third DTA trace is for a pellet prepared using a different precursor powder batch. Again the DTA data are very similar, showing that the DTA data is consistent from powder batch to powder batch.

The DTA data in Figure 1-1 for the Ba-free material show that there are no liquidforming reactions until about $960^{\circ} \mathrm{C}$ which is significantly higher than for the Bacontaining samples. As will be discussed later for the Ba-containing materials, the presence of a liquid accelerates formation of the TI-1223 phase. The problem with the Ba-free composition is that with the liquid forming reaction(s) being so high, it is difficult to prevent the loss of thallium. The Meissner data given in Figure 1-2 illustrates the difficulty in formation of the TI-1223 phase for this composition. The Meissner data show that the TI-1212 phase is formed from a gold-wrapped pellet that was heat treated in oxygen at $920^{\circ} \mathrm{C}$ for 2.5 hours. The $T_{c, o n s e t}$ at $60 \mathrm{~K}$ is indicative of the TI- 1212 phase, 
where as the $T_{c, \text { onset }}$ of TI-1223 is normally about $120 \mathrm{~K}$. In an effort to form Ba-free TI1223 , samples were heated at $940^{\circ} \mathrm{C}$ for time periods of up to 8 hours. We were unable to process materials in the temperature range of the liquid-forming reaction due to excessive loss of thallium. The Meissner data for $940^{\circ} \mathrm{C}$ processed samples with holds of 2.5 and 8 hours (Fig. 1-2) indicate that 40 and $75 \%$ of the $\mathrm{Tl}-1212$ phase has converted to $\mathrm{Tl}-1223$, respectively.

\subsubsection{Effect of the TI:Pb ratio}

The ratio of $\mathrm{Tl}$ to $\mathrm{Pb}$ had a dramatic effect on the temperature where liquid formation occurs, which in turn, effected TI-1223 phase formation and grain size. Figure 1-3 shows DTA data for three samples with an initial stoichiometry of $\left(\mathrm{Tl}_{\mathrm{y}} \mathrm{Pb}_{1-\mathrm{y}}\right)\left(\mathrm{Sr}_{0.6} \mathrm{Ba}_{0.4}\right)_{2}$ $\mathrm{Ca}_{2} \mathrm{Cu}_{3} \mathrm{O}_{x}$, where $\mathrm{y}=0.75,0.50$, and 0.25 . The thermal event between 880 and $900^{\circ} \mathrm{C}$ for the thallium-rich sample did not seem to be related to $\mathrm{Tl}-1223$ formation. Of importance are the thermal events greater than $900^{\circ} \mathrm{C}$ for the three compositions. Although the reactions involved in these liquid-forming reactions (i.e., the thermal events with onsets of about $910^{\circ} \mathrm{C}, 900^{\circ} \mathrm{C}$, and $920^{\circ} \mathrm{C}$ for the $\mathrm{y}=0.75 .0 .50$, and 0.25 compositions, respectively) have not been determined, there influence on the kinetics of Tl-1223 growth is dramatic. Meissner data (Fig. 1-4) for pellet samples of these compositions that were heat treated for 2.5 hours at $920^{\circ} \mathrm{C}$ illustrates this point. The superconducting fraction of sample with $y=0.5$ is clearly $\mathrm{TI}-1223$. From the DTA data (Fig. 1-3) it is seen that a processing temperature of $920^{\circ} \mathrm{C}$ is well into the temperature region where liquid is present. For the other two compositions, a temperature of $920^{\circ} \mathrm{C}$ is only at the onset of the first major thermal event. The high thallium sample $(y=0.75)$ shows no evidence of T1-1223 as shown from the Meissner data. The low thallium sample, where the processing temperature is farther into the thermal event, had approximately $30 \%$ of its superconducting fraction as TI-1223.

Heat treatment of these samples at higher temperatures increases the amount of liquid present, and therefore the kinetics of conversion to TI-1223. For example, using a processing temperature of $940^{\circ} \mathrm{C}$ which is above the DTA signal minimum of the thermal event of interest of the three compositions, and holding for the same 2.5 hour time period as the $920^{\circ} \mathrm{C}$ sample, should increase the volume fraction of TI-1223. This 
is indeed the case for the low and high thallium samples which were mainly TI-1212 after the $920^{\circ} \mathrm{C}$ treatment, as shown by the Meissner data presented in Figure 1-5. The $y=0.5$ sample was already converted to $\mathrm{TI}-1223$ at $920^{\circ} \mathrm{C}$ and shows little change in the Meissner data for the $940^{\circ} \mathrm{C}$ processed sample.

Optical photomicrographs of polished pellet cross-sections illustrate the effect processing in the presence of a liquid phase has on microstructural development. Examples from the three compositions with differing $\mathrm{Tl}: \mathrm{Pb}$ ratios are given in Figures 16 and $1-7$ for the $920^{\circ} \mathrm{C}$ and $940^{\circ} \mathrm{C}$ processing conditions, respectively. At the $920^{\circ} \mathrm{C}$ processing condition only the $y=0.5$ sample had a significant amount of liquid present. Figure 1-6 for $\mathrm{Tl}_{0.5} \mathrm{~Pb}_{0.5}$ shows that large grains of $\mathrm{Tl}-1223$ that formed under these conditions where differences in contrast is due to different grain orientations. The other two compositions shown in Figure $6\left(\mathrm{TI}_{0.75} \mathrm{~Pb}_{0.25}\right.$ and $\left.\mathrm{TI}_{0.25} \mathrm{~Pb}_{0.75}\right)$ have grain sizes much too small to be viewed optically and contain much more porosity (very dark regions) due to the absence of liquid-phase sintering. In Figure 1-7, all three of the samples show very large $\mathrm{Tl}-1223$ grains due to the higher processing temperature of $940^{\circ} \mathrm{C}$. The grain size of the TI-1223 phase decreases with increasing lead content. Apparently increasing the lead content reduces the TI-1223 nucleation rate and/or inhibits the $\mathrm{Tl}-1223$ growth rate.

\subsubsection{Effect of Excess $\mathrm{Ca}$ and $\mathrm{Cu}$}

The effect of excess $\mathrm{Ca}$ and $\mathrm{Cu}$ was investigated to determine if it enhances the formation of the three copper oxide layer $\mathrm{Tl}-1223$ phase in the $\mathrm{Pb}$ - and $\mathrm{Sr}$-substituted materials similar to what has been found in the unsubstituted TI-Ba-Ca-Cu oxide materials. Powder with the same $\mathrm{Tl}$ to $\mathrm{Pb}$ ratios as described above were prepared with $10 \%$ excess $\mathrm{Ca}$ and $\mathrm{Cu}$ and processed under similar conditions. The effect of excess $\mathrm{Ca}$ and $\mathrm{Cu}$ on the liquid-forming reaction temperature is shown for the $\mathrm{y}=0.75$ and $\mathrm{y}=0.25$ compositions. Figure 1-8 show DTA results for the these two $\mathrm{Tl}: \mathrm{Pb}$ content materials with and without excess $\mathrm{Ca}$ and $\mathrm{Cu}$. The figure shows that for both $\mathrm{TI} / \mathrm{Pb}$ stoichiometries the presence of excess $\mathrm{Ca}$ and $\mathrm{Cu}$ reduces the onset temperature of the main thermal event. The reduced temperature promotes formation of the TI-1223 phase. Again, referring to Meissner data, Figure 1-9 shows for the case of the $y=0.75$ 
composition, the sample with excess $\mathrm{Ca}$ and $\mathrm{Cu}$ forms more of the $\mathrm{Tl}-1223$ phase at $920^{\circ} \mathrm{C}$ as would be expected from the DTA data. Processing these materials at $940^{\circ} \mathrm{C}$ converts the remaining $\mathrm{Tl}-1212$ to $\mathrm{TI}-1223$, again as expected.

The addition of excess $\mathrm{Ca}$ and $\mathrm{Cu}$ has been shown to reduce the temperature of the liquid forming reaction(s) important to $\mathrm{Tl}-1223$ phase formation, and therefore improve the kinetics of formation. In addition to altering the formation kinetics, the excess $\mathrm{Ca}$ and $\mathrm{Cu}$ affect the nucleation and growth of the Tl-1223 phase. Back scattered electron images of the $y=0.75$ samples processed at $940^{\circ} \mathrm{C}$ illustrates this effect as shown in Figure 1-10. The Tl-1223 grains in the sample with excess $\mathrm{Ca}$ and $\mathrm{Cu}$ are much finer than those in the stoichiometric sample. Apparently the additional $\mathrm{Ca}$ and $\mathrm{Cu}$ promotes nucleation of the TI-1223 phase leading to finer grained material.

\subsubsection{Effect of Stoichiometry on $T_{c}$}

Another interesting result of this study is the effect stoichiometry has on the $T_{c}$ of TI1223. Near-equilibrium 2-zone experiments by Aselage at SNL on the nominal Hitachi $\left[\left(\mathrm{Tl}_{0.5} \mathrm{~Pb}_{0.5}\right)\left(\mathrm{Sr}_{0.8} \mathrm{Ba}_{0.2}\right)_{2} \mathrm{Ca}_{2} \mathrm{Cu}_{3} \mathrm{O}_{\mathrm{x}}\right]$ composition have shown that the $\mathrm{T}_{\mathrm{c}}$ of a sample decreases systematically with increasing partial pressure of $\mathrm{Tl}_{2} \mathrm{O}$ for a fixed sample temperature. Although the partial pressure of $\mathrm{Tl}_{2} \mathrm{O}$ was not fixed in our pellet processing studies, one might expect that for a given set of processing conditions $T_{c}$ should also vary systematically with the starting $\mathrm{TI}$ to $\mathrm{Pb}$ ratio and the total amount of thallium present. A compilation of Meissner data shows that this is indeed the case. Figure 1-11 presents the Meissner data for the various compositions where $y=0.25$ that were processed at $940^{\circ} \mathrm{C}$ for 2.5 hours. In addition to the compositional variations already discussed, data are included for samples where the total initial $\mathrm{Tl}$ and $\mathrm{Pb}$ content was increased by $30 \%$. Although under these conditions not all of the superconducting material has been fully converted, the $T_{c, \text { onset }}$ 's of the TI-1223 that is present are all the same. A composite plot of the $T_{c, 0 n s e t}$ data as a function of $y$ for the various compositions prepared in this study and processed at $940^{\circ} \mathrm{C}$ is given in Figure 1-12. The figure shows that $T_{c}$ is dependent on the initial $\mathrm{TI}$ to $\mathrm{Pb}$ ratio, where $\mathrm{T}_{\mathrm{c}}$ decreases with increasing thallium content which is consistent with the results of Aselage. Figure 1-13 is a plot of $\mathrm{Tl}-1223$ lattice parameters as a function of $\mathrm{Tl}_{2} \mathrm{O}$ 
partial pressure from the work of Aselage. Also plotted are the lattice parameters of the stoichiometric $y=0.25$ sample. Although the $\mathrm{Tl}_{2} \mathrm{O}$ partial pressure was somewhat arbitrarily chosen, the magnitude of the lattice parameters are consistent with the work of Aselage.

\section{$1.3 \quad$ Future Work}

Results of this work have shown the important role liquids play in the phase formation and microstructural development of Pb-and Sr-substituted TI-1223. Also, the effects of compositional variation on the temperature of liquid formation and the resulting TI-1223 critical temperature and grain size have been identified. Based on this work we will attempt to probe in more detail the composition of the liquid(s) and apply liquid-phase processing to the production of practical superconductors. Specifically, we will initiate a series of quench experiments with $\mathrm{E}$. Hellstrom (University of Wisconsin-Madison). We will focus on the growth of TI-1223 from a melt using powder-in-tube tapes. The work will be coordinated with IGC as part of our TI-wire development collaboration. Results of these experiments will be used to develop processing protocols for both closed system tapes and open system thick films. 


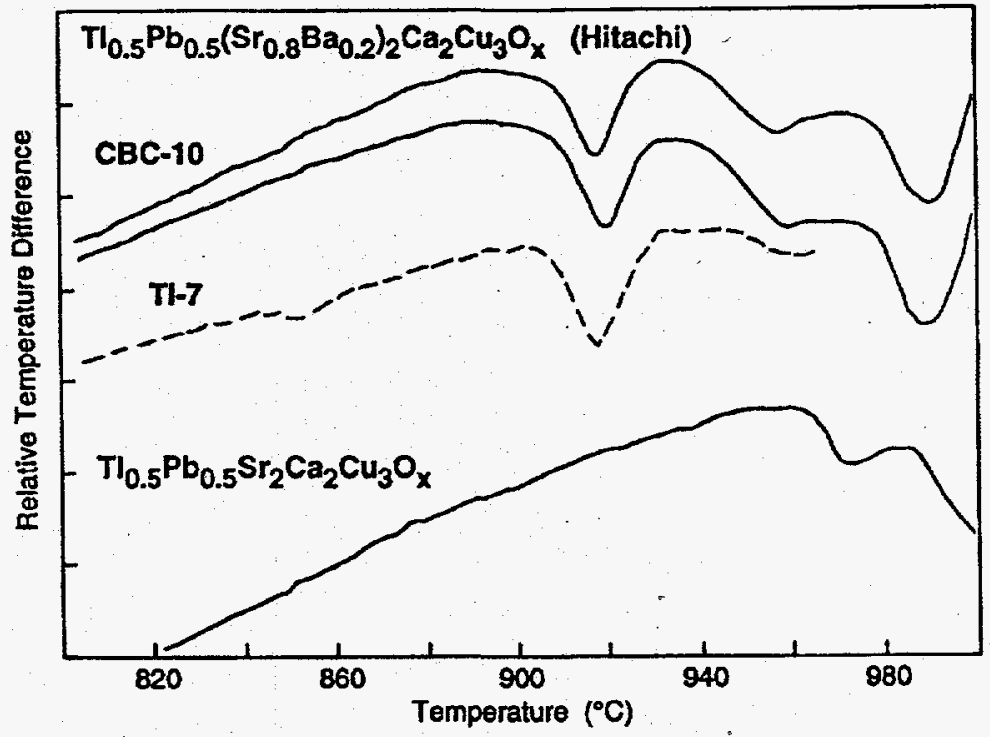

Figure 1-1. DTA of gold foil-wrapped pellets of unreacted $\left(\mathrm{TI}_{0.5} \mathrm{~Pb}_{0.5}\right)\left(\mathrm{Sr}_{0.8} \mathrm{Ba}_{0.2}\right)_{2} \mathrm{Ca}_{2} \mathrm{Cu}_{3} \mathrm{O}_{\mathrm{x}}[\mathrm{CBC}-10, \mathrm{TI}-7]$ and $\left(\mathrm{TI}_{0.5} \mathrm{~Pb}_{0.5}\right) \mathrm{Sr}_{2} \mathrm{Ca}_{2} \mathrm{Cu}_{3} \mathrm{O}_{\mathrm{x}}$ in oxygen.

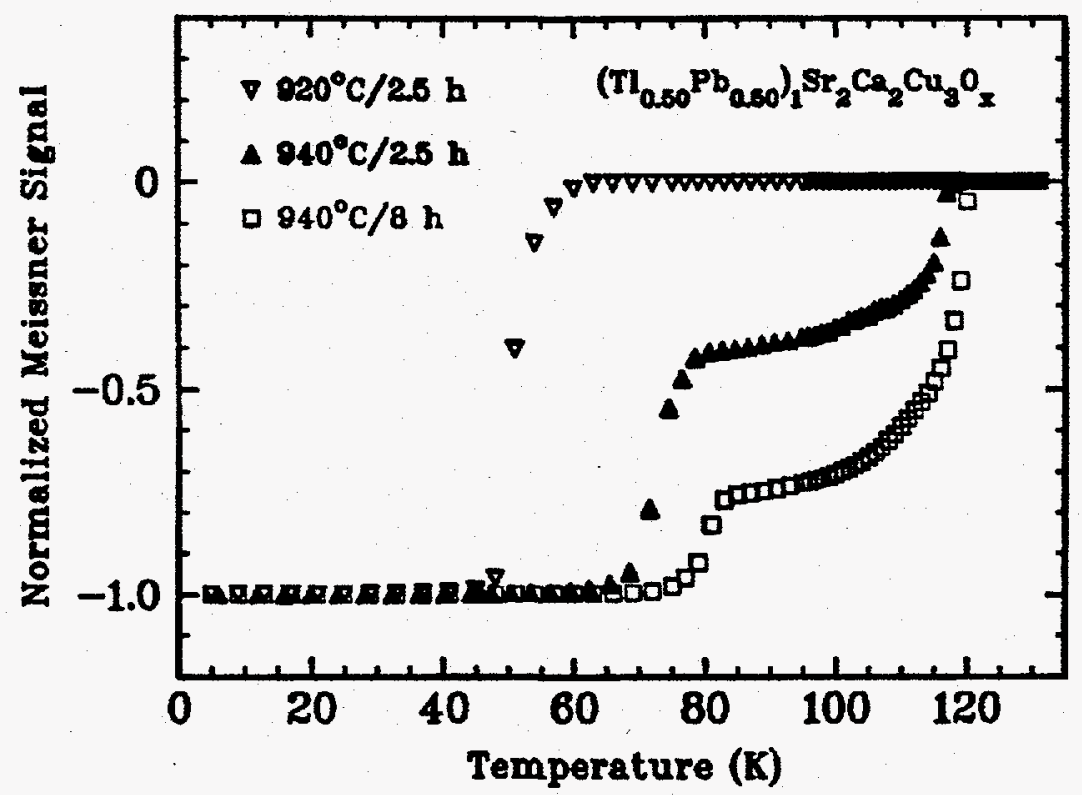

Figure 1-2 Meissner data of $\left(\mathrm{Tl}_{0.5} \mathrm{~Pb}_{0.5}\right) \mathrm{Sr}_{2} \mathrm{Ca}_{2} \mathrm{Cu}_{3} \mathrm{O}_{x}$ processed in oxygen at $920^{\circ} \mathrm{C}$ for 2.5 hours and at $940^{\circ} \mathrm{C}$ for 2.5 and 8 hours. 


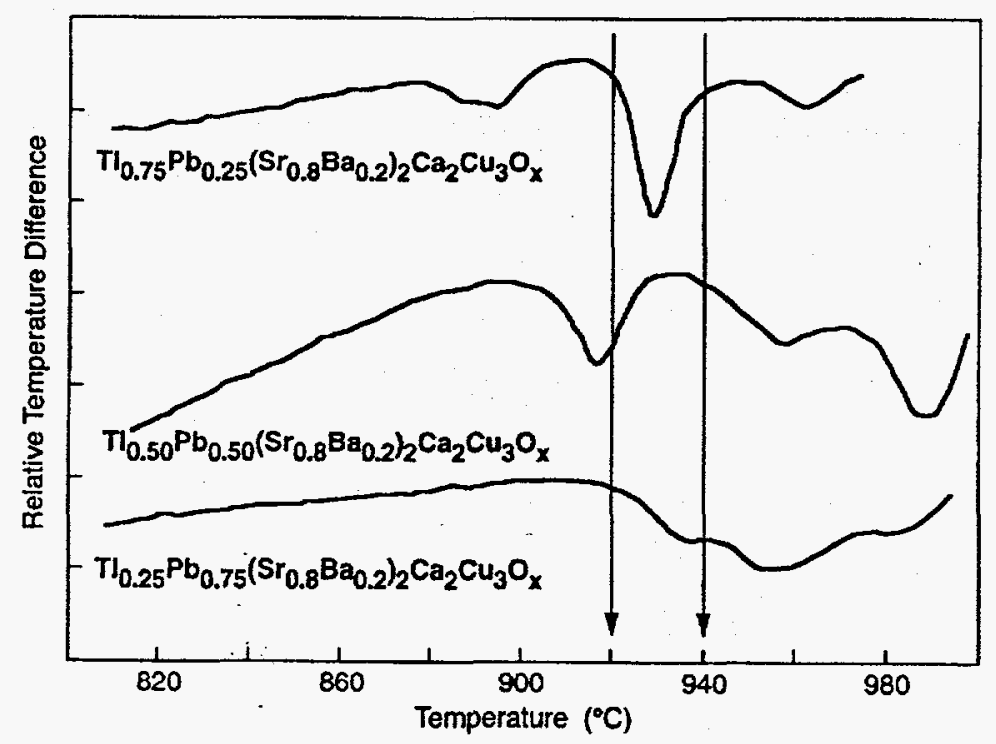

Figure 1-3. DTA of gold foil-wrapped pellets of unreacted $\left(\mathrm{Tl}_{0.75} \mathrm{~Pb}_{0.25}\right)\left(\mathrm{Sr}_{0.8} \mathrm{Ba}_{0.2}\right)_{2} \mathrm{Ca}_{2} \mathrm{Cu}_{3} \mathrm{O}_{x}\left(\mathrm{Tl}_{0.50} \mathrm{~Pb}_{0.50}\right)\left(\mathrm{Sr}_{0.8} \mathrm{Ba}_{0.2}\right)_{2} \mathrm{Ca}_{2} \mathrm{Cu}_{3} \mathrm{O}_{x}$, and $\left(\mathrm{Tl}_{0.25} \mathrm{~Pb}_{0.75}\right)\left(\mathrm{Sr}_{0.8} \mathrm{Ba}_{0.2}\right)_{2} \mathrm{Ca}_{2} \mathrm{Cu}_{3} \mathrm{O}_{x}$ in oxygen.

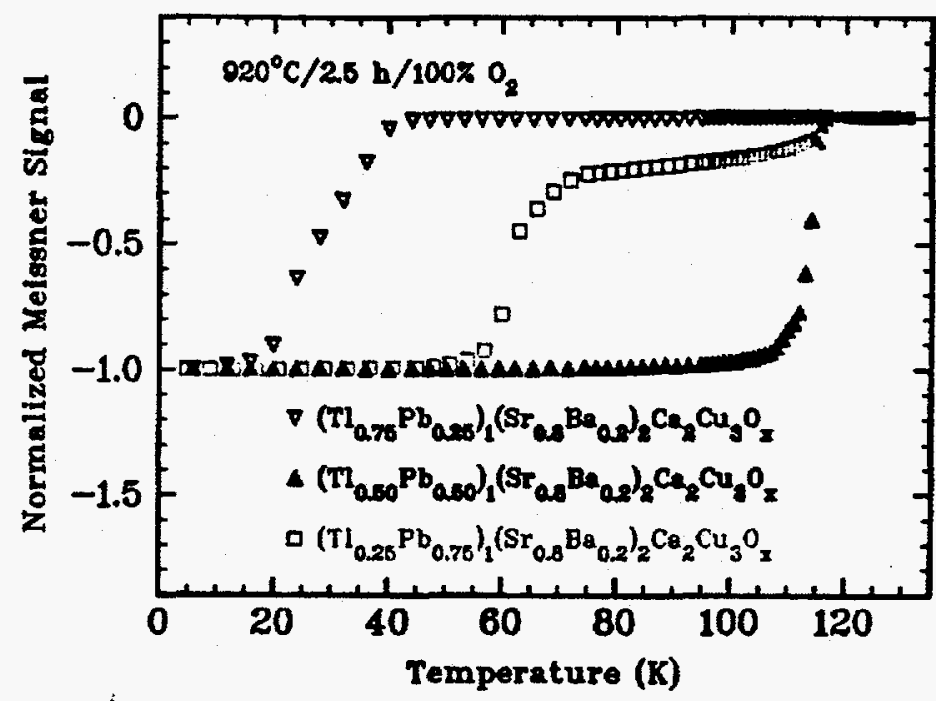

Figure 1-4. Meissner data of $\left(\mathrm{Tl}_{0.75} \mathrm{~Pb}_{0.25}\right)\left(\mathrm{Sr}_{0.8} \mathrm{Ba}_{0.2}\right)_{2} \mathrm{Ca}_{2} \mathrm{Cu}_{3} \mathrm{O}_{\mathrm{x}}$ $\left(\mathrm{Tl}_{0.50} \mathrm{~Pb}_{0.50}\right)\left(\mathrm{Sr}_{0.8} \mathrm{Ba}_{0.2}\right)_{2} \mathrm{Ca}_{2} \mathrm{Cu}_{3} \mathrm{O}_{\mathrm{x}}$ and $\left(\mathrm{TI}_{0.25} \mathrm{~Pb}_{0.75}\right)\left(\mathrm{Sr}_{0.8} \mathrm{Ba}_{0.2}\right)_{2}$ $\mathrm{Ca}_{2} \mathrm{Cu}_{3} \mathrm{O}_{x}$ processed in oxygen at $920^{\circ} \mathrm{C}$ for 2.5 hours. 


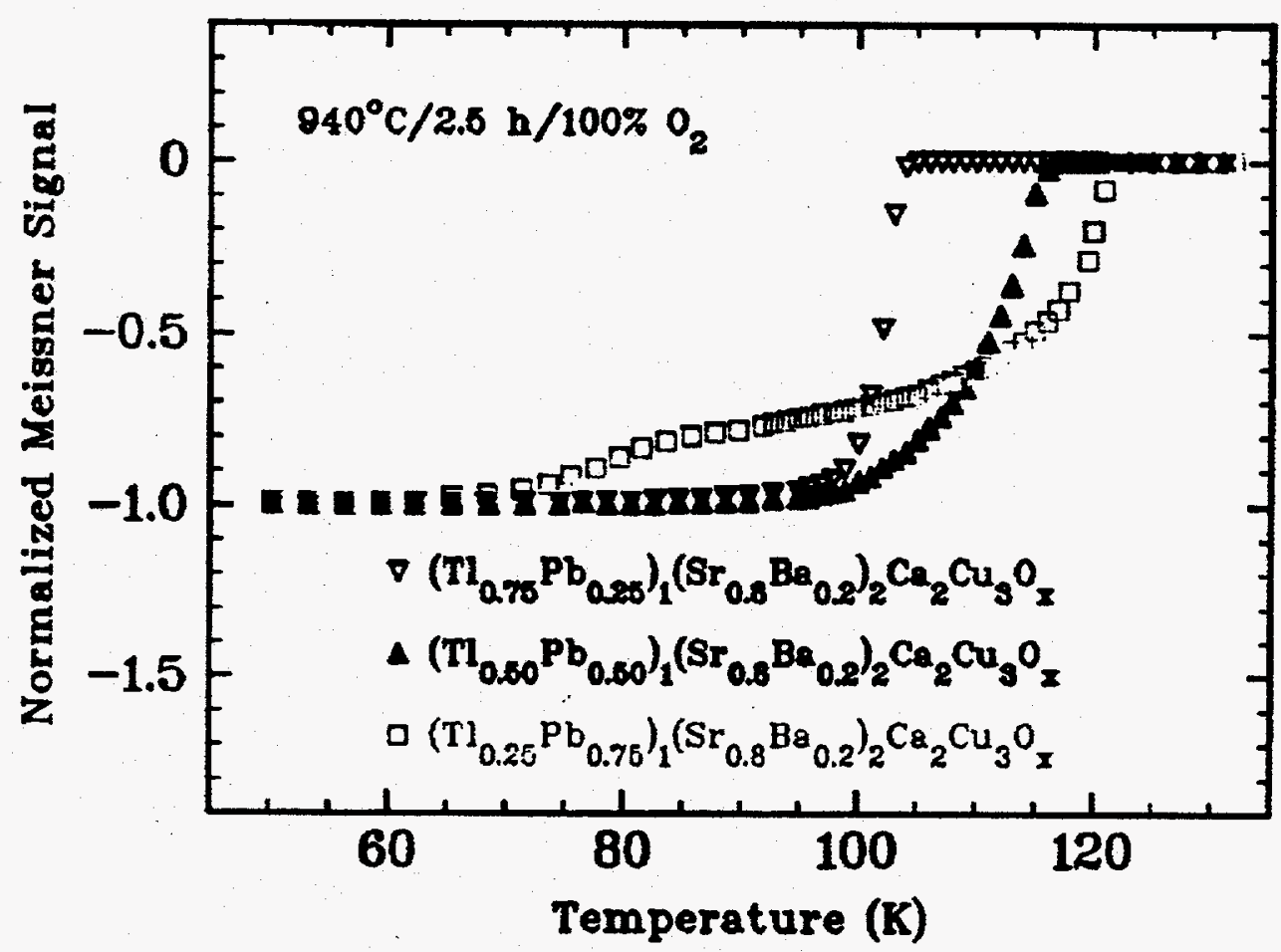

Figure 1-5 Meissner data of $\left(\mathrm{TI}_{0.75} \mathrm{~Pb}_{0.25}\right)\left({ }_{\mathrm{Sro} 0.8 \mathrm{Ba} 0.2}\right)_{2} \mathrm{Ca}_{2} \mathrm{Cu}_{3} \mathrm{O}_{\mathrm{x}}$, $\left(\mathrm{TI}_{0.50} \mathrm{~Pb}_{0.50}\right)\left(\mathrm{Sr}_{0.8} \mathrm{Ba}_{0.2}\right)_{2} \mathrm{Ca}_{2} \mathrm{Cu}_{3} \mathrm{O}_{\mathrm{x}}$, and $\left(\mathrm{TI}_{0.25} \mathrm{~Pb}_{0.75}\right)\left(\mathrm{Sr}_{0.8} \mathrm{Ba}_{0.2}\right)_{2}$ $\mathrm{Ca}_{2} \mathrm{Cu}_{3} \mathrm{O}_{x}$ processed in oxygen at $940^{\circ} \mathrm{C}$ for 2.5 hours. 


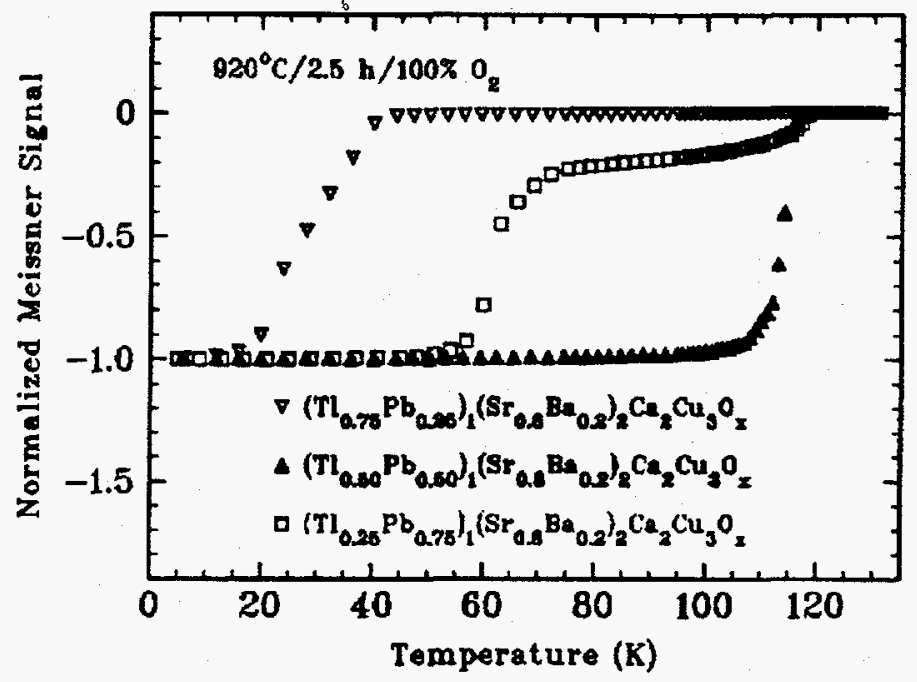

\section{$\mathrm{TI}_{0.75} \mathrm{~Pb}_{0.25}$ \\ $\mathrm{TI}_{0.50} \mathrm{~Pb}_{0.50}$ \\ $\mathrm{TI}_{0.25} \mathrm{~Pb}_{0.75}$}
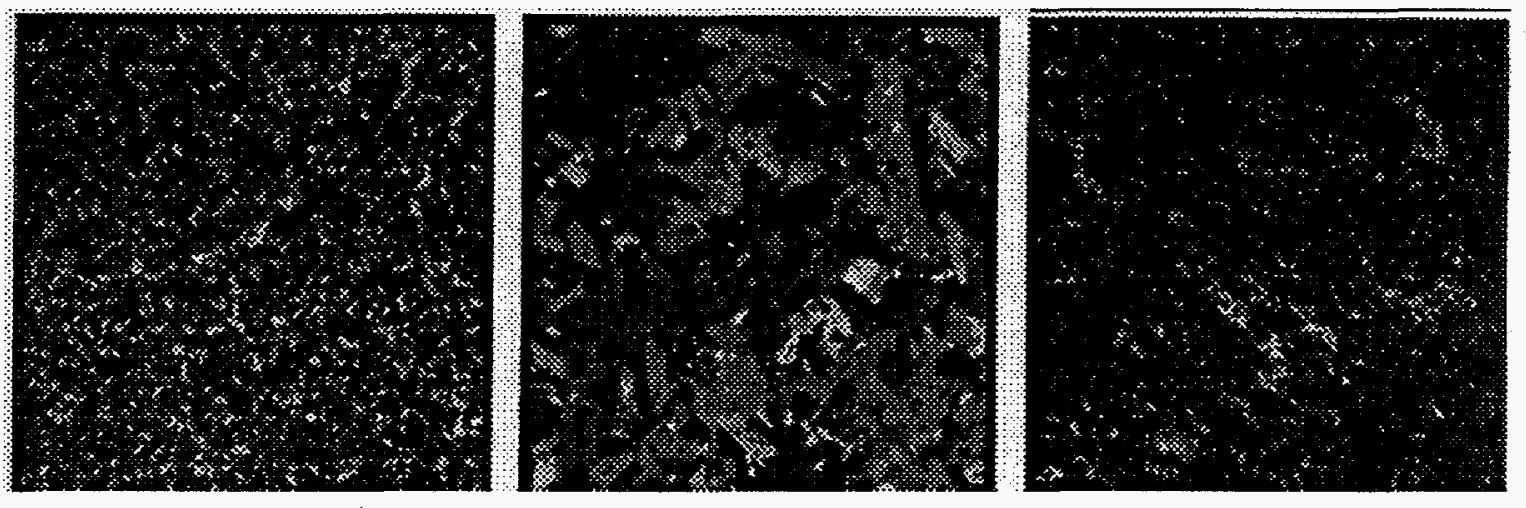

\section{$50 \mu \mathrm{m}$}

Figure 1-6. Optical photomicrographs of $\left(\mathrm{Tl}_{0.75} \mathrm{~Pb}_{0.25}\right)\left(\mathrm{Sr}_{0.8} \mathrm{Ba}_{0.2}\right)_{2} \mathrm{Ca}_{2} \mathrm{Cu}_{3} \mathrm{O}_{\mathrm{x}}$ $\left(\mathrm{TI}_{0.50} \mathrm{~Pb}_{0.50}\right)\left(\mathrm{Sr}_{0.8} \mathrm{Ba}_{0.2}\right)_{2} \mathrm{Ca}_{2} \mathrm{Cu}_{3} \mathrm{O}_{\mathrm{x}}$, and $\left(\mathrm{Tl}_{0.25} \mathrm{~Pb}_{0.75}\right)\left(\mathrm{Sr}_{0.8} \mathrm{Ba}_{0.2}\right)_{2} \mathrm{Ca}_{2} \mathrm{Cu}_{3} \mathrm{O}_{\mathrm{x}}$ processed in oxygen at $920^{\circ} \mathrm{C}$ for 2.5 hours. 

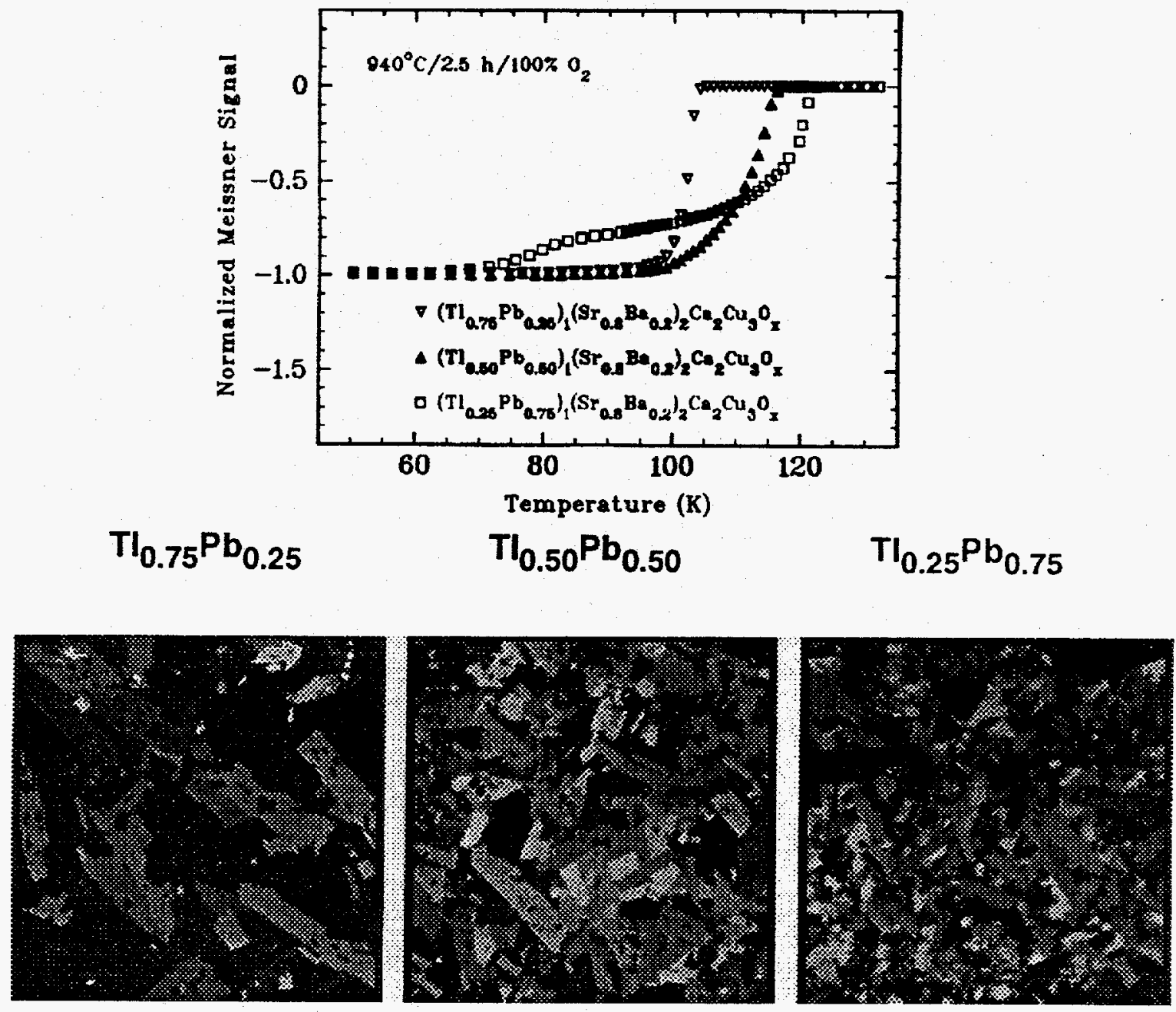

$50 \mu \mathrm{m}$

Figure 1-7. Optical photomicrographs of $\left(\mathrm{Tl}_{0.75} \mathrm{~Pb}_{0.25}\right)\left(\mathrm{Sr}_{0.8} \mathrm{Ba}_{0.2}\right)_{2} \mathrm{Ca}_{2} \mathrm{Cu}_{3} \mathrm{O}_{\mathrm{x}}$, $\left(\mathrm{TI}_{0.50} \mathrm{~Pb}_{0.50}\right)\left(\mathrm{Sr}_{0.8} \mathrm{Ba}_{0.2}\right)_{2} \mathrm{Ca}_{2} \mathrm{Cu}_{3} \mathrm{O}_{\mathrm{x}}$, and $\left(\mathrm{TI}_{0.25} \mathrm{~Pb}_{0.75}\right)\left(\mathrm{Sr}_{0.8} \mathrm{Ba}_{0.2}\right)_{2}$ $\mathrm{Ca}_{2} \mathrm{Cu}_{3} \mathrm{O}_{x}$ processed in oxygen at $940^{\circ} \mathrm{C}$ for 2.5 hours. 


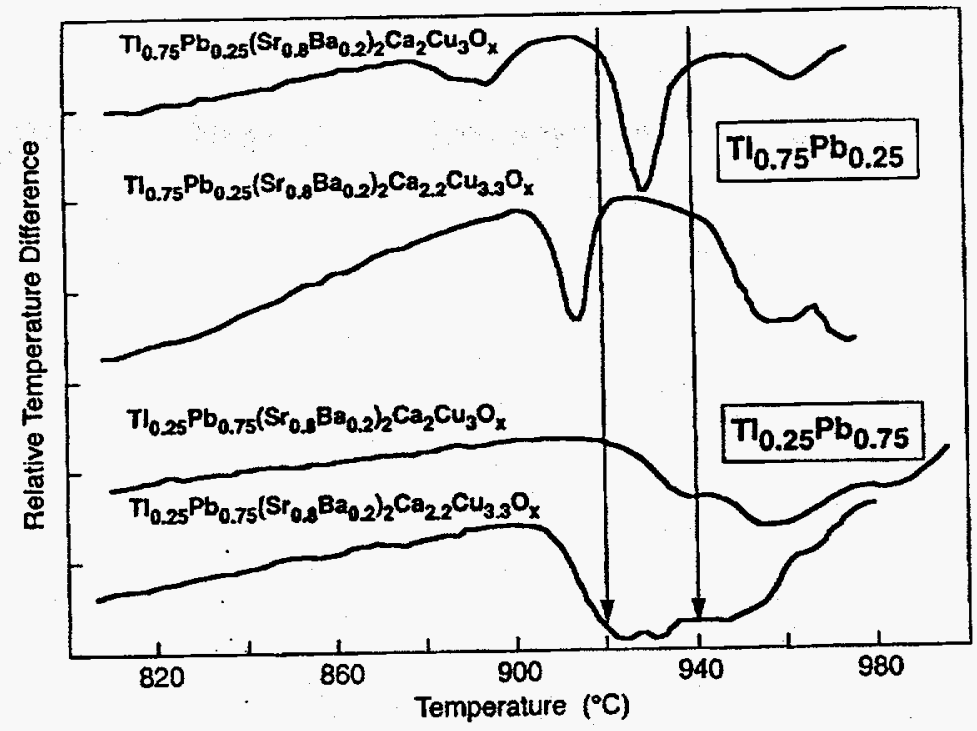

Figure 1-8. DTA of gold foil-wrapped pellets of unreacted $\left(\mathrm{Tl}_{0.75} \mathrm{~Pb}_{0.25}\right)\left(\mathrm{Sr}_{0.8} \mathrm{Ba}_{0.2}\right)_{2}$ $\mathrm{Ca}_{2} \mathrm{Cu}_{3} \mathrm{O}_{\mathrm{x}},\left(\mathrm{Tl}_{0.75} \mathrm{~Pb}_{0.25}\right)\left(\mathrm{Sr}_{0.8} \mathrm{Ba}_{0.2}\right)_{2} \mathrm{Ca}_{2.2} \mathrm{Cu}_{3.3} \mathrm{O}_{\mathrm{x}},\left(\mathrm{Tl}_{0.25} \mathrm{~Pb}_{0.75}\right)\left(\mathrm{Sr}_{0.8} \mathrm{Ba}_{0.2}\right)_{2}$ $\mathrm{Ca}_{2} \mathrm{Cu}_{3} \mathrm{O}_{\mathrm{x}}$, and $\left(\mathrm{Tl}_{0.25} \mathrm{~Pb}_{0.75}\right)\left(\mathrm{Sr}_{0.8} \mathrm{Ba}_{0.2}\right)_{2} \mathrm{Ca}_{2.2} \mathrm{Cu}_{3.3} \mathrm{O}_{\mathrm{x}}$ in oxygen.

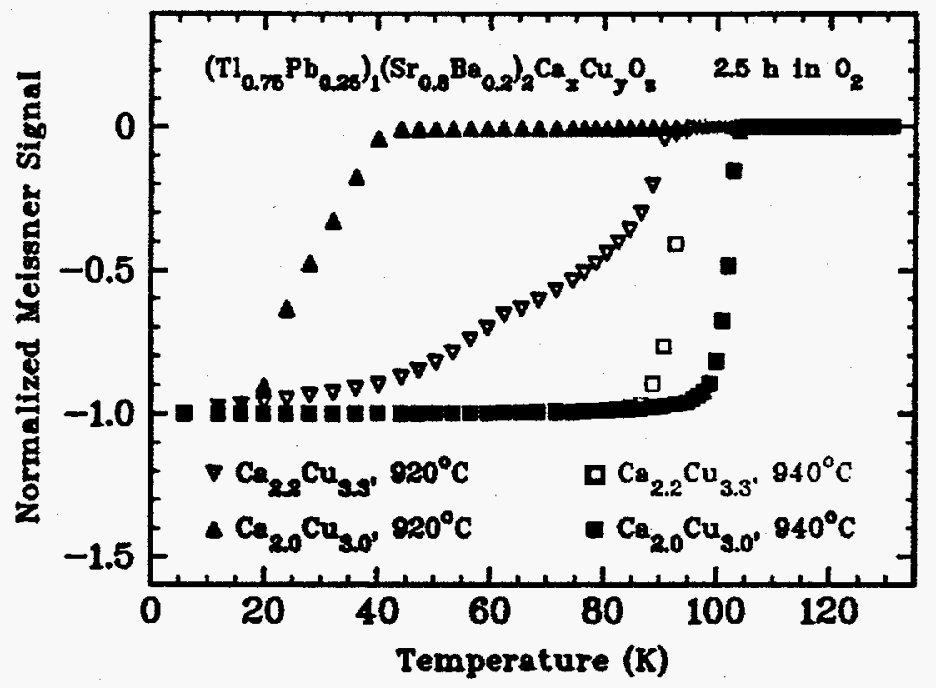

Figure 1-9. Meissner data of $\left(\mathrm{Tl}_{0.75} \mathrm{~Pb}_{0.25}\right)\left(\mathrm{Sr}_{0.8} \mathrm{Ba}_{0.2}\right)_{2} \mathrm{Ca}_{a} \mathrm{Cu}_{b} \mathrm{O}_{x}$, where a,b equal 2.0,3.0, and 2.2,3.3 for samples processed in oxygen at $920^{\circ} \mathrm{C}$ and $940^{\circ} \mathrm{C}$ for 2.5 hours. 


\section{Stoichiometric}

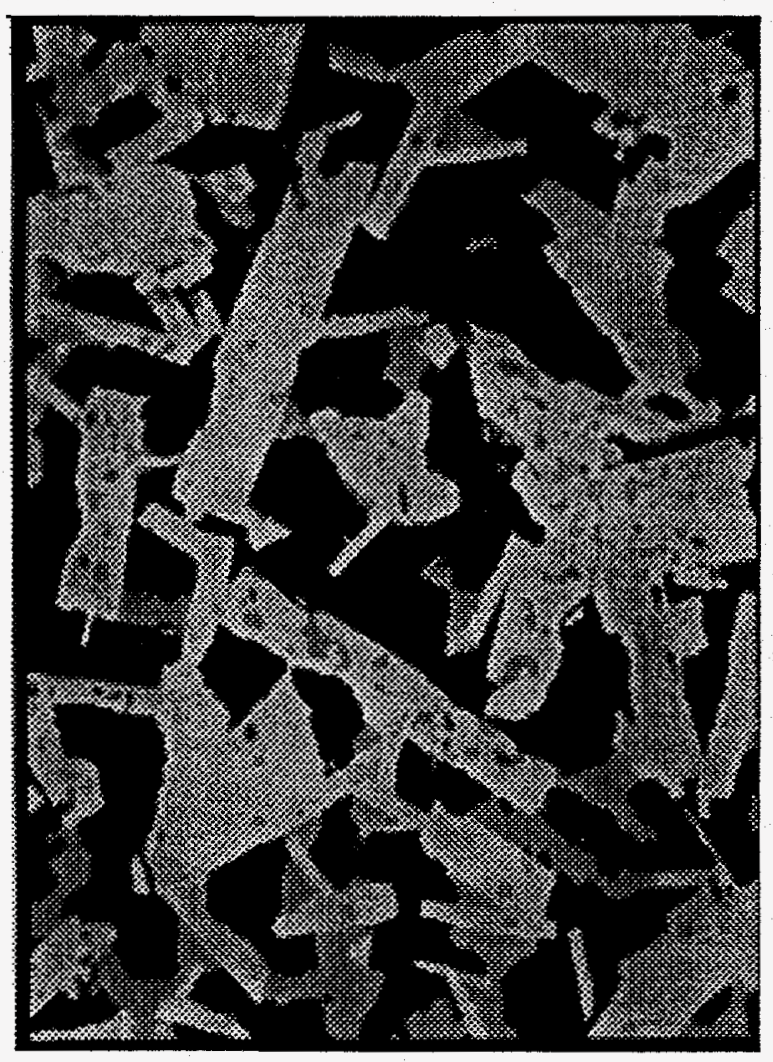

$50 \mu \mathrm{m}$

\section{$10 \%$ Excess $\mathrm{Ca} \& \mathrm{Cu}$}

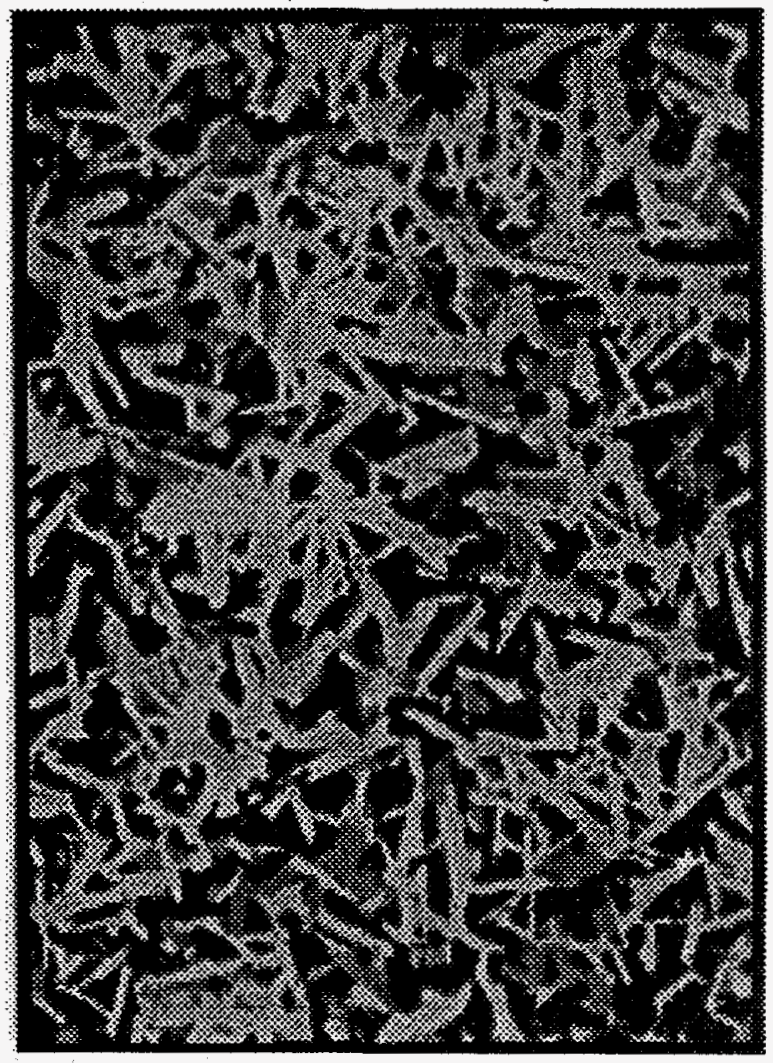

$50 \mu \mathrm{m}$

Figure 1-10. Back scattered electron photomicrographs of $\left(\mathrm{TI}_{0.75} \mathrm{~Pb}_{0.25}\right)\left(\mathrm{Sr}_{0.8} \mathrm{Ba}_{0.2}\right)_{2}$ $\mathrm{Ca}_{a} \mathrm{Cu}_{b} \mathrm{O}_{x}$, where $\mathrm{a}, \mathrm{b}$ equal 2.0,3.0, and 2.2,3.3 for samples processed in oxygen at $940^{\circ} \mathrm{C}$ for 2.5 hours. 


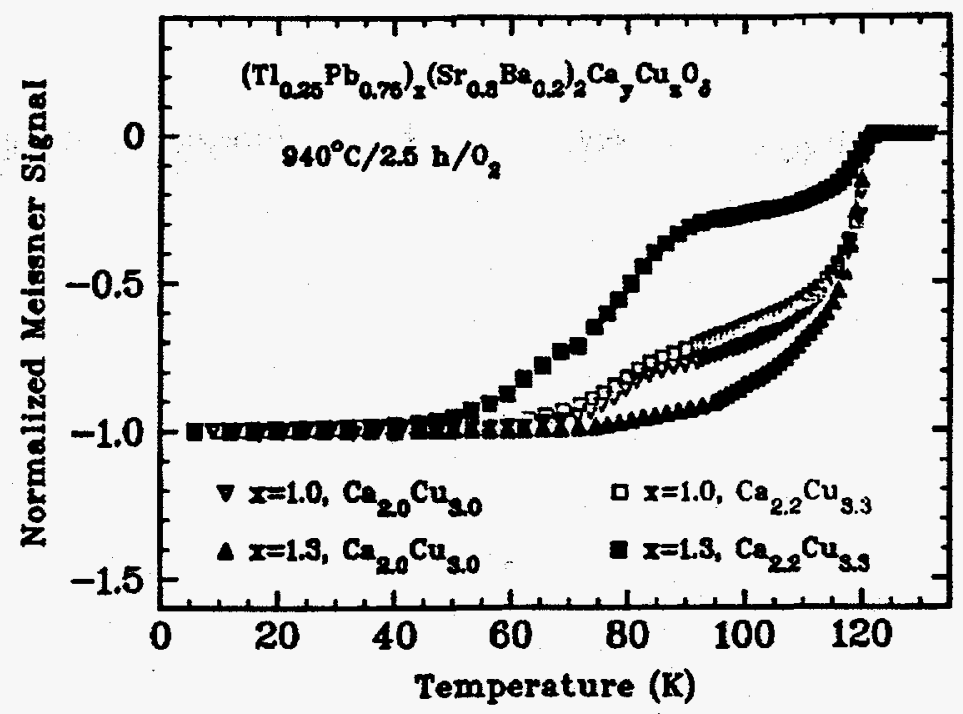

Figure 1-11. Meissner data for various compositions of samples with Tl-to-Pb ratios of $1: 3$ processed in oxygen at $940^{\circ} \mathrm{C}$ for 2.5 hours.

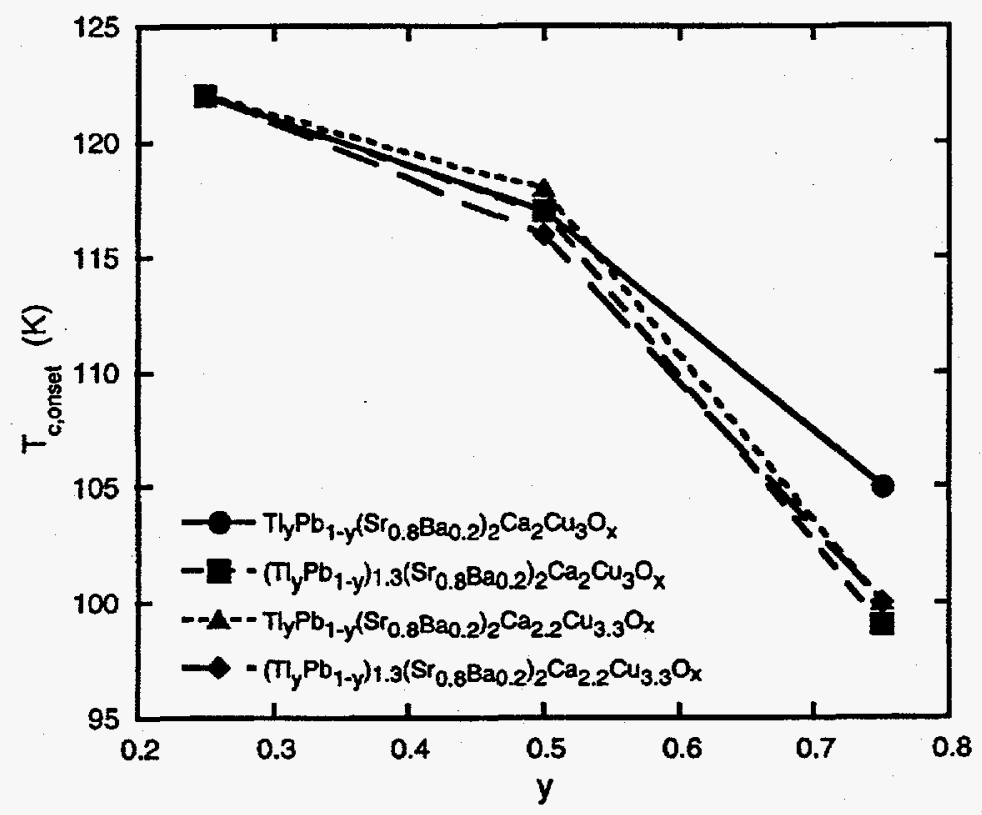

Figure 1-12. $\mathrm{T}_{\mathrm{C} \text {, onset }}$ versus $\mathrm{TI}$ content, $\mathrm{y}$, for samples processed in oxygen at $940^{\circ} \mathrm{C}$ for 2.5 hours. 

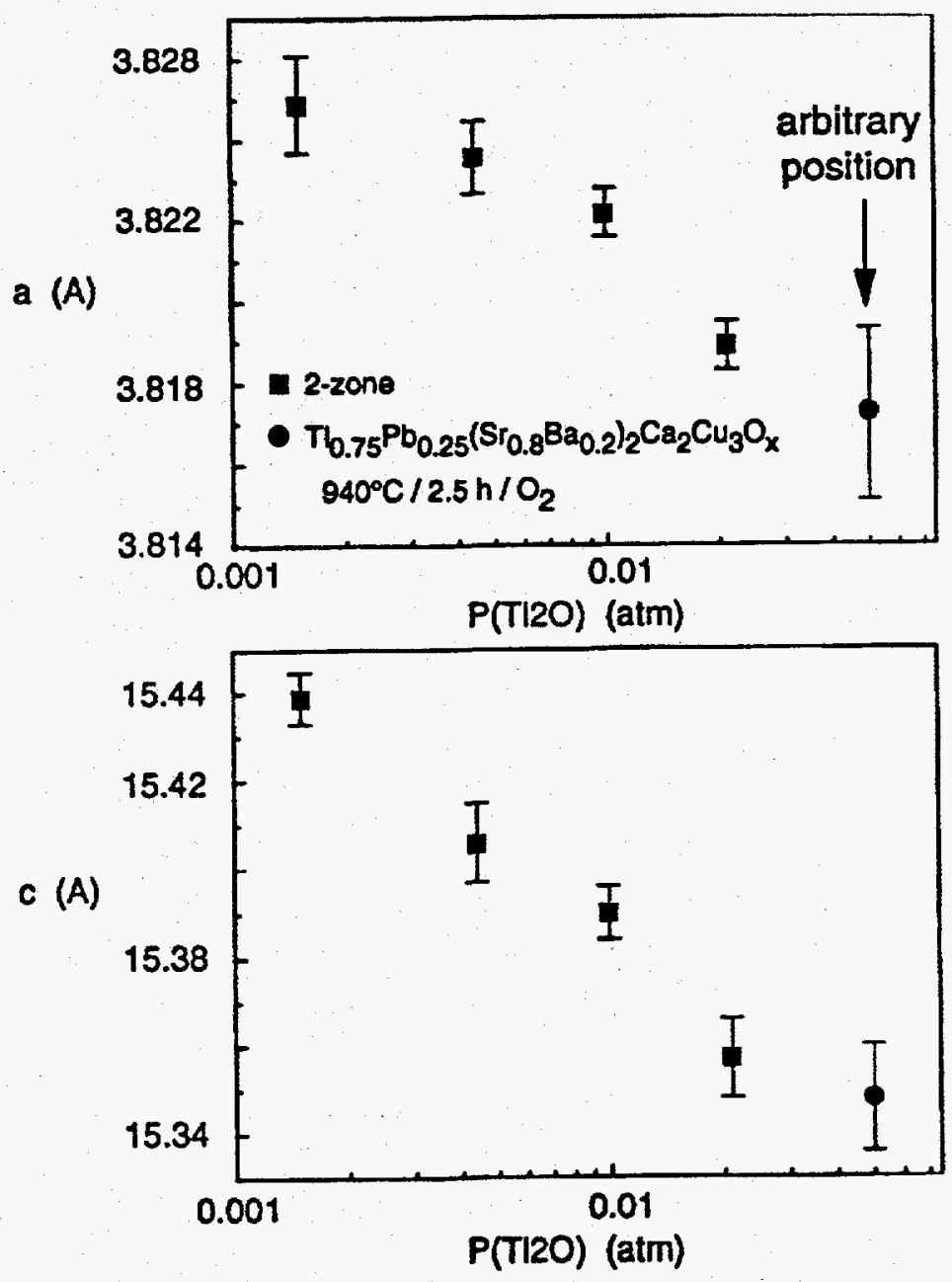

Figure 1-13. Lattice parameters of nominally $\left(\mathrm{Tl}_{0.5} \mathrm{~Pb}_{0.5}\right)\left(\mathrm{Sr}_{0.8} \mathrm{Ba}_{0.2}\right)_{2} \mathrm{Ca}_{2} \mathrm{Cu}_{3} \mathrm{O}_{x}$ as a function of $\mathrm{Tl}_{2} \mathrm{O}$ partial pressure for samples processed in 2-zone furnace and $\left(\mathrm{TI}_{0.75} \mathrm{~Pb}_{0.25}\right)\left(\mathrm{Sr}_{0.8} \mathrm{Ba}_{0.2}\right)_{2} \mathrm{Ca}_{2} \mathrm{Cu}_{3} \mathrm{O}_{\mathrm{x}}$ processed in oxygen at $940^{\circ} \mathrm{C}$ for 2.5 hours. 
2 Growth of thick ( $\mathrm{Tl}, \mathrm{Pb})-(\mathrm{Ba}, \mathrm{Sr})-\mathrm{Ca}-\mathrm{Cu}-\mathrm{O}$ superconducting films using a controlled TI-Oxide source

\subsection{Introduction}

$\mathrm{Pb}$ and $\mathrm{Sr}$ substitution of $\mathrm{TIBaCaCuO}$ materials favors the formation of single TI-layer phases such as the 1212 and the 1223. The superconducting transition temperature $\left(T_{c}\right)$ for the substituted 1223 phase has been demonstrated to be $\sim 114 \mathrm{~K}$. It has been suggested that the high critical current densities $\left(J_{c}\right)$ measured in these materials is due to the reduced anisotropy and greater intrinsic pinning compared to the double TI-layer phases. Such $\mathrm{Pb}, \mathrm{Sr}$-doped 1223 has been used for powder-in-tube (PIT) formation of a superconducting tape with zero field $J_{c}=1 \times 10^{4} \mathrm{~A} / \mathrm{cm}^{2}$. However, weak-linked behavior resulting from a lack of texturing and/or the presence of weak links at grain boundaries causes the current-carrying properties to severely degrade moderate magnetic fields, limiting the usefulness of such tapes.

Open-face tapes resulting from the growth of thick films on a substrate are an alternative to PIT processing. In addition, such an open configuration would allow greater opportunity to study the microstructure of the superconducting material. It is understood that eventual thick film development needs to be pursued on a commercially-available, relatively low-cost substrate material that is flexible and can exist in tape or wire form, such as silver or metal alloys. However, in order to avoid confusion arising from substrate interactions at the interface, we have studied growth of $\sim 15 \mu \mathrm{m}$ thick $\mathrm{Pb}, \mathrm{Sr}$-doped $\mathrm{Tl}-1223$ films on $\mathrm{LaAlO}_{3}(100)$ substrates. Two-zone annealing of $\mathrm{Pb}, \mathrm{Sr}$-doped 1223 powder samples identified stable formation conditions.

\subsection{Progress in FY94}

Precursor films were deposited on $\mathrm{LaAlO}_{3}(100)$ substrates by screen-printing or by spray-brushing chemically-prepared TI-free $\mathrm{Pb}-\mathrm{Sr}-\mathrm{Ba}-\mathrm{Ca}-\mathrm{Cu}-\mathrm{O}$ powders. The films were doped with $5 \mathrm{wt} \% \mathrm{Ag}$, presumably to aid in sintering. The films were then heated to $850^{\circ} \mathrm{C}$ in oxygen to burn out the organic binder used for the screen-printing process. These precursor films were then thallinated and processed in a closed two-zone furnace. This allows independent control of the substrate temperature, oxygen partial 
pressure, and thallous oxide partial pressure, each of which is a critical variable for the formation of the Ti-superconducting phases. The two-zone furnace is capable of achieving temperatures in excess of $950 \pm 5^{\circ} \mathrm{C}$ over a 2.5 inch diameter region. Both substrate and TI-oxide source temperatures have been varied. Most films reported here have been annealed in pure oxygen at $920^{\circ} \mathrm{C}$ for 2 hours, and cooled to $T<100$ ${ }^{\circ} \mathrm{C}$ in about 3 hours for removal. Film properties have been measured using XRD, SEM, and magnetization. Additional experiments to enable superior grain growth using low oxygen partial pressures to achieve low-temperature melting of the precursors has also been pursued.

Figure $2-1$ is a summary of $x$-ray diffraction measurements on the films grown in $p\left(\mathrm{O}_{2}\right)=630$ Torr. Only the (00l) diffraction peaks for either the 1212 or the 1223 phases appear, suggesting c-axis alignment. The 1212 (005) and the 1223 (006) XRD peaks were used. These peaks are the largest $00 l$ peaks for each of these phases which do not overlap with the substrate peaks. At the lowest $T(T I O x)$ temperatures used, mostly $\mathrm{TI}-1212$ forms. Above $\mathrm{T}\left(\mathrm{TIO}_{\mathrm{x}}\right)=730^{\circ} \mathrm{C}$, however, both the $\mathrm{Tl}-1223$ and $\mathrm{Tl}-1212$ phases coexist. As $\mathrm{T}\left(\mathrm{TIO}_{\mathrm{x}}\right)$ is increased, the $\mathrm{Tl}-1223$ phase begins to dominate. It should be noted that the $\mathrm{TI}-1223$ phase peaks at $\mathrm{T}\left(\mathrm{TIO} \mathrm{O}_{\mathrm{x}}\right)=770^{\circ} \mathrm{C}$. Unidentified impurity peaks occurred in all the samples. Some of these peaks were pre-existing in the TI-free precursor films, most likely indicating incomplete reaction for the 2-hour reaction time used. It is also possible that the burn out process for the precursors may result in the formation of undesirable, stable oxide phases.

Scanning electron micrographs show that these two-zone processed films were smooth compared with pure TI-Ba-Ca-Cu-O films previously processed at a substrate temperature of $850^{\circ} \mathrm{C}$, with some evidence of plate-like growth occurring, however, it is likely that this is mainly a result of the higher substrate temperatures used in the present study. Microcracking remains a problem and prevents useful electrical transport characterization. Microcracking is anticipated to be less of a problem on more pliable substrates such as silver foil. Meissner measurements show that these films all have sharp superconducting transition onsets demonstrative of either the 1212 or the 1223 phases, correlating well with the XRD phase information.

Magnetic hysteresis was measured at five temperatures between 5 and $77 \mathrm{~K}$ for a 15 
$\mu \mathrm{m}$ thick film grown at a substrate temperature of $920^{\circ} \mathrm{C}$ and $\mathrm{T}\left(\mathrm{TIO} \mathrm{O}_{\mathrm{x}}\right)=770^{\circ} \mathrm{C}$. Figure 2-2 shows $\mathrm{Jc}$ as determined from these hysteresis data using the Bean model and the sample dimensions. The modest field dependence of $\mathrm{Jc}$ at lower temperatures suggests strong links between the grains after two-zone processing. $J_{c}(5 \mathrm{~K})$ is determined to be $\sim 30,000 \mathrm{Avcm}^{2}$ at low magnetic fields, dropping to $\sim 10,000 \mathrm{Acm}^{2}$ at 40K. Appreciable currents of $\sim 1,500 \mathrm{Acm}^{2}$ continue to flow even at magnetic fields perpendicular to the plane of the films, as high as 5 Tesla at $5 \mathrm{~K}$. It should be noted that magnetization estimates of critical current density are typically a lower bound; transport measurements are usually significantly higher.

It has become apparent that several of the groups studying the growth of thick ( $\mathrm{Tl}, \mathrm{Pb}$ )(Ba, Sr)-Ca-Cu-O with 5 wt. \% Ag (Pb, Sr-doped Tl-1223) superconducting films have each prepared materials with similar morphologies and critical current densities. Grain size and microcracking have become issues. Superconductivity within the grains or even in the larger regions defined by microcracking is determined to be adequate for the applications at hand. Unfortunately, superconducting properties degrade appreciably at the microcracks (which often prevent current transport) and even at the grain boundaries (where for films grown with negligible cracking on Ag substrates have greatly reduced critical current behavior).

Rapid Thermal Processing (RTP) of TI-free precursor films in a 1 atm Ar ambient has been used to achieve partial melting of the films in an attempt to improve the morphological character of the material. The samples were then processed in a conventional furnace anneal in the presence of TI-oxide to convert the material into $\mathrm{Pb}$, $\mathrm{Sr}$-doped $\mathrm{Tl}-1223$. The results were quite promising and led to an experiment designed to perform both tasks (melting and thallination) in a single two-step process using a two-zone furnace. The first stage consists of a high-temperature substrate anneal in a low oxygen ambient to achieve partial or complete melting of the oxide precursor grains, followed by a thallination reaction in a high oxygen ambient to convert the material into large-grain, well-connected TI-1223 thick films. We have found that the TI-free precursor melts completely in a pure nitrogen ambient at temperatures as low as $775^{\circ} \mathrm{C}$. Unfortunately, a surface wetting problem occurs resulting in a film with a high density of pinholes separated by only a few micrometers. This narrow necking of the film material severely limits the current transport across the film. Changes in the 
substrate temperature during the 'melt-stage', or in the duration of the stage, or in the actual oxygen partial pressure used each affect the density and size of these pinholes. An example is shown for a film processed first at $900^{\circ} \mathrm{C}$ in $\mathrm{p}\left(\mathrm{O}_{2}\right)=63 \mathrm{Torr}$, followed by a thallination at the same temperature in $p\left(\mathrm{O}_{2}\right)=630$ Torr, each for one hour. Figure 23 is an optical microscope image taken in transmission mode. The clear areas were voids in the film, and the problem of current transport across this film becomes obvious. Figure $2-4$ is a backscattered electron image clearly illustrating the shape and depth of the pinholes. Intriguing is the incredibly smooth surface morphology of the surrounding film surface. The magnification used here is similar to that used by others to show evidence of plate-like TI-1223 grains. Figure 2-5 is taken at 10 times higher magnification to observe the surface features of these smooth regions from Figure 2-4. Here we find that the surface has a rippled appearance, which may result from solidification from the melt in transition between the two stages of the growth process, or from severe microcracking as a result of the differences in thermal expansion between the $\mathrm{LaAlO}_{3}(100)$ substrate and the superconducting film. Cross-sectional microscope analysis is underway to determine if these features lie only on the surface or go through the entire film thickness. X-ray diffraction identifies the film as $\mathrm{Pb}$, Sr-doped Tl-1223, however the peak intensities were weak, correlating with magnetization data that demonstrates superconducting behavior, albeit quite poor. Obviously, more work needs to be done on improving both the wetting problem and the thallination procedure from the 'melted' precursor.

\subsection{Future Work}

Although this work is preliminary, it does demonstrate that massive melting and thallination of precursors can be accomplished in a single-process using a two-zone furnace. We presently separate the two stages from each other to study the optimization of each. For the next fiscal year, we will concentrate on studying the wetting issue during the melt stage so that a smooth pinhole-free precursor is available for the thallination. stage. We will emphasize the development of thick films on flexible substrates, particularly silver and its alloys. We will also perform comparison of microstructure development in both the ( $\mathrm{Pb}, \mathrm{Sr})$ doped and undoped systems. 


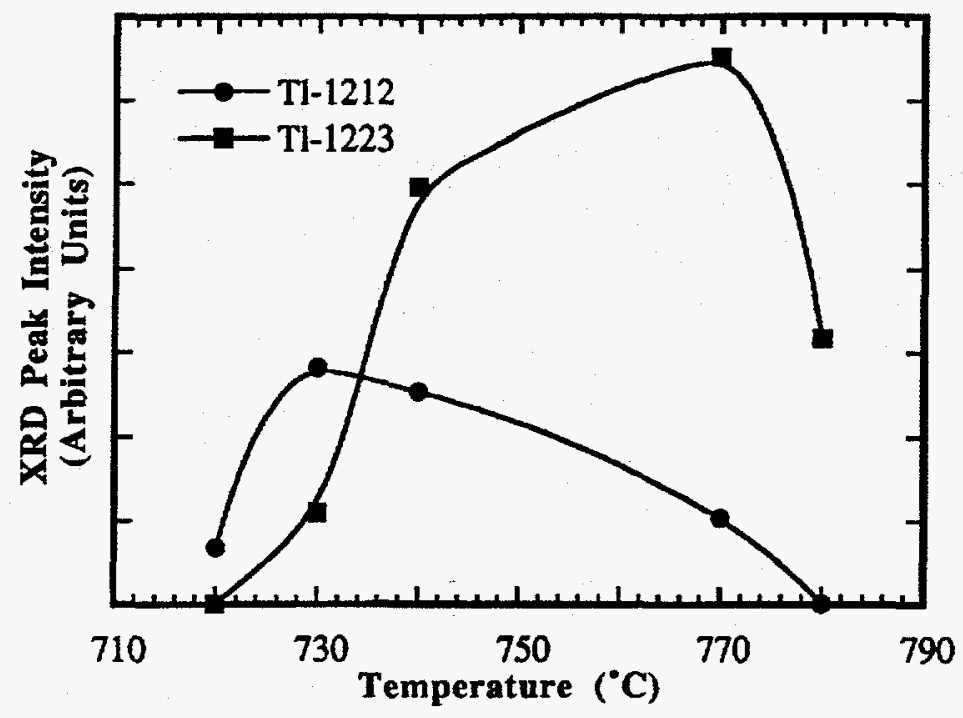

Figure 2-1. X-ray diffraction peak intensities as a function of Tl-oxide source temperature for the $\mathrm{TI}-1212$ and $\mathrm{TI}-1223$ superconducting phases.

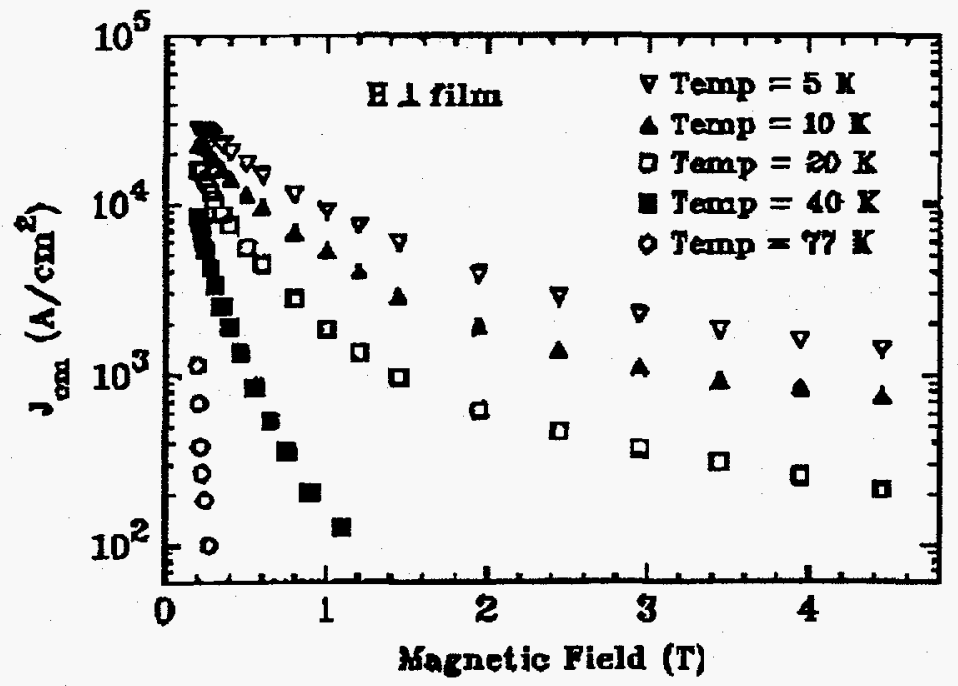

Figure 2-2. $\quad J_{c}$ versus applied magnetic field at various temperatures. 


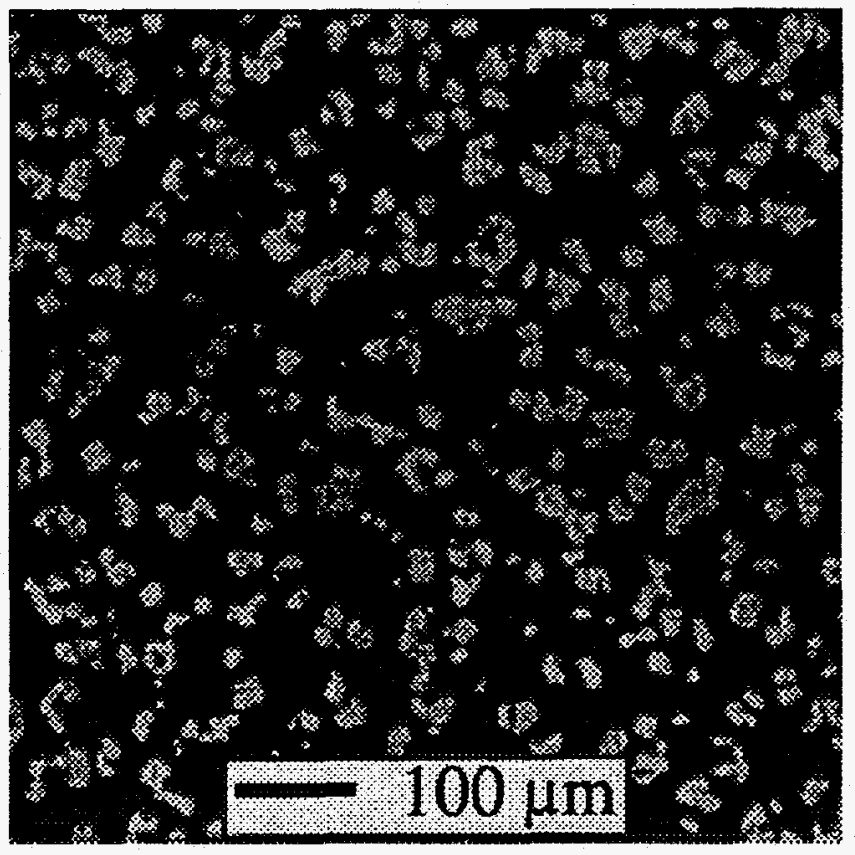

Figure 2-3. Optical microscope image in transmission mode from a $15 \mu \mathrm{m}$ thick film processed in two stages to achieve both melting and thallination.

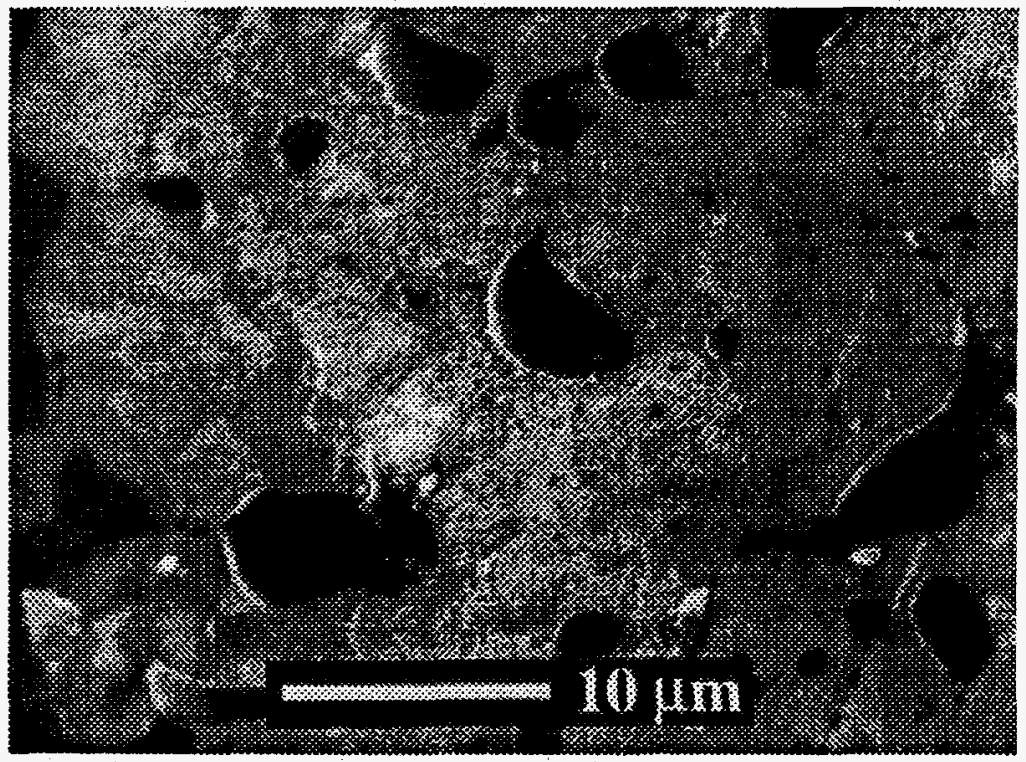

Figure 2-4. Backscattered electron microscope image from a $15 \mu \mathrm{m}$ thick film processed in two stages to achieve both melting and thallination. 


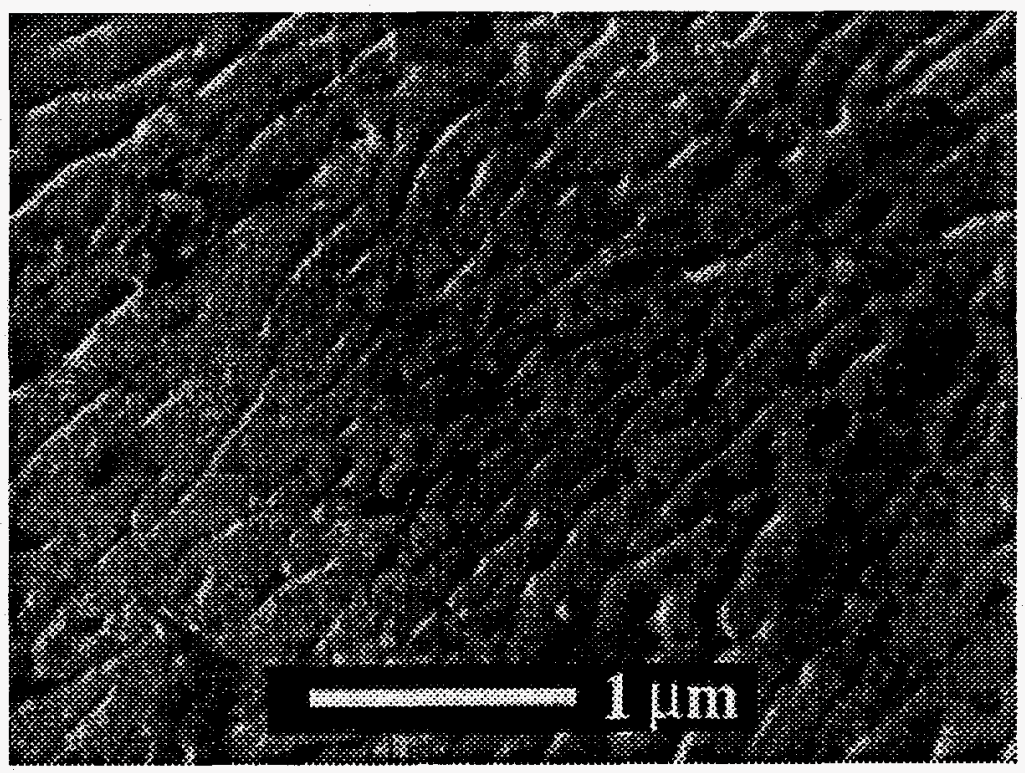

Figure 2-5. Backscattered electron microscope image from a $15 \mu \mathrm{m}$ thick film processed in two stages to achieve both melting and thallination. 
3 Process Development and Characterization of High-Temperature Superconducting Wire and Tape

\subsection{Introduction}

The objective of this project is to develop high-temperature superconducting wire capable of meeting the requirements for high-power electrical devices of interest to industry. Primary interest has been to develop materials and processes which can lead to the practical production of wires which can carry high currents in the presence of typical operating magnetic fields at liquid nitrogen temperature or higher, although lower temperature operation is considered for special applications. The thalliumbased single layer system is considered the only viable material for operation in moderate magnetic fields at $77 \mathrm{~K}$. In particular, the $\mathrm{Pb}$ - and $\mathrm{Sr}$-substituted system is believed to have the best performance in magnetic field and most readily results in the TI-1223 phase desired. During the last year we have continued to devote our research efforts exclusively in this system, developing techniques in the areas of powder preparation, wire production, and process development.

Sandia's patented co-precipitation process has been used to produce fine-grained, precursor powders to which thallium has been added by bulk mixing with $\mathrm{Tl}_{2} \mathrm{O}_{3}$ or by vapor phase addition. We have used this process to custom manufacture powders with variations in the baseline stoichiometry of $\left(\mathrm{TI}_{0.5} \mathrm{~Pb}_{0.5}\right)\left(\mathrm{Sr}_{0.8} \mathrm{Ba}_{0.2}\right)_{2} \mathrm{Ca}_{2} \mathrm{Cu}_{3} \mathrm{O}_{\mathrm{x}}$ to determine the effects of compositional induced melting. Various compositions have been processed both in bulk pellet form and used in the production of silver-clad wires and tapes. Thermal processing schedules using both conventional furnace annealing and Rapid Thermal Annealing (RTP) have been investigated to determine conditions which might lead to the development of strong links and texture.

Wire development efforts have included conventional powder-in-tube (PIT) methods for producing wire and tape, as well as extrusion techniques for producing near theoretical dense core wires. Tapes have been produced using our powders in collaboration with Los Alamos and Argonne National Labs, as well as with Los Alamos and Intermagnetics General Corporation (IGC). Under a four-way pilot center CRADA between Sandia, Los Alamos, Nuclear Metals, Inc. (NMI), and AT\&T Bell Labs, wires 
were produced by coextrusion and hydrostatic extrusion methods. Conditions for stable extrusion were investigated for each method.

Sandia has actively collaborated with several National Laboratories and industrial laboratories in the area of powder production and conductor processing. Our coprecipitation powders have been shown to be superior to conventional mixed oxide prepared powders for the preparation of wires and tapes. Thus, several laboratories have shown interest in incorporating our powders into their wire development efforts. Our Rapid Thermal Processing system has allowed us to perform unique controlled melt processing of these tapes in order to determine possible new approaches to enhanced strong link development. Sandia also has a full range of advanced characterization facilities which have allowed us to quantify the microstructural changes occurring during processing. We also have advanced $x$-ray image analysis capabilities which have been used to perform non-destructive evaluation of superconducting cores in wires and tapes.

\subsection{Progress in FY94}

Work this year in tape and wire development has centered on three main areas:

i) phase analysis of RTP transient-melt TI-1223 tapes

ii) effects of stoichiometry variation in the $\left(\mathrm{TI}_{0.5} \mathrm{~Pb}_{0.5}\right)\left(\mathrm{Sr}_{0.8} \mathrm{Ba}_{0.2}\right)_{2} \mathrm{Ca}_{2} \mathrm{Cu}_{3} \mathrm{O}_{x}$ system on microstructure development and melt interaction

iii) effects of time/temperature processing on $J_{c}$ in the TI-1223 system

\subsubsection{Phase analysis of RTP transient-melt TI-1223 tapes}

Rapid Thermal Processing (RTP) is a method by which the superconducting grains can be subjected to melt conditions for controlled, short duration periods of time. It is possible that melt interactions between the grains will result in improved grain contact, less non-superconducting secondary phases at the boundaries, and improved strong links between the grains. Tapes were prepared using fully reacted Sandia chemprep powder with composition $\left(\mathrm{TI}_{0.5} \mathrm{~Pb}_{0.5}\right)\left(\mathrm{Sr}_{0.8} \mathrm{Ba}_{0.2}\right)_{2} \mathrm{Ca}_{2} \mathrm{Cu}_{3} \mathrm{O}_{9}$, known as the "Hitachi" composition. The tapes were prepared at Intermagnetics General Corporation (IGC) using standard oxide powder-in-tube (OPIT) methods. The tapes were subjected to 
RTP at temperatures of $930^{\circ} \mathrm{C}\left(10 \mathrm{sec}\right.$ in $\mathrm{Ar}$ ), $940^{\circ} \mathrm{C}$ ( $7 \mathrm{sec}$ in $\mathrm{Ar}$ ), and $945^{\circ} \mathrm{C}$ ( $20 \mathrm{sec}$ in $\mathrm{Ar}$ ). All tapes were then annealed in $\mathrm{O}_{2}$ at $900^{\circ} \mathrm{C} / 1 \mathrm{~h}$ followed by $850^{\circ} \mathrm{C} / 3 \mathrm{~h}$. These temperatures are above the known peritectic temperature of the superconducting phase and also high enough to result in the onset of silver melting. Figure 3-1 shows the DTA results for this composition silver tape in atmospheres of both oxygen and argon. This figure shows that in an argon atmosphere the superconductor endotherms broaden and shift to lower temperature while the silver melt endotherm shifts to higher temperature, thus giving a broader processing window. Previous analysis of conventional furnace processed wires, from which these tapes were made, showed secondary phases of $\mathrm{BaPbO}_{2}, \mathrm{CaO}, \mathrm{CuO},(\mathrm{Sr}, \mathrm{Ca}) \mathrm{CuO}_{2}, \mathrm{CaPbO}_{2},\left(\mathrm{Sr}_{0.66}, \mathrm{Ba}_{0.33}\right) \mathrm{CO}_{3}$, $\left(\mathrm{Ba}_{0.66}, \mathrm{Sr}_{0.33}\right) \mathrm{CO}_{3}$, and free Ag. These RTP-tapes showed fewer secondary phases, with $\mathrm{BaPbO}_{2},(\mathrm{Sr}, \mathrm{Ca}) \mathrm{CuO}_{2}, \mathrm{Ca}_{2} \mathrm{CuO}_{3}$ and free $\mathrm{Ag}$ as the most observed compositions as shown in Figure 3-2a. No carbonates or simple oxides were found. Although silver was observed throughout the core as seen in Figure 3-2b, no evidence of reaction of the silver with the superconductor was noted and no thallium was observed in the silver. Quantitative electron microprobe analysis of the superconducting grains showed only the $\mathrm{Tl}-1223$ phase. The electron microprobe showed that the TI/Pb ratio was consistently 1.2:1 at all temperatures with slight variations around $\mathrm{Tl}_{0.5}$ and $\mathrm{Pb}_{0.5}$. However, the average $\mathrm{Sr} / \mathrm{Ba}$ ratio was observed to increase at the higher temperatures although the total $\mathrm{Sr}+\mathrm{Ba}$ level remained constant at 2.2. At $930^{\circ} \mathrm{C}$ the $\mathrm{Sr} / \mathrm{Ba}$ ratio was $4.0: 1$ as expected, but at the higher temperatures of $940^{\circ} \mathrm{C}$ and $945^{\circ} \mathrm{C}$ the ratio increased to $4.6: 1$ and 4.3:1 respectively. Due to the limited number of grains analyzed, the uncertainty in these ratios is about $+1-0.3$, but the trend was evident that more $\mathrm{Sr}$ and less $\mathrm{Ba}$ was being incorporated into the superconductor after the higher temperature melts. However, transport measurements of the critical temperature was a constant $112 \mathrm{~K}$ for all RTP samples, indicating no significant change in superconducting structure. Transport measurement of the critical current was about 6 amps for the $930^{\circ} \mathrm{C}$ RTP sample but for the higher temperature RTP samples the $E$ vs. J data showed a disconnected grain structure. Obviously, melt interactions can lead to degradation of the structure if the melt interactions proceed too far. Field dependent measurement of the critical current likewise showed no improvement in the strong link component of the current transport. RTP schedules at lower temperature would result in a less severe interaction. 
A second powder composition was prepared with $5 \%$ excess $(\mathrm{Ca}, \mathrm{Cu})$ and $15 \%$ excess $(\mathrm{Tl}, \mathrm{Pb})$ to enhance the lower temperature melt interactions. Silver tape was again produced from this powder by IGC and the tapes were given a RTP schedule of $880^{\circ} \mathrm{C} / 40 \mathrm{sec}, 890^{\circ} \mathrm{C} / 40 \mathrm{sec}, 900^{\circ} \mathrm{C} / 40 \mathrm{sec}$, and $910^{\circ} \mathrm{C} / 40 \mathrm{sec}$ in an argon atmosphere and then annealed at $860^{\circ} \mathrm{C}$ for 8 hours in oxygen. These temperatures probed different levels of the first endotherm as shown in Figure 3-1 but did not enter into the silver melt region. Figure 3-3 shows SEM micrographs for the tapes processed at these temperatures. These pictures show that at $880^{\circ} \mathrm{C}$ the grains are just starting to melt at the interfaces. It is believed that at $880^{\circ} \mathrm{C}$, the 1223 grains start to decompose into 1212 and $(\mathrm{Sr}, \mathrm{Ca})-\mathrm{Cu}-\mathrm{O}_{\mathrm{x}}$ solid phases. TEM images showed, in general, the 1212 separated from the 1223 by the $(\mathrm{Sr}, \mathrm{Ca})-\mathrm{Cu}-\mathrm{O}_{\mathrm{x}}$, indicating a solid state reaction. From $890^{\circ} \mathrm{C}$ to $900^{\circ} \mathrm{C}$, the 1223 decomposed even further into $1212,(\mathrm{Sr}, \mathrm{Ca})-\mathrm{Cu}-\mathrm{O}_{\mathrm{x}}$, and a $(\mathrm{Ba}, \mathrm{Sr})-(\mathrm{TI}, \mathrm{Pb})-\mathrm{O}_{3}$ phase. This final phase might have been liquid at temperature due to a flow like structure seen in the micrographs. At $900^{\circ} \mathrm{C}, 1223$ grains are seen to be growing from apparent nucleation sites, possibly from this liquid phase. By $910^{\circ} \mathrm{C}$, no evidence of the original structure was seen, and large blocks of the 1223 and 1212 phase were seen embedded in secondary phase structure of the $(\mathrm{Sr}, \mathrm{Ca})-\mathrm{Cu}-\mathrm{O}_{\mathrm{x}}$. Meissner data, Figure 3-4, showed an increasing level of the 1212 phase for increasing RTP temperature. These results show that transient melt interactions must be carefully controlled to prevent the development of unwanted secondary phases and breakdown of the 1223 structure.

\subsubsection{Processing Optimization of Aq-Clad TI-1223 Tapes}

Processing studies have been performed on tapes prepared using Sandia chemprep precursor with the stoichiometry $\mathrm{Pb}_{0.5} \mathrm{Sr}_{1.6} \mathrm{Ba}_{0.4} \mathrm{Ca}_{2} \mathrm{Cu}_{3} \mathrm{O}_{\mathrm{y}}$. This work is part of a collaborative effort between Sandia, Los Alamos, and IGC. The precursor oxide powder was reacted with $\mathrm{Tl}_{2} \mathrm{O}_{3}$ to produce the nominal "Hitachi" composition. A second powder was prepared at Los Alamos by regrinding the "Hitachi" powder and adding additional $\mathrm{Tl}_{2} \mathrm{O}_{3}$ to achieve a $\mathrm{Tl}_{0.78} \mathrm{~Pb}_{0.5}$ composition. IGC produced several meters of Ag-clad tape from these powders: TW010 with the "Hitachi" powder and TW016 with the excess $\mathrm{Tl}_{2} \mathrm{O}_{3}$ composition. We processed these tapes at $860^{\circ} \mathrm{C}$ in $\mathrm{O}_{2}$ for periods of $1 \mathrm{hr}, 2 \mathrm{hr}, 3 \mathrm{hrs}, 5 \mathrm{hrs}, 7 \mathrm{hrs}, 10 \mathrm{hrs}$, and $15 \mathrm{hrs}$. Repeat measurements were run with separate tapes and from multiple pieces from the same tape. A 
variability of $+/-10 \%$ was seen in the $J_{c} s$. The tapes were also processed for shorter times ( $1-3$ hours) at $900^{\circ} \mathrm{C}$. Figure $3-5$ summarizes the $J_{c}$ data for these runs. The data show that for both compositions the $J_{c}$ improved with annealing time at $860^{\circ} \mathrm{C}$ with a maximum occurring at approximately 8 hours while at $900^{\circ} \mathrm{C}$ no such improvement was seen for either composition. The correlation between $J_{c}$ and $T_{c}$ is shown in Figure 3-6. These data suggest that the zero field $J_{c}$ is improved primarily by improvements in the grains themselves and not by the formation of new intergranular links. Measurements of the field dependence support this as can be seen in Figure 37. For the $860^{\circ} \mathrm{C}$ processed samples, a small remnant current is maintained up to fields as high as $0.15 \mathrm{~T}$. This small elevated field $\mathrm{J}_{\mathrm{c}}$ was not affected by increased annealing time. For the $900^{\circ} \mathrm{C}$ processed tapes, the $J_{c} s$ were reduced and although higher field $J_{c}$ measurements were not performed, the low field data indicated that no higher field $\mathrm{J}_{\mathrm{c}}$ remnant existed. Although furnace processing at $860^{\circ} \mathrm{C}$ produces modest intergranular coupling for reacted core tapes, our work shows that the weak link behavior observed in these tapes at all temperatures will severely restrict potential applications. Our previous work on rapid thermally processed thick films with the same stoichiometry shows that considerable melting may be required for strong links.

\subsubsection{Effects of Stoichiometric Variations in the ( $\mathrm{Pb}, \mathrm{Sr})$-doped $\mathrm{TI}-1223$ System}

More and more evidence shows that texturing is necessary to achieve high current densities in the TI-based superconductors. Texturing is also believed necessary to obtain strong links, which are required for current transport in magnetic fields. Our experience with this system shows that conventional sintering is not sufficient to achieve strong links, but instead, melt processing is required to produce platelets which can develop into a well connected textured structure. We believe that changes in the stoichiometry of the precursor powders can lead to enhanced melt-phase formation at lower processing temperatures. We designed an experimental matrix with variations in the TI/Pb ratio, the total TI/Pb content, and the $\mathrm{Ca} / \mathrm{Cu}$ level. These parameters are believed to have the greatest effect on liquid formation and subsequent grain growth. We prepared a series of 13 powders using our chemprep method to investigate grain development over a range of thermal processing conditions. These powders were processed in pellet form and also used to make Agclad tapes. IGC agreed to collaborate in this compositional matrix study by producing 
the tapes using our unreacted powders while Sandia agreed to thermally process these tapes using our Rapid Thermal Processing capabilities as well as conventional furnace annealing. Figure 3-8 shows a parametric representation of the compositional design matrix.

Characterization of the powders was necessary before a processing schedule could be selected for the tapes. First, all stoichiometries were verified by ICP analysis. Then DTA analysis was performed on pellets of the starting oxides and the unreacted oxide $/ \mathrm{Tl}_{2} \mathrm{O}_{3}$ mixtures( wrapped in Au foil to prevent $\mathrm{TI}$ loss). Figure 3-9 shows a comparison of the DTA results for the unreacted Hitachi composition $\left(\left(\mathrm{TI}_{0.5} \mathrm{~Pb}_{0.5}\right)\left(\mathrm{Sr}_{0.8} \mathrm{Ba}_{0.2}\right)_{2} \mathrm{Ca}_{2} \mathrm{Cu}_{3} \mathrm{O}_{\mathrm{x}}\right)$ for both pellets and $\mathrm{Ag}$-clad tapes. In general, the starting oxide powders $\left(\right.$ no $\mathrm{Tl}_{2} \mathrm{O}_{3}$ ) had melting peaks of $950^{\circ} \mathrm{C}$ or higher. The addition of $\mathrm{Tl}_{2} \mathrm{O}_{3}$ reduced the melting peak by an average of $35^{\circ} \mathrm{C}$.

Measurements of the Ag-clad cores showed that the Ag resulted in a further reduction of the melt transitions of about $30^{\circ} \mathrm{C}$. We choose $900^{\circ} \mathrm{C}$ as a common processing temperature for the tapes. This temperature was above or close to the onset of at least the first endothermic interaction for all of the tapes. This temperature allowed a comparison among the tapes but was not an optimized processing temperature for any individual composition.

DTA analysis was then performed on the Ag-clad tapes which had undergone the thermal processing step $\left(900^{\circ} \mathrm{C} / 2 \mathrm{hr}\right.$ in $\left.\mathrm{O}_{2}\right)$ to convert the powder to the $\mathrm{TI}-1223$ state. These "reacted" tapes were measured in both $\mathrm{O}_{2}$ and Ar atmospheres to determine the extent of the processing window available for each composition which is set by the endothermic reaction temperature of the core and the melt temperature of the $\mathrm{Ag}$ sheath. The data for the reacted Hitachi composition are shown in Figure 3-10. The Ar atmosphere resulted in a broadening and lowering of the core endothermic reactions while the $\mathrm{Ag}$ melt increased from about $930^{\circ} \mathrm{C}$ to $945^{\circ} \mathrm{C}$. Thus processing in an $\mathrm{Ar}$ atmosphere gives a broader processing window for the tapes.

Changes in stoichiometry also had a significant effect on the melt reactions in the Agclad tapes. An example of the effect of changing TI/Pb ratio around the nominal Hitachi composition is shown in Figure 3-11. In general, increasing Tl/Pb ratio 
resulted in lower temperature and more widely spread endothermic reactions. This would result in enhanced melting at lower temperatures. Increasing the $\mathrm{Ca} / \mathrm{Cu}$ cation level had little effect on the endothermic reactions, causing some reactions to shift slightly to higher temperature and others to shift to lower temperature. Increasing the total $(\mathrm{Tl}, \mathrm{Pb})$ level resulted in a slight lowering of the reaction temperatures and the appearance of a new lower endotherm for most of the compositions. The compositions with the $\mathrm{Tl}_{0.5} \mathrm{~Pb}_{0.5}$ stoichiometry showed a very stable melt profile for varying $(\mathrm{Ca} / \mathrm{Cu})$ and $(\mathrm{TI}, \mathrm{Pb})$ levels as can be seen in Figure 3-12.

These processed tapes were characterized by transport measurements, magnetization measurements, and SEM analysis. Figures 3-13 and 3-14 show the microstructures of the Hitachi composition $\mathrm{TI}-7,\left(\mathrm{TI}_{0.5} \mathrm{~Pb}_{0.5}\right)\left(\mathrm{Sr}_{0.8} \mathrm{Ba}_{0.2}\right)_{2} \mathrm{Ca}_{2} \mathrm{Cu}_{3} \mathrm{O}_{\mathrm{x}_{1}}$ and the center point composition TI-1, $\left(\mathrm{Tl}_{0.5} \mathrm{~Pb}_{0.5}\right)_{1.15}\left(\mathrm{Sr}_{0.8} \mathrm{Ba}_{0.2}\right)_{2} \mathrm{Ca}_{2.1} \mathrm{Cu}_{3.15} \mathrm{O}_{x}$ as reference microstructures. These microstructures consist primarily of unaligned grains of $\mathrm{TI}-1223$, small amounts of $\mathrm{TI}-1212$ and considerable voids. Secondary phases of ( $\mathrm{Sr}, \mathrm{Ca})-\mathrm{Cu}-\mathrm{O}, \mathrm{BaPbO}_{3}$ and isolated $\mathrm{Ag}$ particles are quite abundant. The effects of stoichiometry variation are shown in Figure 3-15 for the variables $\mathrm{Tl}_{x} \mathrm{~Pb}_{1-x},(\mathrm{Tl}, \mathrm{Pb})_{y}$ and $\left(\mathrm{Ca}_{2} \mathrm{Cu}_{3}\right)_{z}$. In general, these figures show that increasing the $\mathrm{Pb}$ ratio in the samples resulted in a much smaller microstructure while the high TI ratio composition resulted in large blocky grains. Increasing the total amount of $(\mathrm{TI}, \mathrm{Pb})$ resulted in slightly larger grains, indicating some enhanced melt reaction. However, increasing the $\left(\mathrm{Ca}_{2}, \mathrm{Cu}_{3}\right)$ level did not result in any systematic improvement in grain structure, but instead only showed the increased presence of secondary phases. These results are consistent with the DTA curves discussed previously.

Magnetization was used to characterize the processed tapes and pellets. These measurements were able to identify the superconducting phases and the relative amounts of each. The pellets were sealed in gold foil and processed over the range $920^{\circ} \mathrm{C}-960^{\circ} \mathrm{C}$. Magnetization showed phase structures ranging from the 1223 phase with a $T_{c}$ above $120 \mathrm{~K}$ to the 1212 phase with $T_{c}$ in a range around $60 \mathrm{~K}$. Processing at temperatures below the main melt transitions resulted in the 1212 phase. It was observed that the pellets processed at $920^{\circ} \mathrm{C}$ showed a great similarity to the tapes processed at $900^{\circ} \mathrm{C}$. Figure 3-16 shows the Meissner data for composition 
$\left(\mathrm{TI}_{0.5} \mathrm{~Pb}_{0.5}\right)_{1.15}\left(\mathrm{Sr}_{0.8} \mathrm{Ba}_{0.2}\right)_{2} \mathrm{Ca}_{2.1} \mathrm{Cu}_{3.15} \mathrm{O}_{x}(\mathrm{TI}-1)$ consisting of the 1223 phase while Figure 3-17 shows the composition $\left(\mathrm{TI}_{0.25} \mathrm{~Pb}_{0.75}\right)\left(\mathrm{Sr}_{0.8} \mathrm{Ba}_{0.2}\right)_{2} \mathrm{Ca}_{2} \mathrm{Cu}_{3} \mathrm{O}_{x}$ (TI-2) which was a mixture of 1223 and 1212. These similarities between the pellets and tapes were also seen for the other compositions and are consistent with the lowered melt transitions seen in the Ag-clad tapes.

Figure 3-18 summarizes the transport $T_{c}$ and $J_{c}$ values for each composition of Ag-clad tapes. Those samples showing no $\mathrm{J}_{c}$ at $75 \mathrm{~K}$ were predominantly 1212 phase material with $T_{c}$ below $75 \mathrm{~K}$. This figure shows that all tapes with the TI/Pb ratio of 1:1 exhibited very similar $T_{c}$ values $(100 \mathrm{~K}-106 \mathrm{~K})$ and $J_{c}$ values $\left(450-1000 \mathrm{Acm}^{2}\right)$. The microstructures all exhibited an interconnecting platey 1223 grain structure with no 1212 phase observed. This resulting microstructure is consistent with the similarity in the DTA data which showed very similar endothermic reactions for the $\mathrm{TI}_{0.5} \mathrm{~Pb}_{0.5}$ compositions. $\mathrm{Tl}-13$ had the lowest $\mathrm{J}_{c}$ in this group $\left(450 \mathrm{Acm}^{2}\right)$ corresponding to a microstructure with higher amounts of non-superconducting secondary phases. For all compositions, large quantities of secondary phases were seen to reduce grain interconnectivity and transport current.

In summary, variations in starting composition resulted in complicated changes in subsequent phase development. For tapes processed at $900^{\circ} \mathrm{C}$ for $2 \mathrm{hrs}, \mathrm{TI} / \mathrm{Pb}$ ratios of 1:1 or higher result in a connected 1223 grain structure but with no evidence of grain alignment. Without grain alignment, high $J_{c}$ values with strong-linked grains may not be achievable. Significant shifts in composition from the nominal "Hitachi" stoichiometry do not result in marked improvement in $\mathrm{J}_{c}$ and the resultant secondary phases may impose a limit on the degree of grain connectivity. Detailed measurements of the thermal interactions for the different stoichiometries are necessary to choose a processing sequence which can produce a microstructure with highly interconnected, aligned 1223 grains and minimal non-superconducting phases.

\subsubsection{Extrusion of Tl-core Wires}

The development of high intergranular transport current density is significantly affected by microstructural properties such as grain size, porosity(density), and secondary phases. Conventional powder-in-tube methods using wire drawing and 
rolling subject the superconducting material to shear stresses which result in cracking and low density which subsequently requires long-time, high-temperature anneals to repair. We have investigated the effects of high-densification methods of wire production using the techniques of coextrusion and hydrostatic extrusion. These methods offer the advantage of uniformly compressing the superconducting powder in a protective, conductive sheath which leaves the ceramic material in a high-density, compressive state. This compressive state minimizes crack formation and propagation and offers the possibility of enhancing grain sintering at lower temperatures.

The coextrusion technique is based on using a hydraulic ram to extrude a billet containing the superconductor core and sheath material through a reduction die to obtain a highly densified and elongated core encased in the outer extrusion billet material. In collaboration with Nuclear Metals, Inc., we have available extrusion presses ranging from 100 tons to 1400 tons capacity which allows extrusion over a wide range of geometries. Figure 3-19 shows a schematic diagram of the extrusion process.

NMI has produced a multicore superconductor using previously extruded YBCO cores in silver sheaths. YBCO has mechanical properties similar to those seen for the thallium based system. The densified superconductor cores were remachined and put into a four-core copper billet and extruded at $600^{\circ} \mathrm{C}$ with an area reduction ratio of $4: 1$. The extruded billet was radiographed at Sandia and was found to have continuous, uniform cores with continuous silver sheaths. We then used computer aided tomography to generate a three-dimensional image of the cores as shown in Figure 320. The CAT scans clearly reveal the superconducting cores and the silver sheaths in the extruded billet. This imaging technique shows promise of being a valuable tool for non-destructive testing of superconductor wires and tapes. This coextrusion result also shows that this technique, with the appropriate choice of material, can produce multi filamentary wires suitable for high-current leads and starting billets for further wire extrusion.

Coextrusion and hydrostatic extrusion methods have yielded contrary results for the extrusion behavior of composite billets as a function of strain hardening rate of the 
sheath material. Hydrostatic extrusion has yielded the most uniform cores for sheath material with a high strain hardening rate, such as Glidcop. However, coextrusion has yielded the best results for very low strain hardening material such as aluminum, as shown in Figure 3-21, where very uniform cores of approximately 0.1 inch diameter and 4 inch length are shown. Coextrusion is being used to prepare densified billets for the hydrostatic extrusion technique where the coextruded copper/silver sheathed billet will be placed in a Glidcop billet for further extrusion. This will combine the advantages of both techniques. However, this is a sensitive technique requiring a delicate balance of mechanical properties between core and sheath in order to obtain a uniform extrusion core.

\subsection{Future Work}

Characterization of thermally processed Ag-clad tapes has shown that the precursor oxides react quickly to form the $\mathrm{TI}-1223$ phase at temperatures as low as $860^{\circ} \mathrm{C}$. However, the microstructure is filled with voids and secondary phases. Our work for FY95 will be directed toward developing techniques to reduce porosity and secondary phase development. Preliminary work with IGC has shown that sequential pressing of the tapes, followed by thermal annealing, greatly reduces the developing porous structure. We will investigate the developing microstructure during the early stage conversion of the unreacted cores as a function of pressing and annealing conditions and compare the properties to conventional furnace anneals. We will also look at variations in stoichiometry, building on our results for the FY94 compositional study, to determine if secondary phase structure can be reduced and 1223 grain structure enhanced. We will also look at alternative TI-based compositions as a substitute to the standard $\mathrm{Tl}_{2} \mathrm{O}_{3}$ currently used as a $\mathrm{Tl}_{2} \mathrm{O}$ source. Reducing the rate and increasing the temperature at which the $\mathrm{Tl}_{2} \mathrm{O}$ is released may allow enhancement of the $\mathrm{Tl}-1223$ grain development over the TI-1212 development which occurs at low temperatures. Rapid Thermal Processing will also be used as a tool to probe the early time phase development in these tapes as well as to modify the grain interconnections after the $\mathrm{TI}-1223$ grains have been formed. 
We will continue in our extrusion collaboration with NMI, AT\&T and LANL. We will look at microstructure development of the highly densified superconductor cores and how to further improve the grain interconnections. We will also continue our $\mathrm{x}$-ray imaging technique development as needed to characterize the extrusion cores and sheaths.

Sandia will continue to collaborate with the other National Labs and private industry in the development of TI-based superconductors. We will provide our services in the areas of custom powder production, thermal processing and characterization. These efforts will hopefully accelerate development of a liquid nitrogen temperature superconducting tape. 


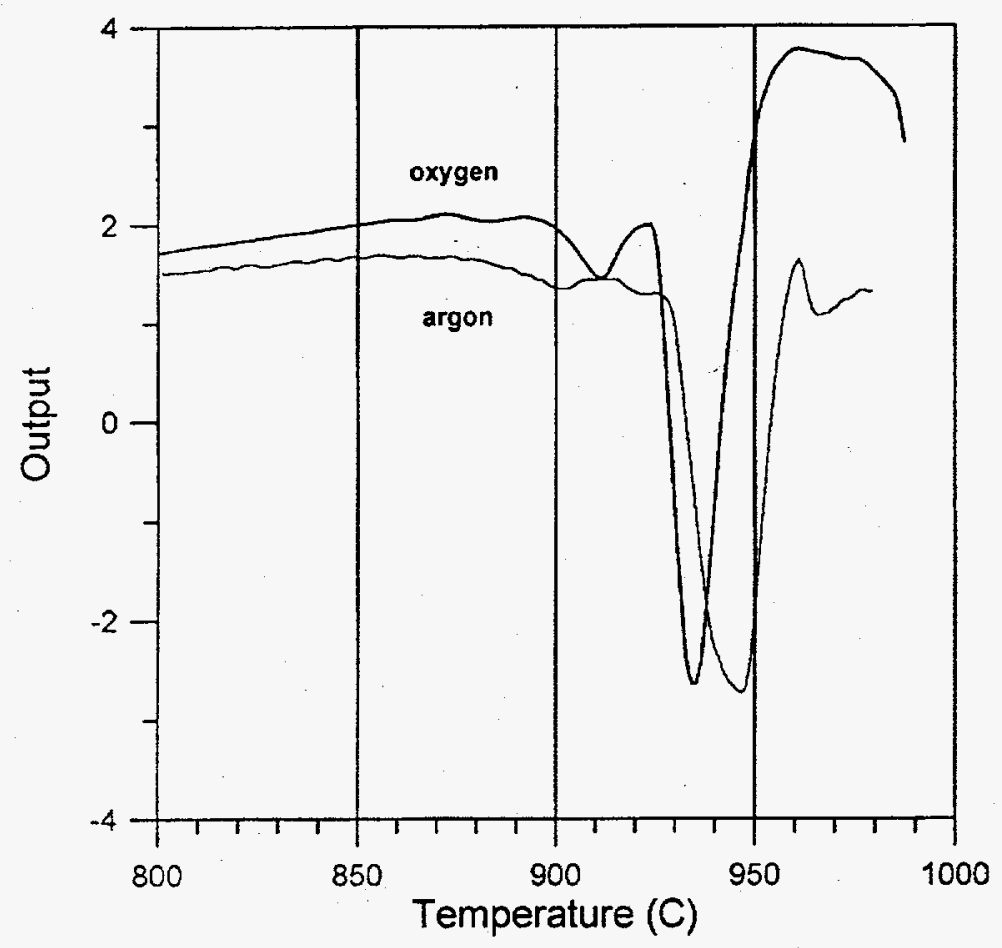

Figure 3-1. DTA of TI-1223 Ag tape in oxygen and argon atmospheres. 


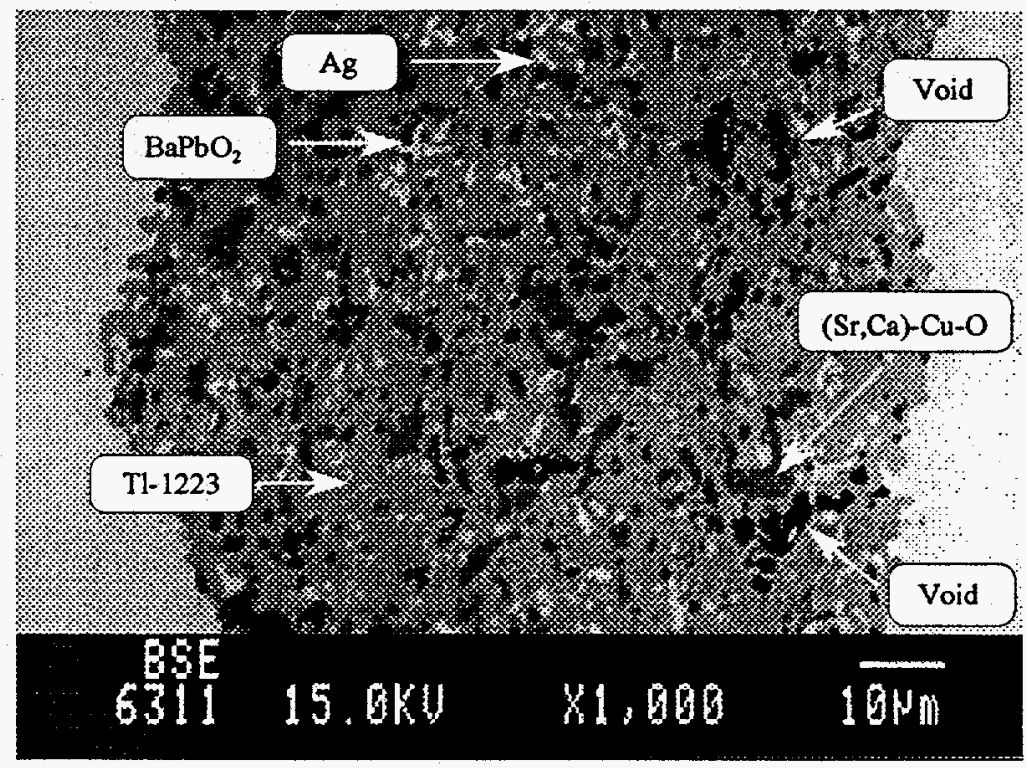

Figure 3-2a. Microstructure of TI-1223 Ag tape subjected to a RTP of $930^{\circ} \mathrm{C} / 10$ sec/Ar then a $900^{\circ} \mathrm{C} / 1 \mathrm{hr}$ anneal in $\mathrm{O}_{2}$.

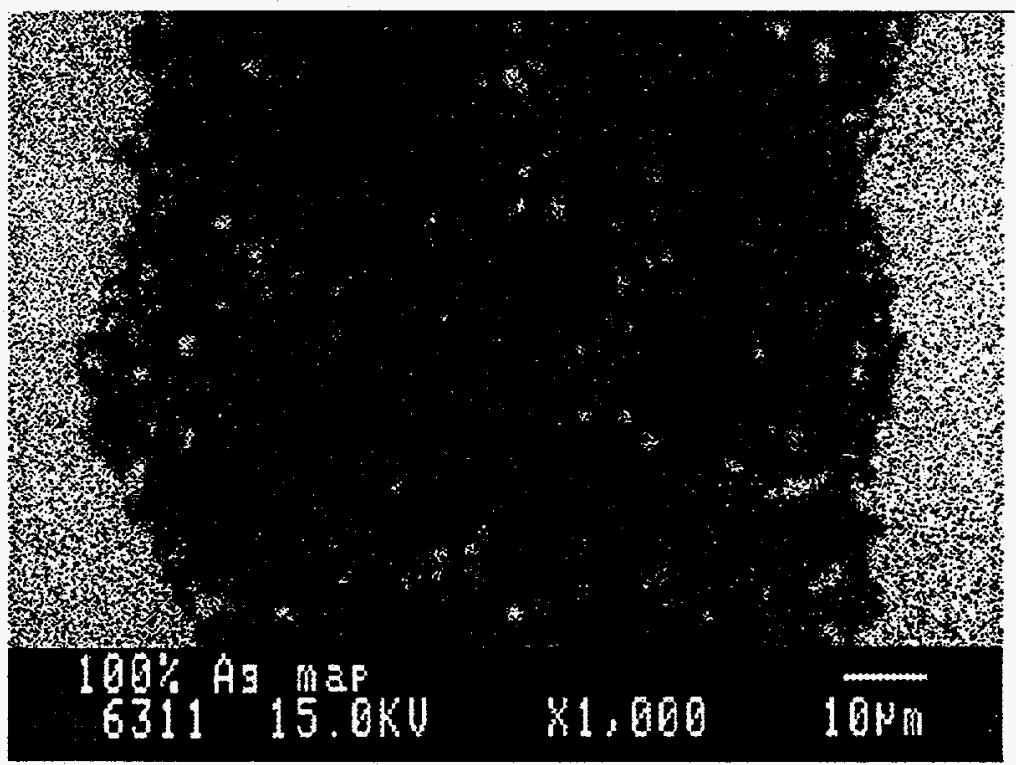

Figure 3-2b. Ag x-ray map of RTP processed Tl-1223 Ag tape. 


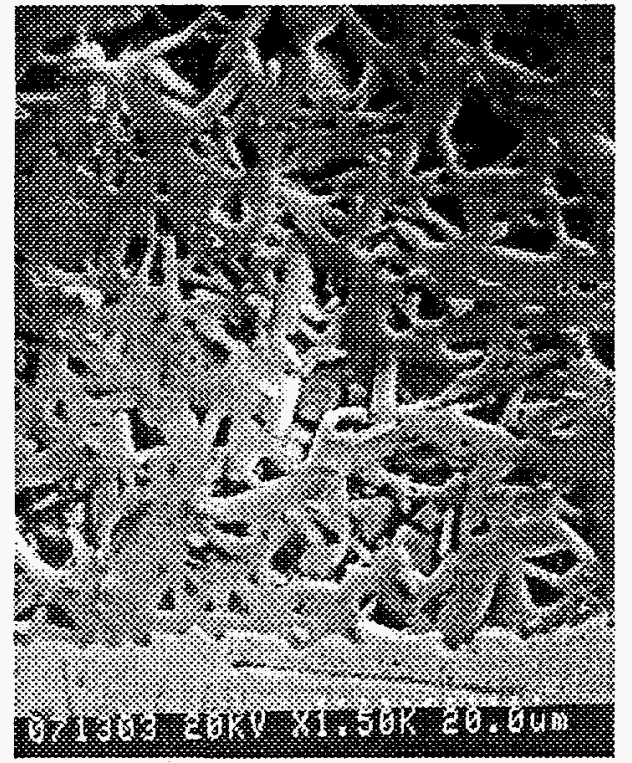

RTP $880^{\circ} \mathrm{C} 40 \mathrm{sec}$ ArlAnneal $860^{\circ} \mathrm{C} /$ $8 \mathrm{~h}_{2}$

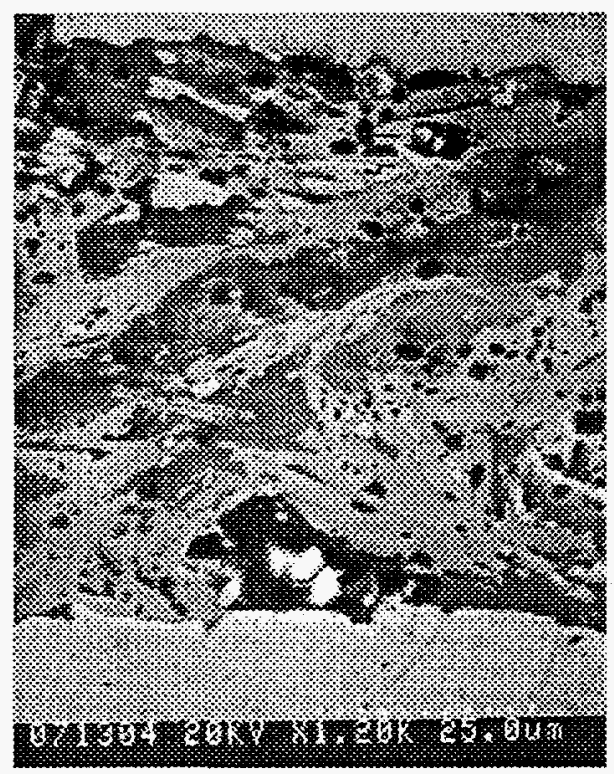

RTP $900^{\circ} \mathrm{C} 40 \mathrm{sec}$ Ar/Anneal $860^{\circ} \mathrm{Cl}$ $8 \mathrm{hO}_{2}$
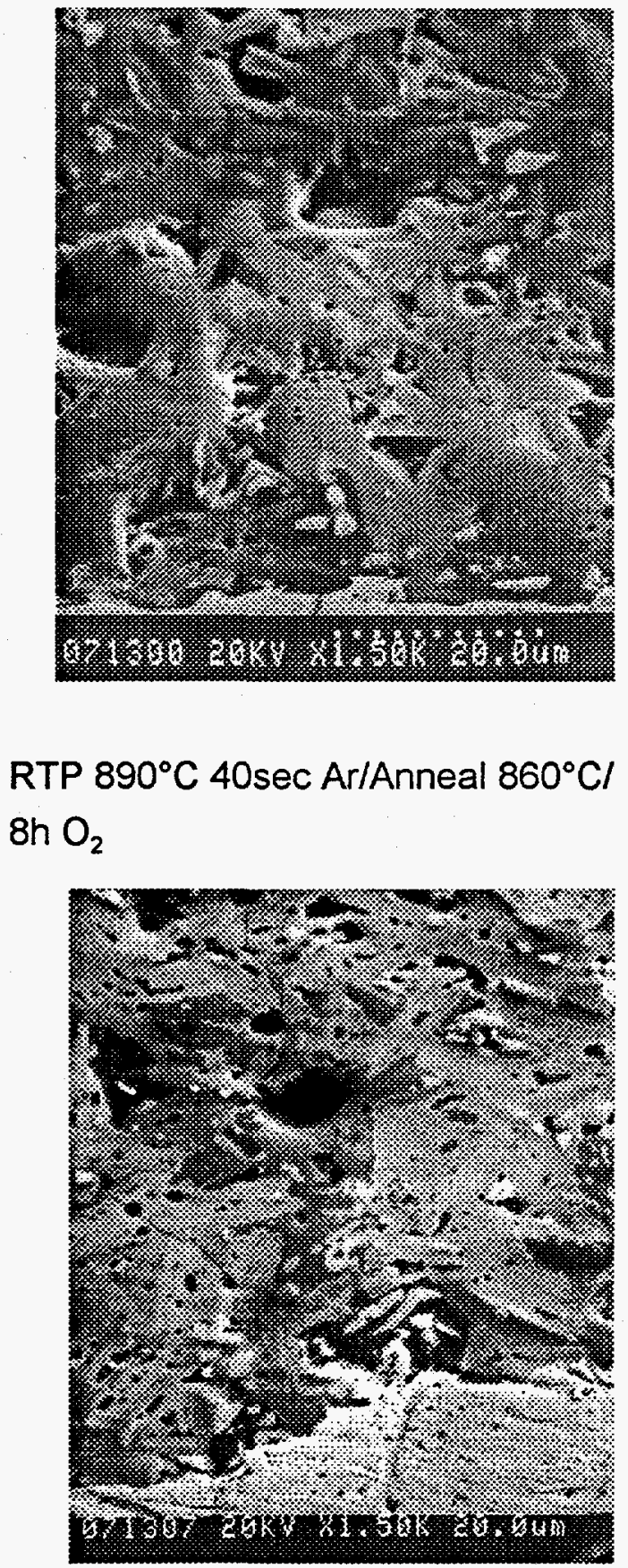

RTP $910^{\circ} \mathrm{C} 40 \mathrm{sec}$ Ar/Anneal $860^{\circ} \mathrm{C} /$ $8 \mathrm{~h} \mathrm{O}_{2}$

Figure 3-3. Rapid Thermal Processing of Ag-clad tape in argon atmosphere followed by oxygen anneal. 


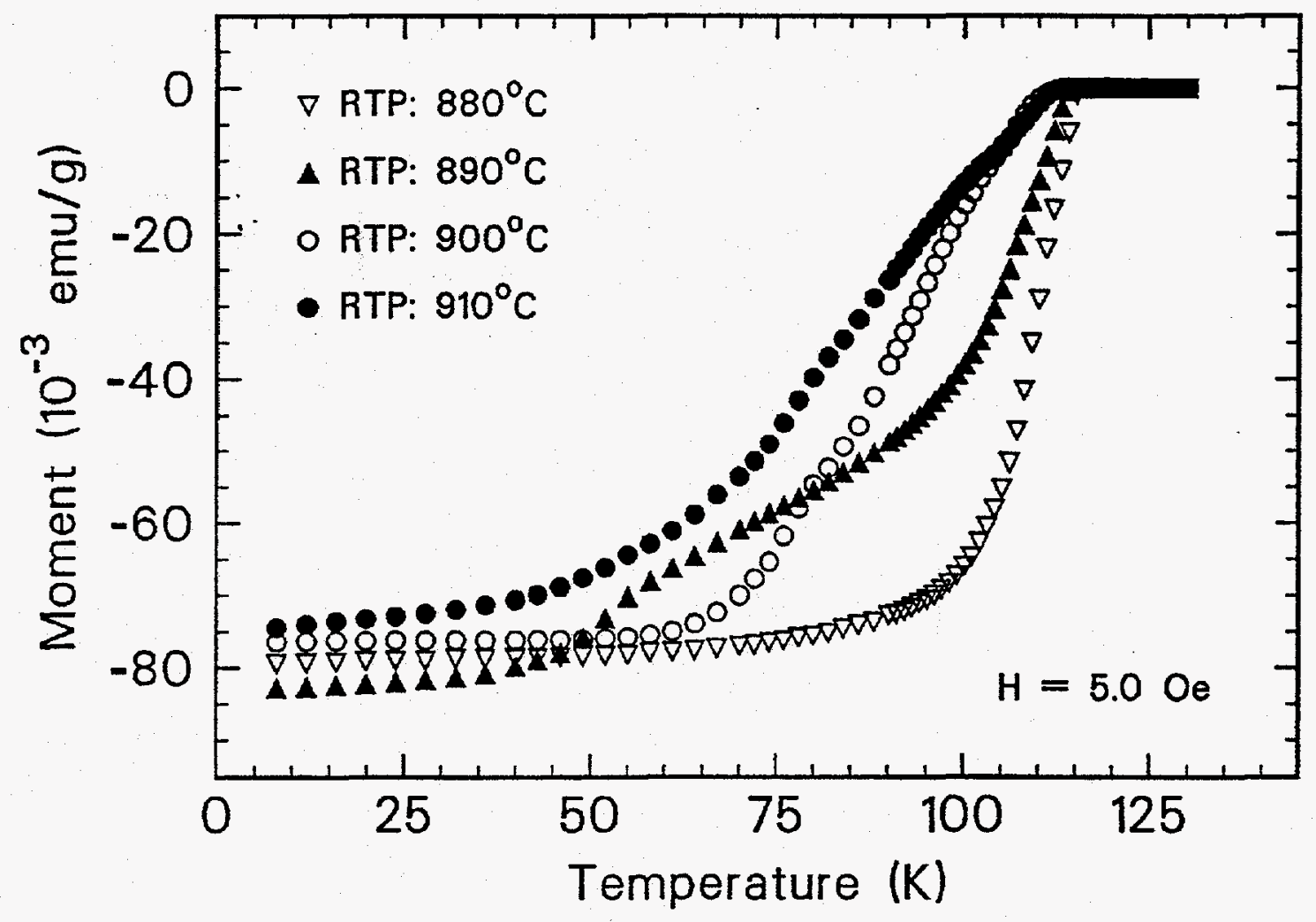

Figure 3-4. Meissner data for RTP and $860^{\circ} \mathrm{C} / 8 \mathrm{hr} / \mathrm{O}_{2}$ annealed tapes. 


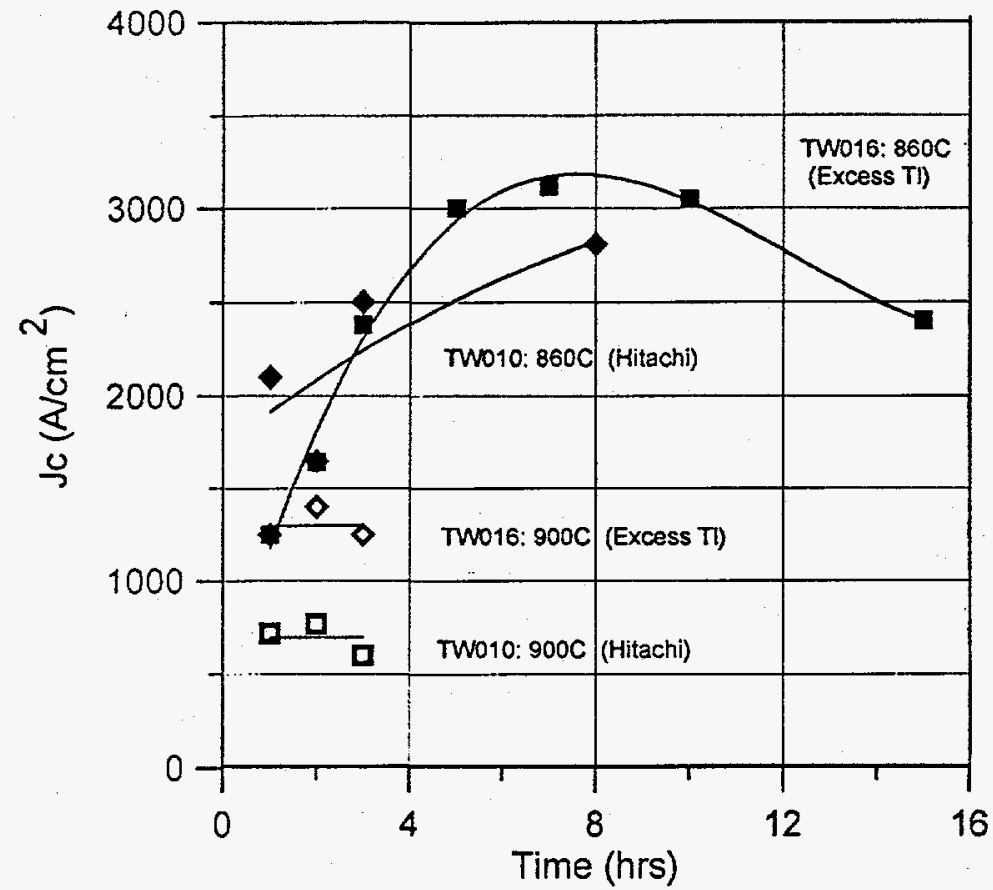

Figure 3-5. Effect of time-temperature processing of TI-1223 tapes.

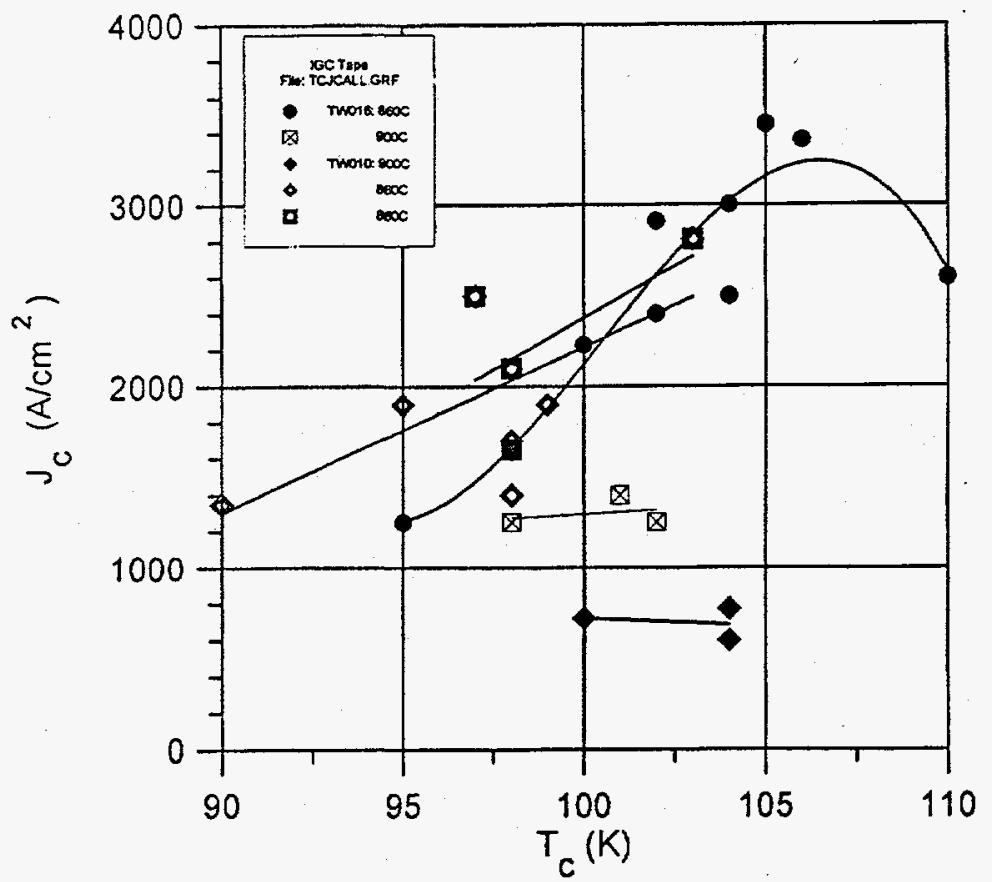

Figure 3-6. $J_{c}$ vs. $T_{c}$ as a function of anneal time and temperature 


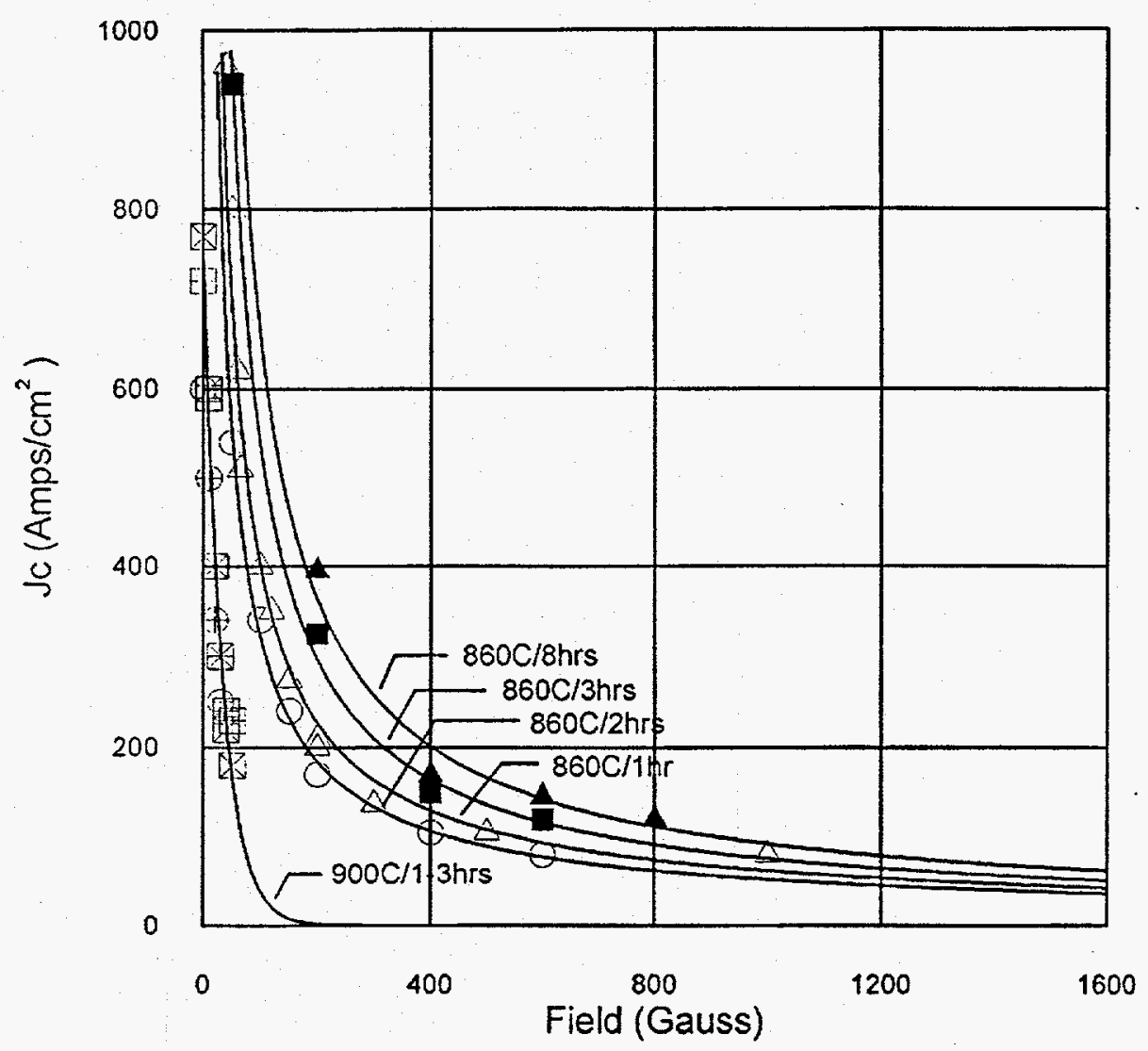

Figure 3-7. $\quad J_{c}$ field dependence of TI-1223 tapes as a function of anneal temperature and time. 


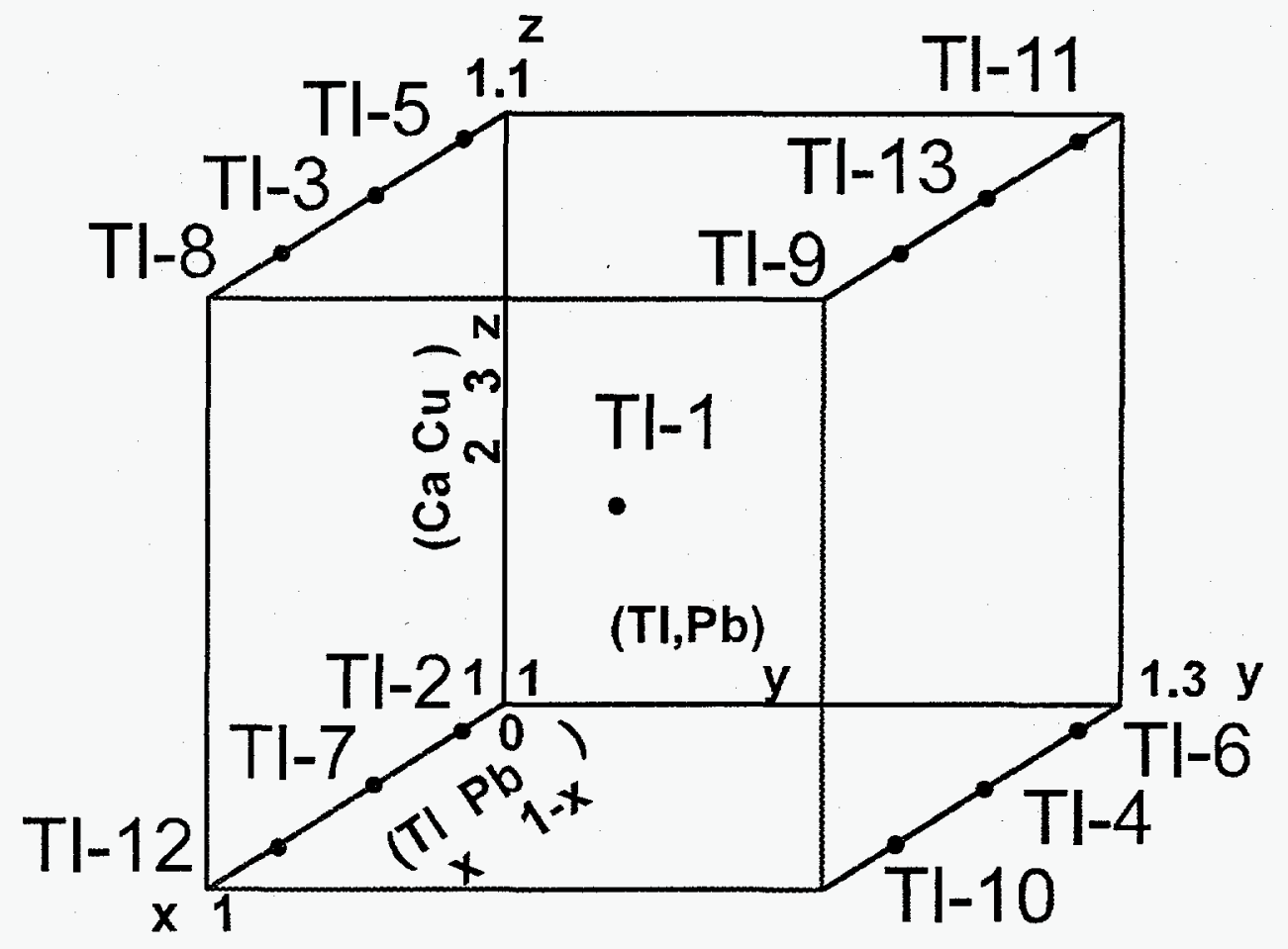

Figure 3-8. Compositional design matrix for the TI-1223 system. 


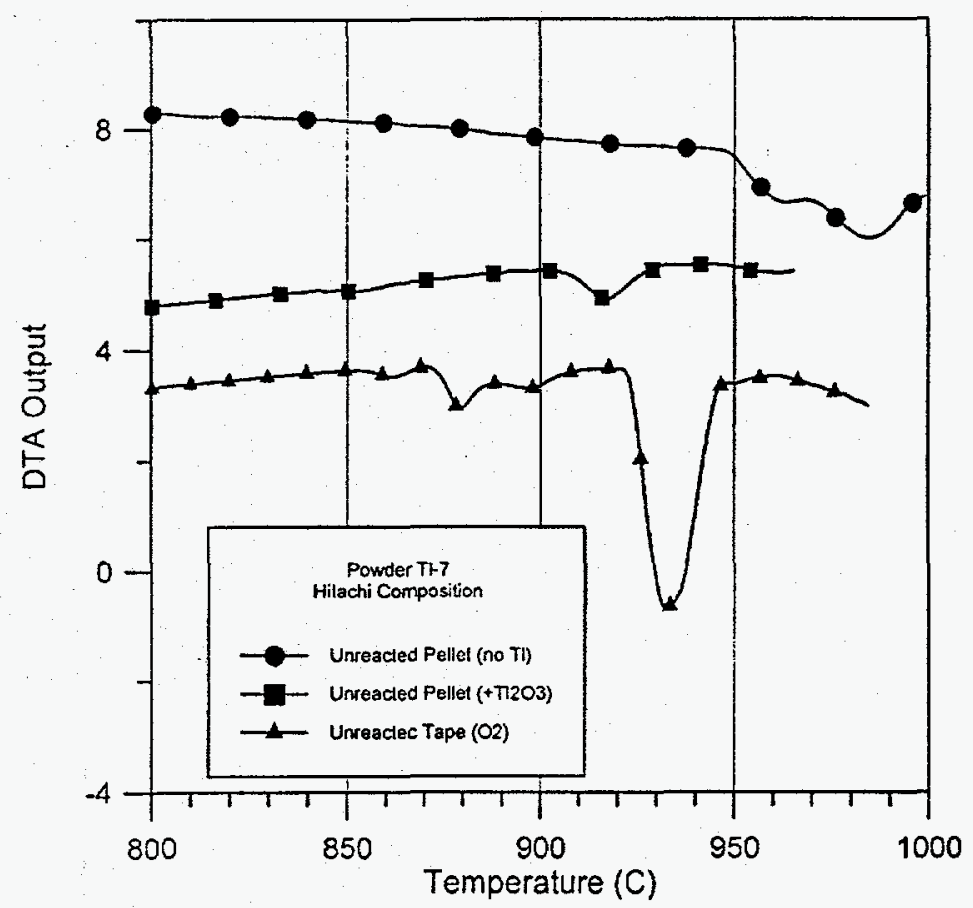

Figure 3-9. DTA comparison of unreacted Hitachi composition powders.

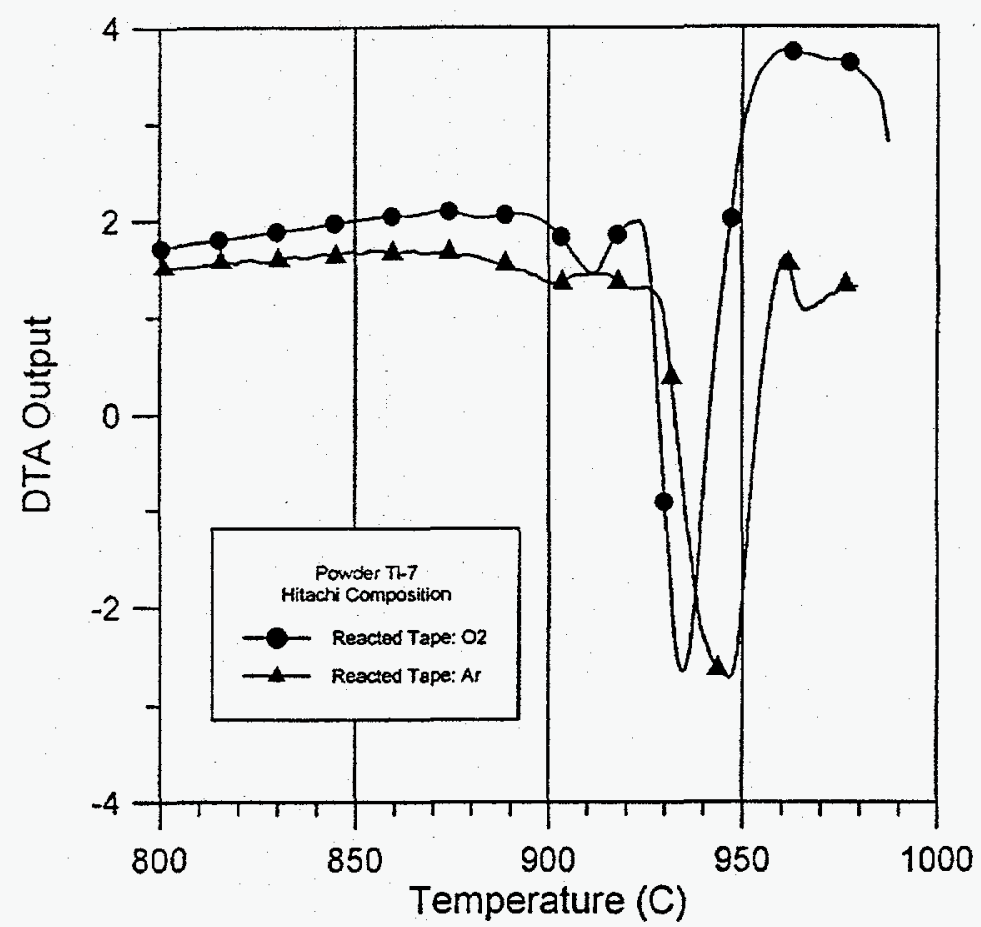

Figure 3-10. DTA comparison of reacted TI-1223 Ag-clad tape measured in $\mathrm{O}_{2}$ and $\mathrm{Ar}$. 


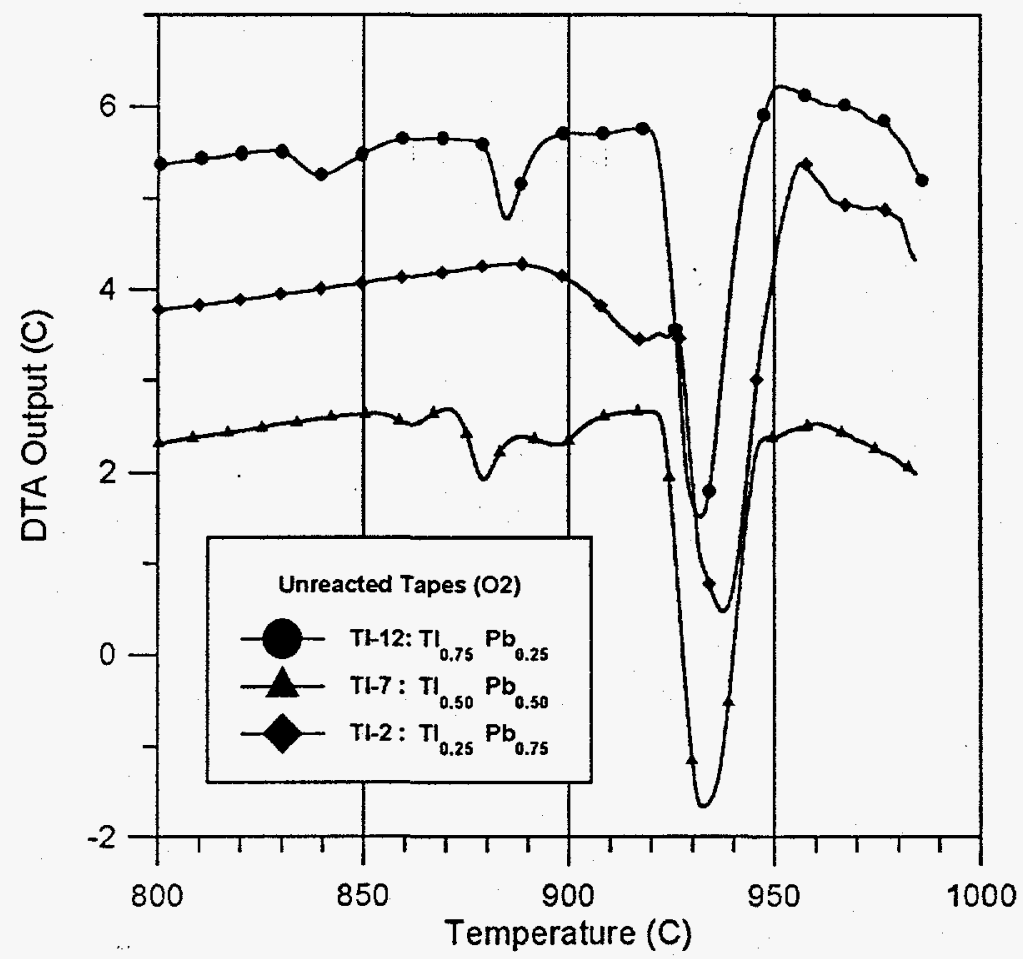

Figure 3-11. DTA comparisons for Ag-tapes in $\mathrm{O}_{2}$ as a function of $\mathrm{Tl} / \mathrm{Pb}$ ratio.

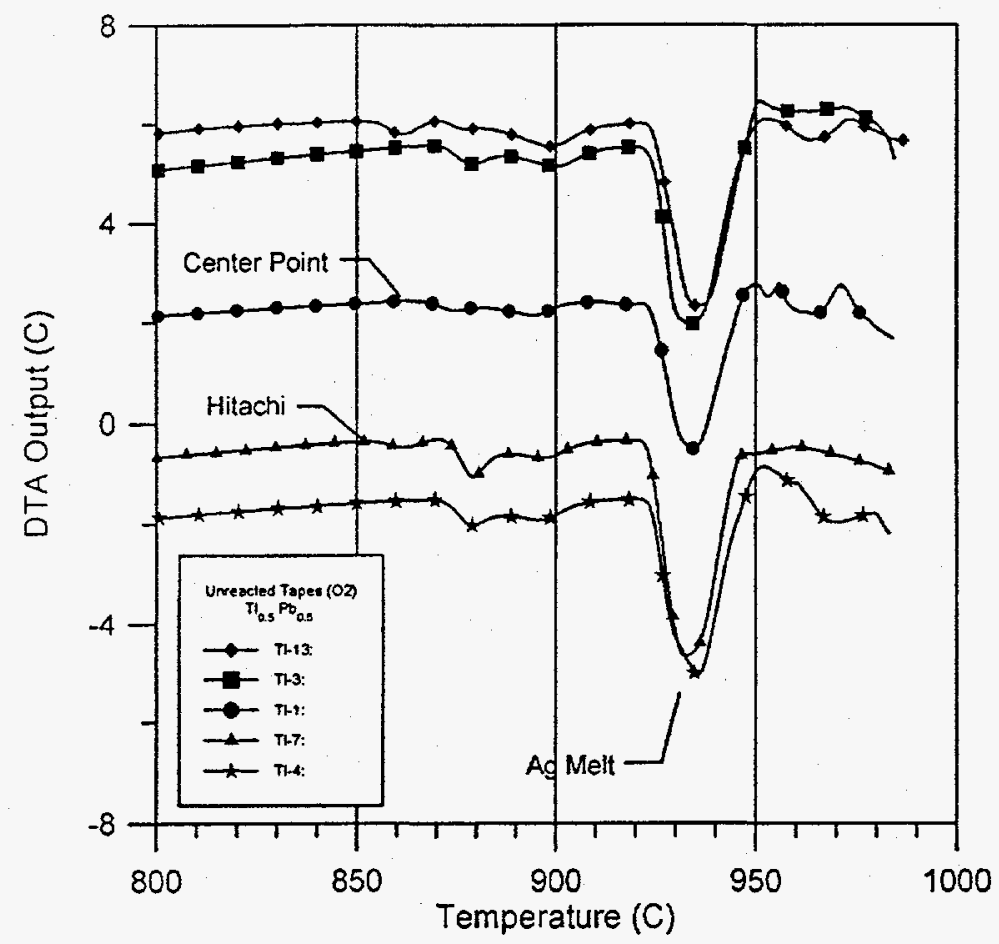

Figure 3-12. DTA comparisons for Ag-tapes with $\mathrm{TI}_{0.5} \mathrm{~Pb}_{0.5}$ composition. 


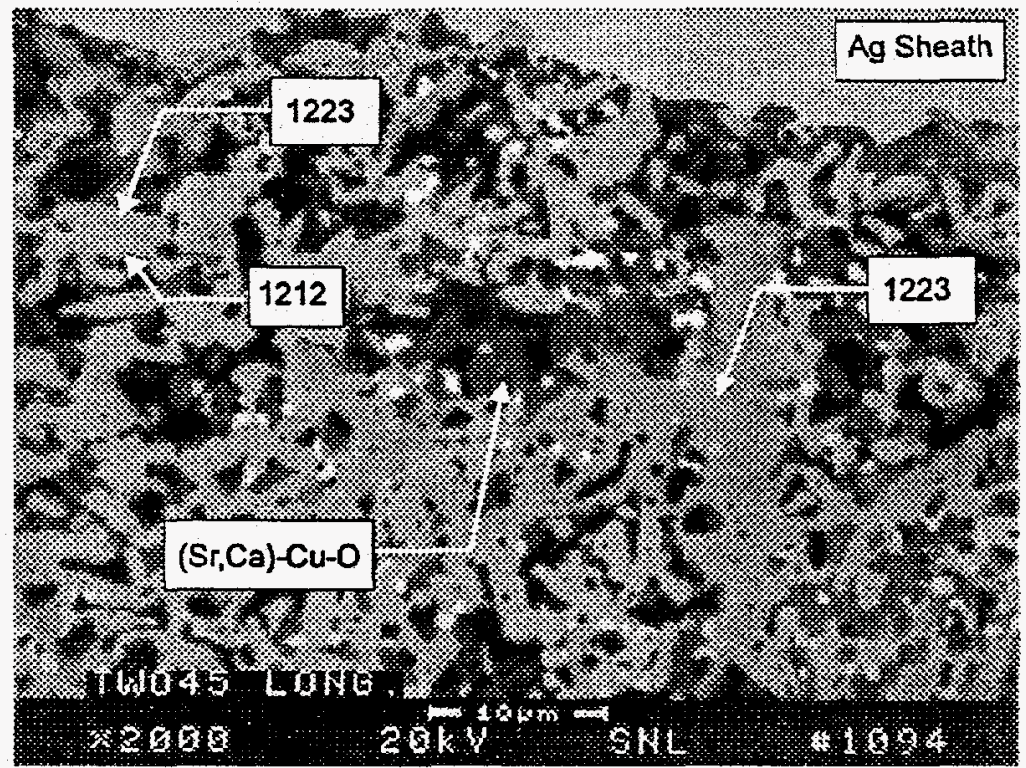

Figure 3-13. SEM micrograph of Hitachi composition (TI-7) annealed at $900^{\circ} \mathrm{C} / 2 \mathrm{hr} / \mathrm{O}_{2}$.

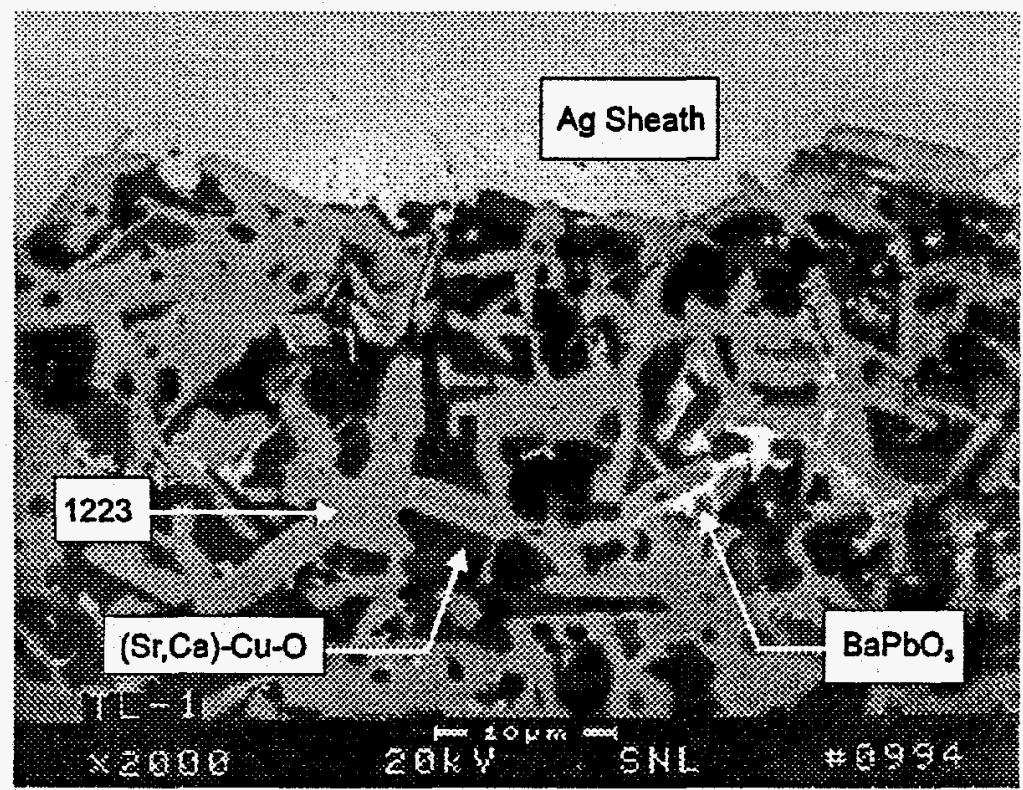

Figure 3-14. SEM micrograph of center point composition (TI-1) annealed at $900^{\circ} \mathrm{C} / 2 \mathrm{hr} / \mathrm{O}_{2}$. 
$\mathrm{Tl}_{0.25} \mathrm{~Pb}_{0.75}$
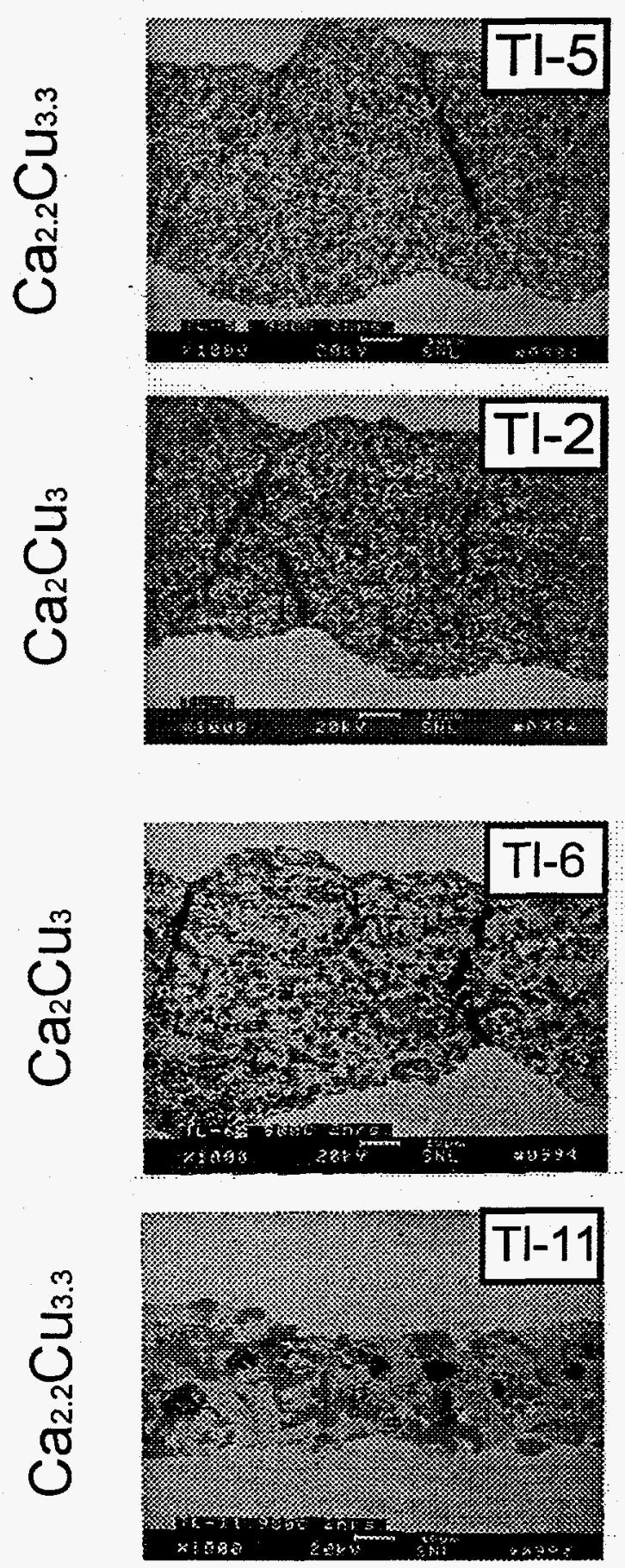

$\mathrm{TI}_{0.75} \mathrm{~Pb}_{0.25}$
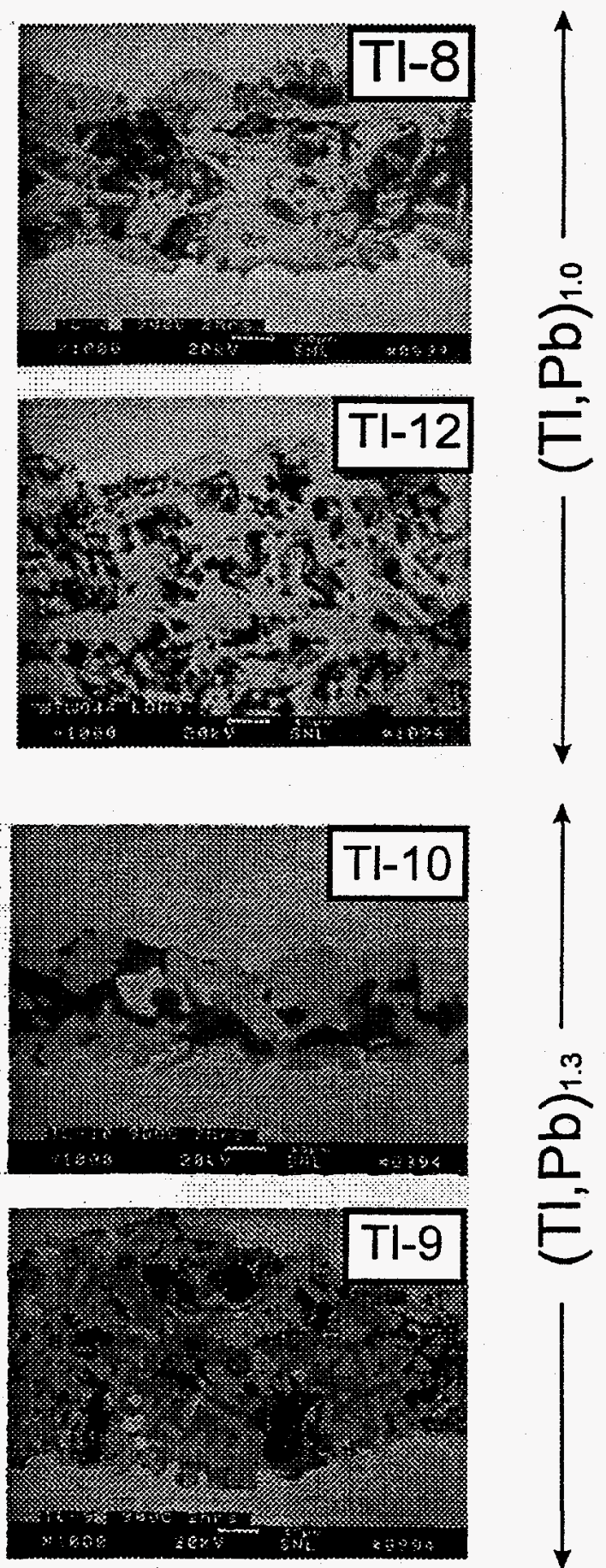

Figure 3-15. SEM micrographs of Ag tapes from compositional matrix study annealed at $900^{\circ} \mathrm{C} / 2 \mathrm{hrs}$. 


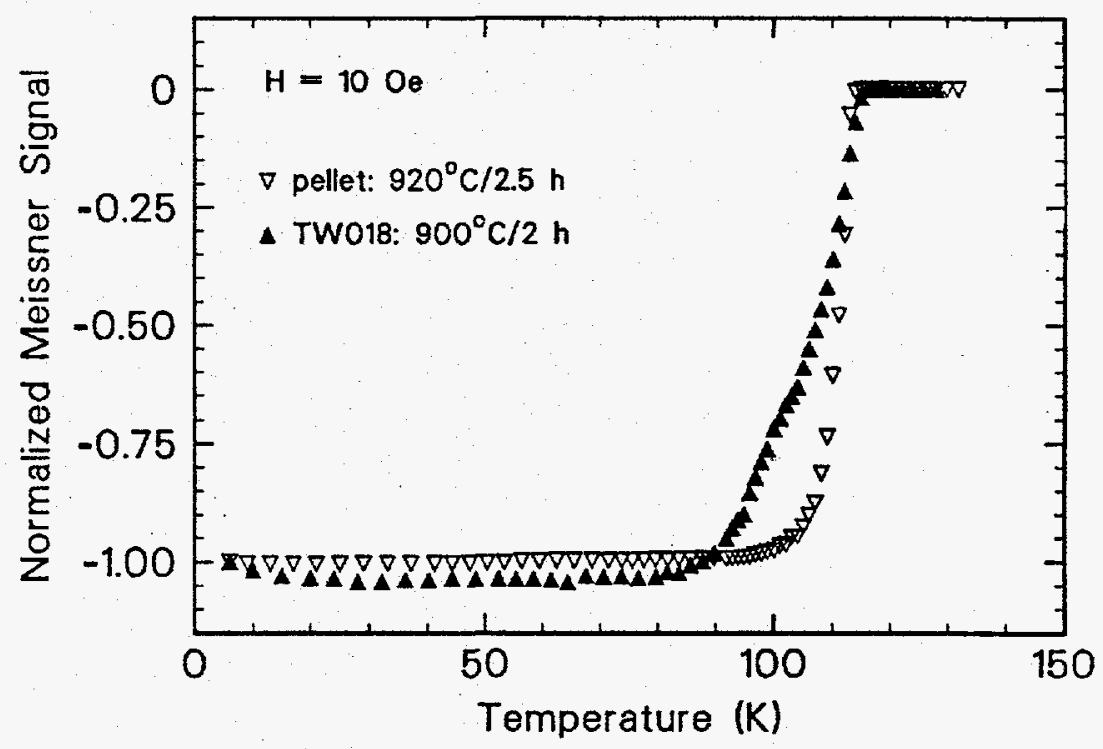

Figure 3-16. Meissner comparison of $920^{\circ} \mathrm{C}$ processed pellet and $900^{\circ} \mathrm{C}$ processed $\mathrm{Ag}$ tape with predominantly $\mathrm{TI}-1223$ phase.

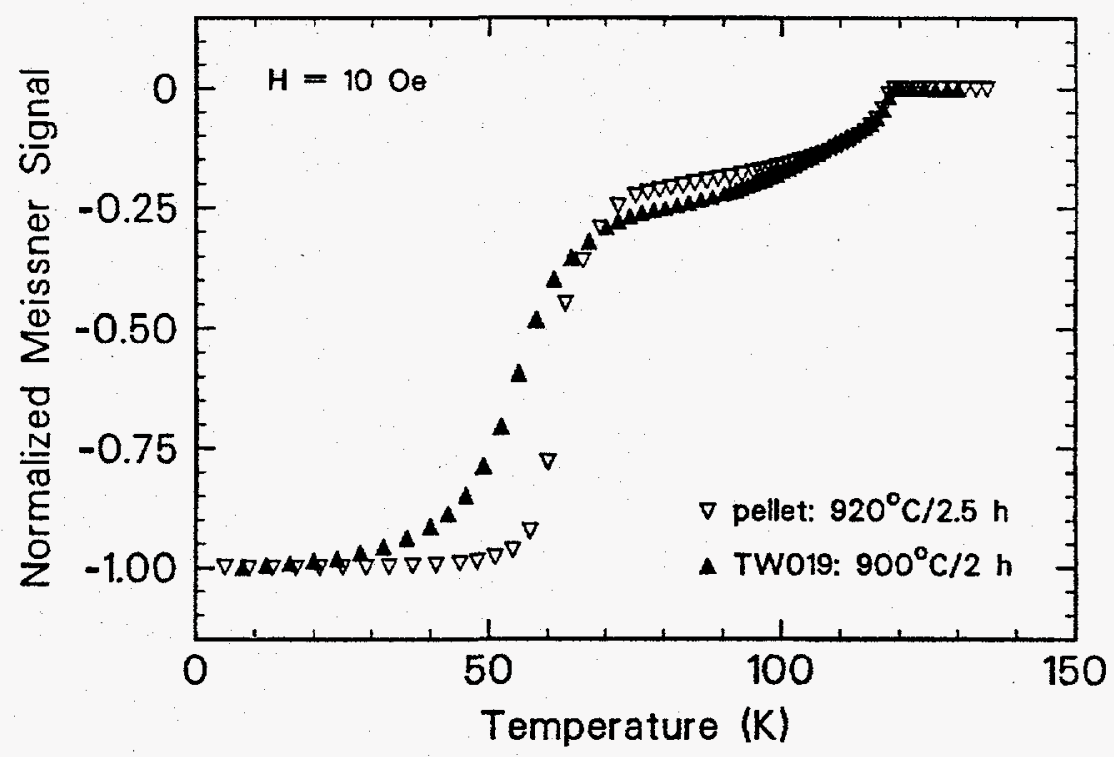

Figure 3-17. Meissner comparison of $920^{\circ} \mathrm{C}$ processed pellet and $900^{\circ} \mathrm{C}$ processed $\mathrm{Ag}$ tape showing predominantly $\mathrm{TI}-1212$ phase. 


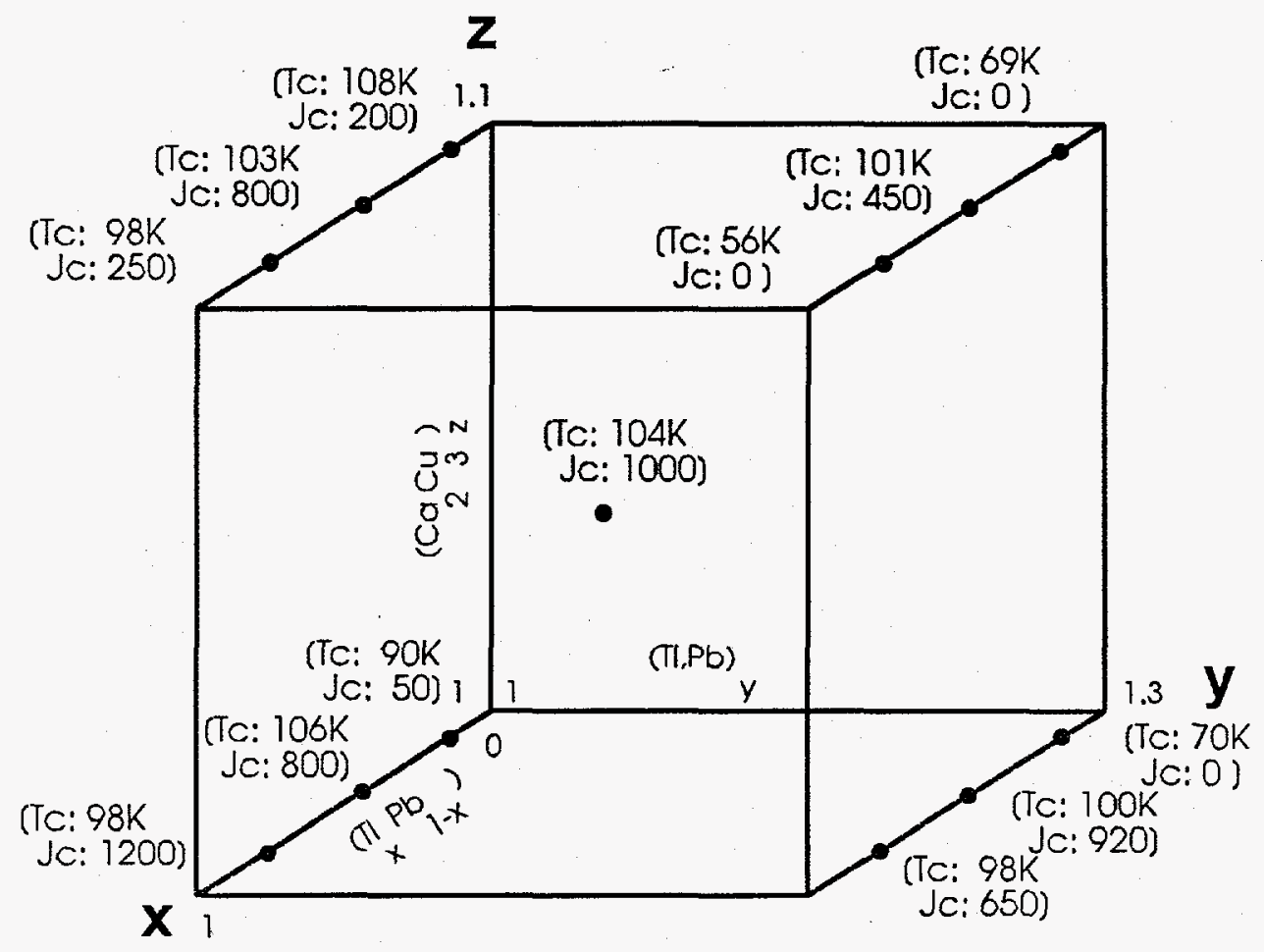

Figure 3-18. Summary of $T_{c}$ and $J_{c}$ results for Ag-clad tapes produced from compositional matrix. $\mathrm{J}_{c}$ values are in $\mathrm{A} / \mathrm{cm}^{2}$ measured at $75 \mathrm{~K}$ in zero field. 


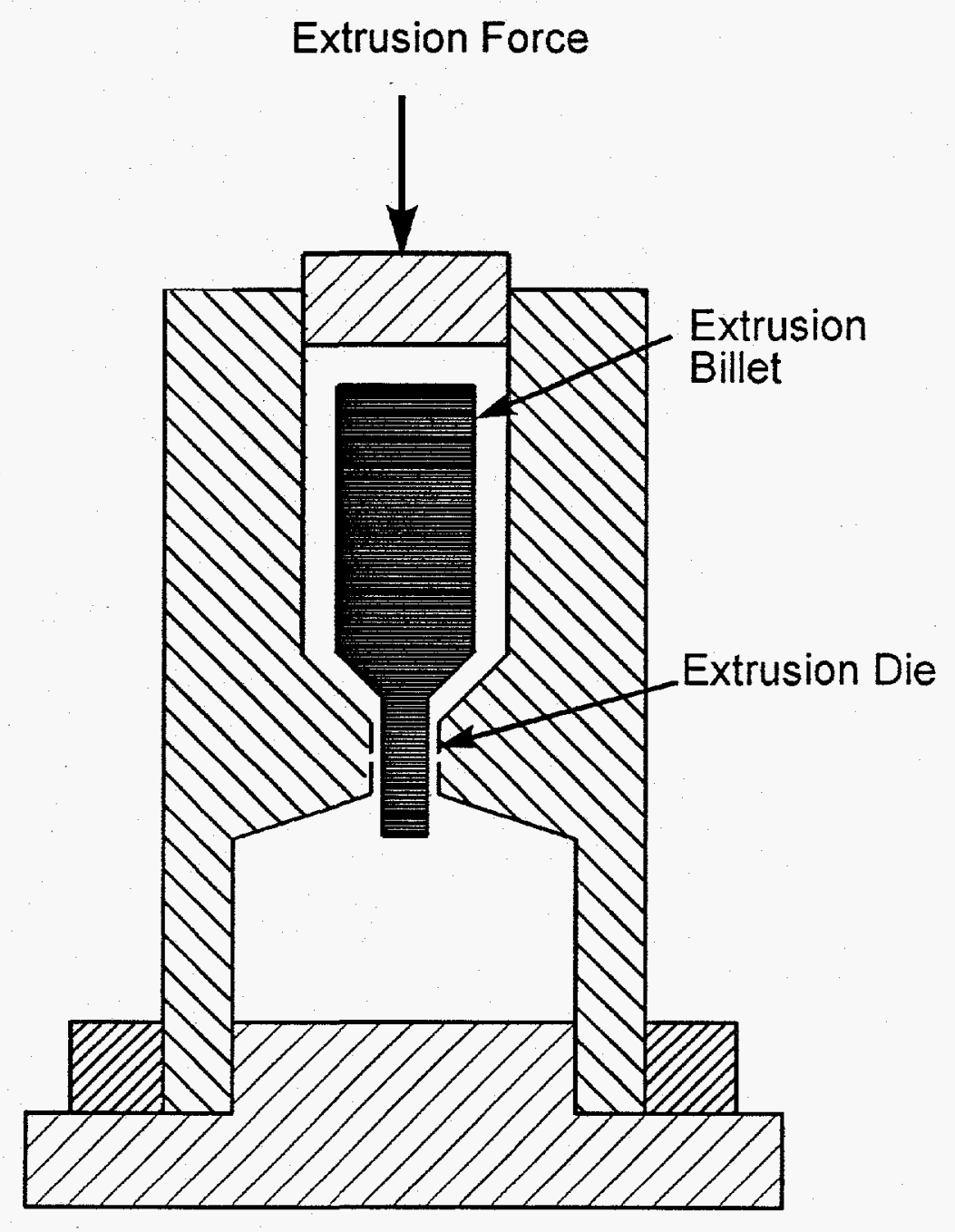

Figure 3-19. Schematic of extrusion press. 


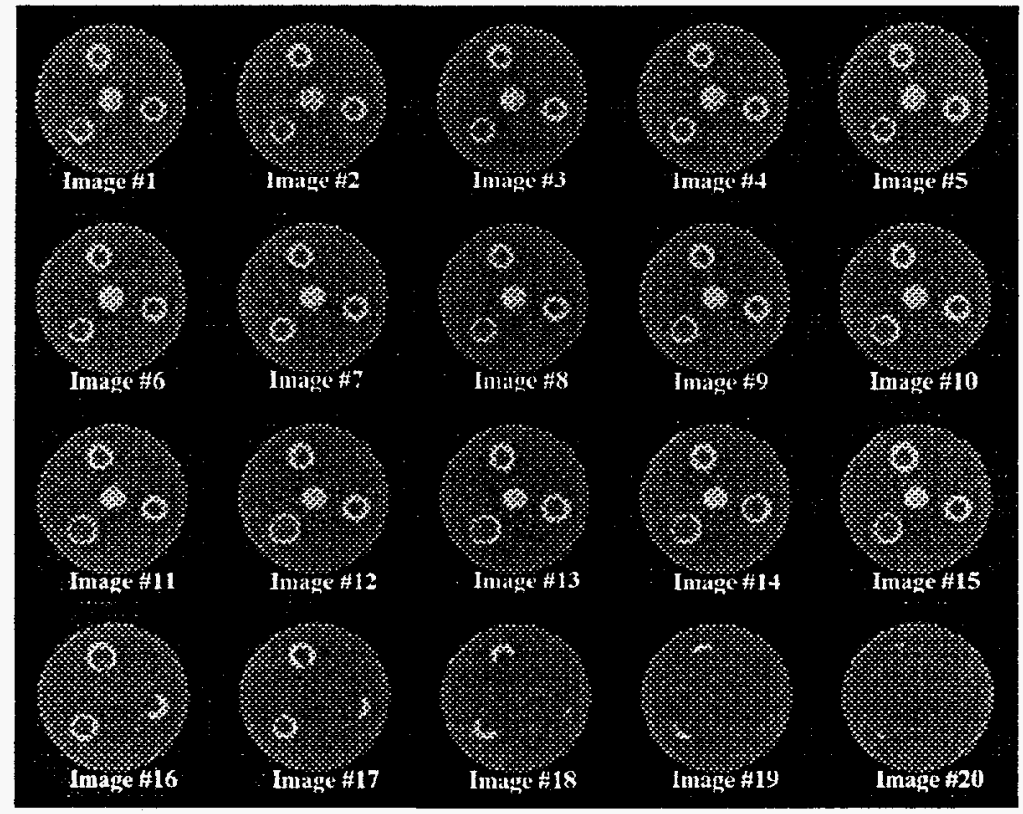

Figure 3-20. Computer aided tomograms of multi-core extruded rod.

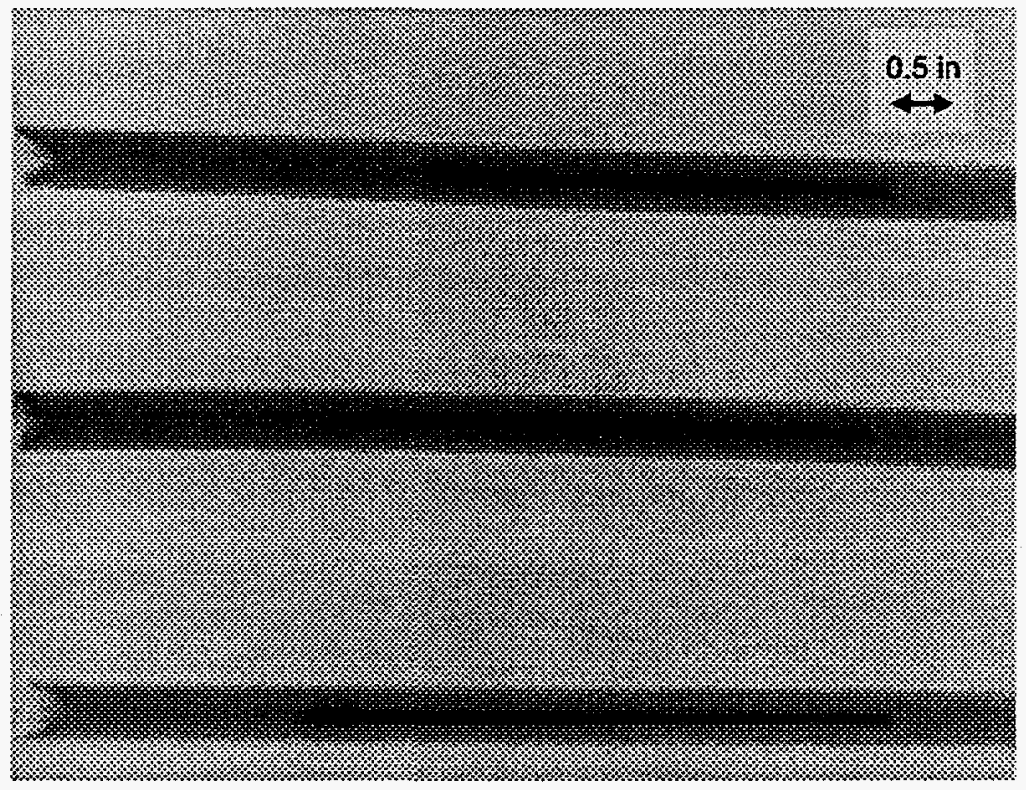

Figure 3-21. X-radiograms of coextruded superconductor core in Al sheath. 


\subsection{Introduction}

This project is designed to support Reliance Electric in the design and analysis of a high temperature superconductor (HTS) motor as shown in Figure 4-1. It is funded by the Department of Energy through its Superconducting Partnership Initiative (SPI). Development of HTS motors can offer significant electrical power savings for industrial users, and material cost savings for the manufacturers. This program is tasked with investigating the cryogenic cooling of a HTS motor. The cooling of a superconducting motor presents a unique problem due to the rotational motions involved. The rotational motion establishes significant radial pressure gradients that complicate the flow distribution. Also, the strong radial acceleration may introduce a variety of potential instability mechanisms that may reduce the effectiveness of the gas coolant. The Reliance motor design relies upon both natural convection and forced convection modes of heat transfer to the gaseous helium coolant.

\subsection{Progress in FY94}

It is most important to estimate the HTS temperatures during operation and the time required for cool-down of the rotor. To accomplish this one has to consider thermal conduction, convection and radiation. During normal operation, a steady flow of cold helium gas will be maintained to remove the heat load of the rotor. The steady state (during operation) heat load is made up of heat leaks into the rotor, and heat sources within the rotor. These small losses are due to electrical resistance (mainly in the connections) and fluid friction. Sandia has aided in the determination of the thermal loads to the motor.

Once the heat loads are determined, it is a trivial exercise to calculate the coolant flow required to maintain the rotor at a constant temperature. However, one must also guarantee that the rotor will be cooled in such a way that all of the HTS coils are maintained below their critical temperature. Since the motor has only one inlet for the coolant, it is not a trivial problem to assure that the coolant is distributed adequately to maintain a uniform rotor temperature. 
Due to the rapid rotational motion, large radial pressure gradients are produced. When radial flow channels exist, the rotor acts as a pump. This self pumping nature of the rotor will pull coolant from its reservoir into the rotor. Thus, a pump will not be required. The flow rate will be adjusted by flow resistances in the coolant feed line.

However, the large radial pressure gradients also make it difficult to maintain the desired coolant flow distribution within the rotor. The radial gradients due to rotation are much larger than the pressure gradients caused by the frictional losses. If at one axial location the fluid density is different than another, then the radial pressure gradients will not be equal. This will result in unequal pumping of the coolant through the various radial channels. Calculations presented by Sandia have shown that it is even possible to have reverse flow in some of the channels if care is not taken in designing the radial coolant channels. This can result in unacceptable variations in the rotor temperatures.

The large radial gradients due to rotation can result in secondary flows (greater than the net flow) in large axial channels. Since the axial channels are often over-sized for normal operations (they were sized based on the large cool-down coolant flows), the secondary flows can result in convection of heat into the rotor through the axial insulation layers. Secondary flows have been observed in the cryogenic generators designed by Westinghouse, MIT and General Electric. Sandia has evaluated the models proposed by the cryogenic generator designers, and put them in a consistent form. This allowed us to determine their difference, and estimate the effects of secondary flows on heat leaks into the Reliance Electric cryogenic rotor.

Finally, the radial gradients due to rotation can also affect the portions of the rotor that are cooled by natural convection of the helium coolant. A literature search has uncovered an instability mechanism that will greatly inhibit the natural convection capabilities of the helium coolant. Design modifications were suggested by Sandia that will help promote better natural convection heat transfer. These modifications will also help maintain more uniform temperatures within the rotor. 


\subsection{Future Work}

The models developed by Sandia have been directly used by Reliance Electric in the design of their HTS motor. It has become obvious that the various instability mechanisms identified can have a significant effect on the cooling performance of the motor. It is imperative that the stability problems must be identified before construction of the prototype motor. By avoiding these stability problems, the development effort for the motor will be much less expensive. Sandia has been chosen by Reliance Electric to continue with the proposed Phase II of the SPI. If this effort receives continued funding, Sandia will continue to provide assistance to the team through advanced thermal modeling and data analysis of the prototype motor. The goal of this program is to develop a 5000hp cryogenic electric motor utilizing state of the art high temperature superconducting wires. 


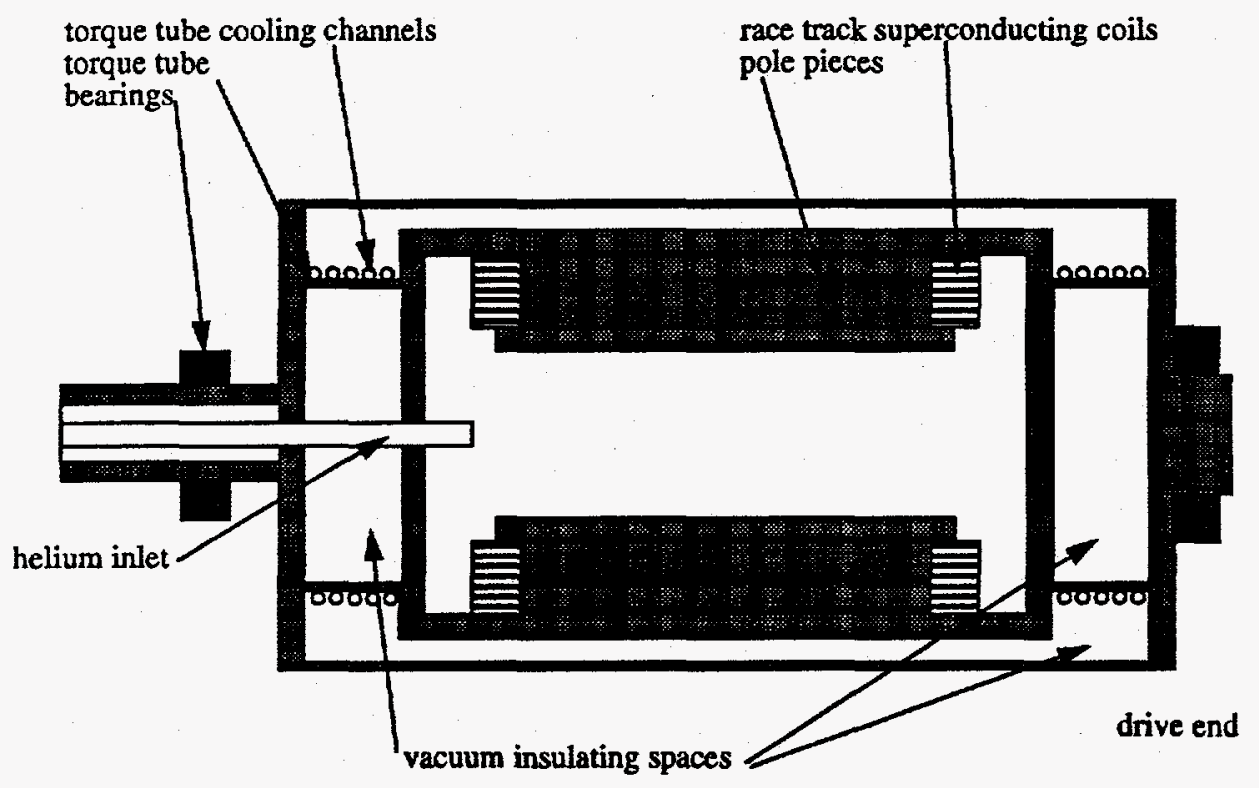

Figure 4-1. Simplified geometry of Reliance Electric cryogenic motor. 
Distribution:

Dr. James Daley

EE-14

Forrestal Building, US Department of Energy 1000 Independence Avenue, S. W.

Washington, DC 20585

Dr. Christine Platt

CE-32

Forrestal Building, US Department of Energy 1000 Independence Avenue, S. W.

Washington, DC 20585

Dr. Richard Blaugher

NREL

Branch 210, Location 16/3

1617 Cole Boulevard

Golden, CO 80401

Dr. R. A. Hawsey

Oak Ridge National Laboratory

Superconducting Technology Program

Post Office Box 2008

Oak Ridge, TN 37831-6040

Dr. David O. Welch

Brookhaven National Laboratory

Building 480

Upton, NY 11973

Mr. J. Badin

Energetics

7164 Gateway Drive

Columbia, MD 21046

Mr. Rich Schifer

Reliance Electric

24701 Euclid Avenue

Cleveland, $\mathrm{OH} 44117$

Mr. James R. Gaines, Jr.

Superconductive Components, Inc.

1145 Chesapeake Avenue

Columbus, $\mathrm{OH} 43212$

Dr. Nancy Levoy

Nuclear Metals, Inc.

2229 Main Street

Concord, MA 01742

Mr. Marc Lemmond

MK Associates

1920 "N" Street, N. W.

Suite 750

Washington, DC 20036
Mr. Chris Kang

EE-14

Forrestal Building, US Department of Energy

1000 Independence Avenue, S. W.

Washington, DC 20585

Mr. Richard Balthaser

US Department of Energy

Kirtland AFB-East, " $H$ " Street at Pennsylvania

Post Office Box 5400

Albuquerque, NM 87115

Dr. James Dirks

Battelle, Pacific Northwest Laboratories

Technology and Planning Center

Post Office Box 999

Richland, WA 99352

Dr. Dean E. Peterson

Los Alamos National Laboratory

MS-K763

Post Office Box 1663

Los Alamos, NM 87545

Dr. Balu Balachandran

Argonne National Laboratory, ET

Building 212

9700 South Cass Avenue

Argonne, IL 60439-4838

Mr. C. Matzdorf

Energetics

7164 Gateway Drive

Columbia, MD 21046

Dr. Susan M. Schoenung

Longitude 122 West, Inc.

1241 Hobart Street

Menlo Park, CA 94025

Mr. David W. Johnson, Jr.

AT\&T

Room 6D-321

600 Mountain Avenue

Murray Hill, NJ 07974

Mr. William T. Nachtrab

Nuclear Metals, Inc.

2229 Main Street

Concord, MA 01742

Dr. Pradeep Haldar

Intermagnetics General Corporation

Post Office Box 566

Charles Industrial Park, New Karner Road

Guilderland, NY 12084 
MS-9018

Central Technical Files

Org. 8523-2

MS-0619

Print Media

Org. 12615

MS-0609

W. F. Hammetter

MS-0752

T. C. Bickel

MS-0752

E. P. Roth

MS-0835

R. C. Dykhuizen

MS-0959

S. Lockwood

MS-1405

D. Lamppa

MS-1421

'B. Morosin
MS-0899

Technical Library

Org. 13414 (5)

MS-0100

Document Processing for DOE/OSTI

Org. 7613-2 (2)

MS-0702

D. E. Arvizu

MS-0752

F. D. Chavez

MS-0835

R. D. Skocypec

MS-0959

F. P. Gerstle, Jr.

MS-1405

J. A. Voigt

MS-1421

E. B. Stechel

MS-1421

T. L. Aselage

MS-1421

M. Siegal
MS-1421

E. L. Venturini 